\title{
Optimization of Operating Conditions and Design Parameters on Coal Ultra-Fine Grinding Through Kinetic Stirred Mill Tests and Numerical Modeling
}

\author{
Francisco Patino \\ West Virginia University, fjp00002@mix.wvu.edu
}

Follow this and additional works at: https://researchrepository.wvu.edu/etd

Part of the Mining Engineering Commons

\footnotetext{
Recommended Citation

Patino, Francisco, "Optimization of Operating Conditions and Design Parameters on Coal Ultra-Fine Grinding Through Kinetic Stirred Mill Tests and Numerical Modeling" (2021). Graduate Theses, Dissertations, and Problem Reports. 10312.

https://researchrepository.wvu.edu/etd/10312

This Thesis is protected by copyright and/or related rights. It has been brought to you by the The Research Repository @ WVU with permission from the rights-holder(s). You are free to use this Thesis in any way that is permitted by the copyright and related rights legislation that applies to your use. For other uses you must obtain permission from the rights-holder(s) directly, unless additional rights are indicated by a Creative Commons license in the record and/ or on the work itself. This Thesis has been accepted for inclusion in WVU Graduate Theses, Dissertations, and Problem Reports collection by an authorized administrator of The Research Repository @ WVU. For more information, please contact researchrepository@mail.wvu.edu.
} 
Optimization of Operating Conditions and Design Parameters on Coal Ultra-Fine Grinding Through Kinetic Stirred Mill Tests and Numerical Modeling

Francisco Patino 


\title{
OPTIMIZATION OF OPERATING CONDITIONS AND DESIGN PARAMETERS ON COAL ULTRA-FINE GRINDING THROUGH KINETIC STIRRED MILL TESTS AND NUMERICAL MODELING
}

\author{
Francisco Patino \\ Thesis submitted to the Benjamin M. Statler College of \\ Engineering and Mineral Resources \\ at West Virginia University \\ in partial fulfillment of the requirements for the degree of
}

Master of Science in

Mining Engineering
Qingqing Huang, Ph.D., Chair Yi Luo, Ph.D.
Hassan Amini, Ph.D.

\author{
Department of Mining Engineering \\ West Virginia University
}

Morgantown, West Virginia

2021

Keywords: Ultra-fine Grinding; Coal, Grinding Media Materials; Specific Energy; $\mathrm{P}_{80}$; Population Balance Modeling.

Copyright 2021, Francisco Patino 


\begin{abstract}
OPTIMIZATION OF OPERATING CONDITIONS AND DESIGN PARAMETERS ON COAL

ULTRA-FINE GRINDING THROUGH KINETIC STIRRED MILL TESTS AND

NUMERICAL MODELING
\end{abstract}

Francisco Patino

Ultra-fine grinding is an energy-intensive process that usually results in operational inconvenience due to the high operating costs associated with energy consumption. Nevertheless, it plays a vital role in numerous industries that seek to produce high-purity materials, synthetic compounds, or by-products derived from coal. In addition to providing the particle size ranges suitable for downstream coal cleaning processes, comminution also provides the grade of liberation necessary to release the valuable minerals from organic substances and gangue minerals. This liberation size is commonly associated with mineral grain size, although it is not the only determining parameter. Stirred milling is a power-efficient method to produce micronized particles industrially. Also known as attrition mills, this concept of mills consists of an agitated vessel and grinding media on the scale of millimeters. Stirred mills can supply high power densities, and their versatility allows working efficiently with a broad range of materials under distinct conditions. Considering the high energy consumption and low efficiencies, the optimization of grinding operations and the search for innovative alternatives are crucial to making size reduction processes economically feasible.

The optimization of ultra-fine coal grinding performance using a laboratory scale stirred mill was approached in this research project. A series of kinetic stirred mill tests were conducted under various controlled test conditions to comprehend the influence of four main operating and design parameters on the particle size reduction process. The effects of low- and moderate-cost grinding media materials (ceramic balls, alumina beads, granular sand, and silica beads), media size range, solids concentration of slurry, and grinding aids such as viscosity modifiers were examined throughout this study. Moreover, comprehensive characterization studies in terms of particle size, power draw, shape, and surface morphology were further carried out to support the experimental findings. Ultimately, grinding simulation using population balance modeling was performed in Matlab to forecast the product size distributions based on the specific energy input and experimental size-related data.

As expected, the characteristic inverse relationship between power consumption and product size was corroborated when testing the media materials. Alumina beads and ceramic balls were found to be low-power consumption grinding media, whereas silica beads can demand up to $432 \mathrm{kWh} / \mathrm{t}$ 
representing 3 times more energy. However, this difference is reflected in the product size, in which finer coal particles (below $6 \mu \mathrm{m}$ ) and reduction ratios up to 9:1 were obtained using silica beads. Thus, tests indicated that silica beads were the most suitable grinding media due to the superior grinding performance along with a significant performance improvement when employing coarse beads. On the other hand, granular sand and fine silica beads were found inappropriate for ultra-fine grinding. Unlike other materials employed, media degradation and their fine sizes made wet screening a challenging and complex process.

The rheological properties of slurry were modified by either changing solids concentration by weight between 20 and $40 \%$ or adding different dosages of sodium silicate as a viscosity modifier. Low solids concentrations improved the reduction ratio; however, the energy consumption was significantly impacted, increasing up to 5 times depending on the media material used. Thus, the use of dispersants is a promising alternative to produce micronized particles at low operating costs. Nevertheless, the impact on downstream processes like flocculation must be considered, as well as a reduction in throughput at a low solids content of slurry.

Ultimately, a numerical simulation using population balance modeling (PBM) was performed in Matlab. Mathematical models were proposed based on the selection function, breakage function, and particle swarm optimization (PSO) algorithm to indirectly predict the product particle size distributions resulting from comminution. According to the statistical analyses, this method provided accurate results in which the mean square error between the experimental and numerical models was reduced below 0.003207 . Thus, population balance modeling represents a powerful forecasting tool in grinding simulation, and its application in other fields is undergoing remarkable growth.

Keywords: Ultra-fine Grinding; Coal, Grinding Media Materials; Specific Energy; $\mathrm{P}_{80}$; Population Balance Modeling. 
"You will face many defeats in life, but never let yourself be defeated" 


\section{ACKNOWLEDGMENT}

I would like to express my deep and sincere gratitude to my advisor, Dr. Qingqing Huang, for giving me the opportunity to make one of my dreams come true. Without her patience, guidance, and continuous support this accomplishment would not have been possible.

I would also like to express my sincere thanks to Dr. Oscar Jaime Restrepo, for his unconditional support. Undoubtedly, he has always been working for his students and many of us owe him our professional career abroad.

I would also like to extend my gratitude to my committee members, Dr. Yi Luo and Dr. Hassan Amini, for their continued willingness to help, motivation, and advice throughout my research project.

I thank my lab mates, professors, friends, fellow graduate students, and staff of the WVU Mining Engineering department for making my journey a memorable experience. I also would like to express my special gratitude to Victor Valencia and his family, it was a privilege to have been welcomed into their home and shared special moments with them.

Finally, I cannot thank my family enough for always being in my up and downs. They are the source of motivation that inspires me to go further. This achievement belongs to my parents, Olga Lucia Sepulveda and Carlos Patiño, who have unconditionally been supporting me. My siblings, Emmanuel Patiño, Yajaira Patiño, and Cindy Patiño, for being the reason why I strive to be better every day. And my princess, Milú, for her faithful company and madness. 


\section{TABLE OF CONTENTS}

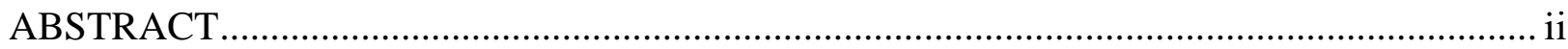

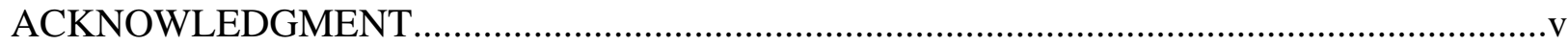

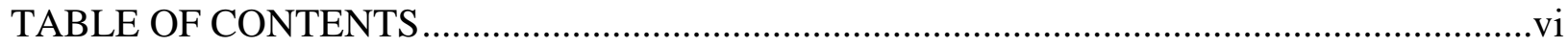

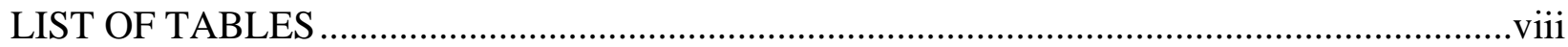

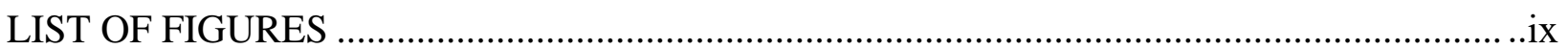

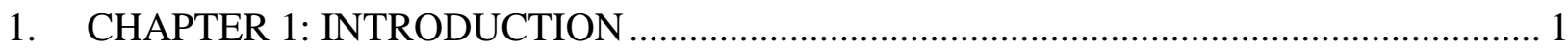

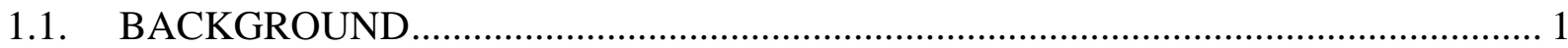

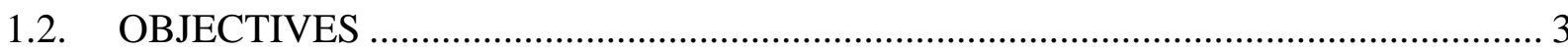

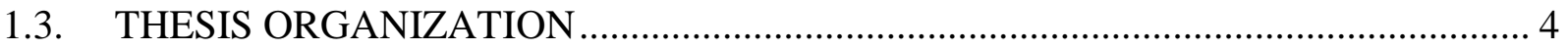

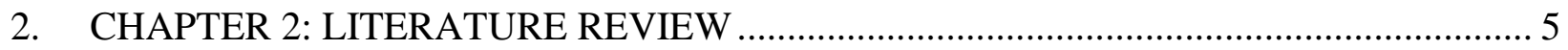

2.1. FUNDAMENTALS OF COMMINUTION .......................................................... 5

2.1.1. Breakage Mechanisms and Liberation................................................................. 5

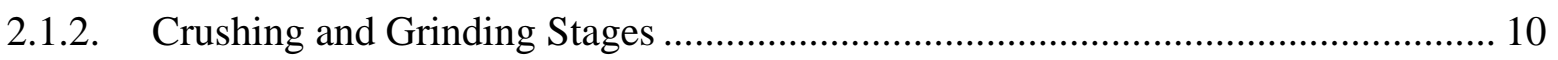

2.1.3. Comminution Equipment.................................................................................. 13

2.1.4. Energy-Size Relationship........................................................................... 18

2.2. ADVANCES IN ULTRAFINE GRINDING ………............................................ 22

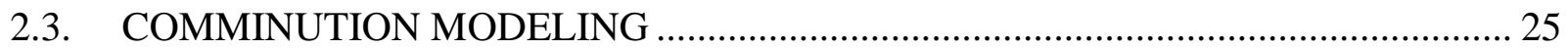

2.3.1. Energy-based Models......................................................................................... 26

2.3.2. Population Balance Modeling ........................................................................... 28

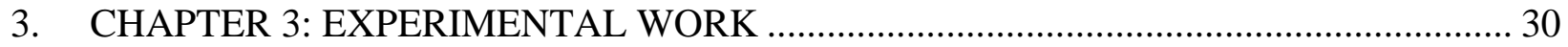

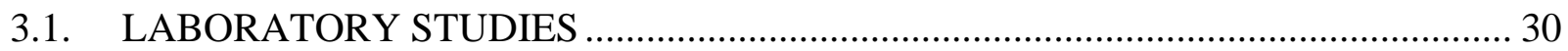

3.1.1. Sample and Grinding Media Materials ………………………………………...... 30

3.1.2. Experiment Design and Stirred Mill Grinding Tests ................................................ 31 
3.1.3. Specific Energy Input Measurement .................................................................. 33

3.1.4. Particle Size, Shape, and Surface Morphology Analyses ........................................ 34

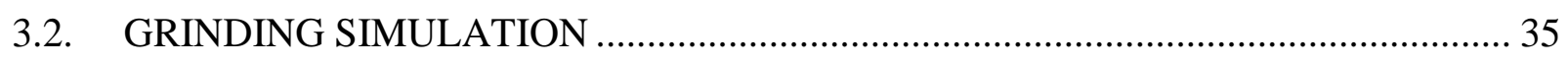

3.2.1. Population Balance Modeling (PBM) .................................................................... 35

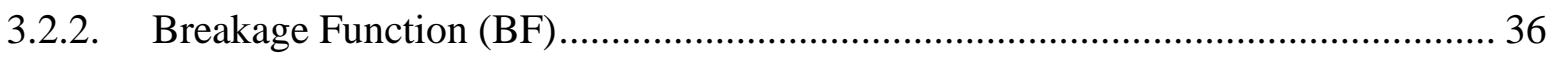

3.2.3. Selection Function/Breakage Probability (BP) ....................................................... 36

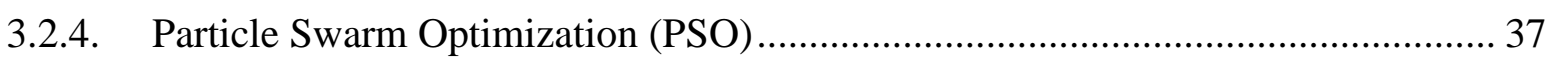

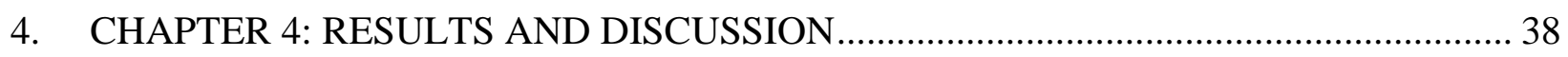

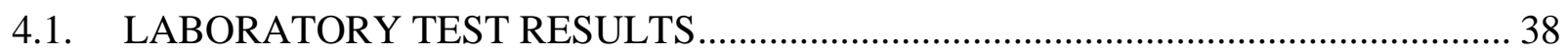

4.1.1. Coal Sample Characterization............................................................................. 38

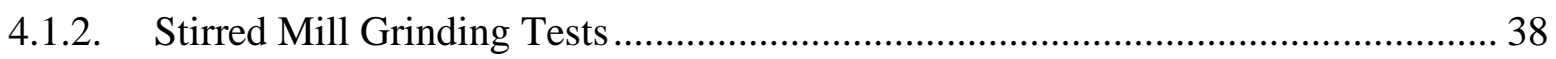

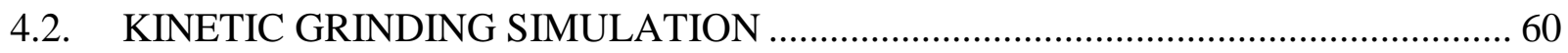

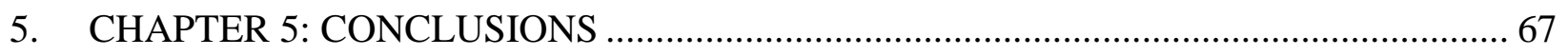

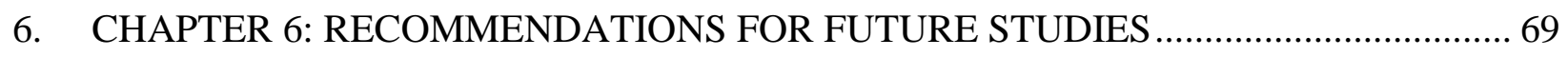

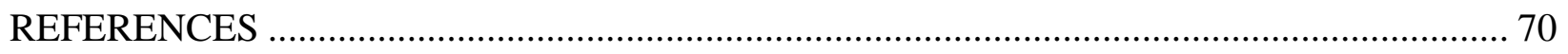

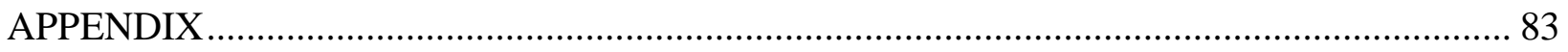




\section{LIST OF TABLES}

Table 1. Size-energy relationship of stirred mills. ........................................................... 2

Table 2. Quantitative assessment of the crack density in thin sections of taconite and ilmenite ores

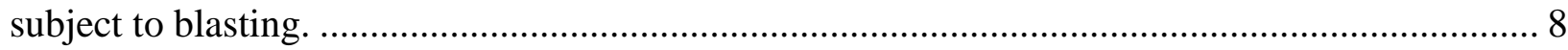

Table 3. Energy production and consumption in the U.S in 2019.................................... 18

Table 4. Operating parameters of crushing and grinding operations.................................... 20

Table 5. Properties of various types of ceramic grinding media. ........................................ 23

Table 6. Grinding media material specifications. .......................................................... 31

Table 7. Detailed test conditions for stirred mill grinding tests.......................................... 33

Table 8. Test conditions for kinetic grinding tests employing various grinding media materials.39

Table 9. Test conditions for kinetic grinding tests employing different size ranges of silica beads.

Table 10. Test conditions for kinetic grinding tests employing coarse silica beads and ceramic balls to analyze the effect of solids concentration.

Table 11. Test conditions for kinetic grinding tests employing coarse silica beads and ceramic balls to analyze the effect of different doses of dispersant............................................................... 52

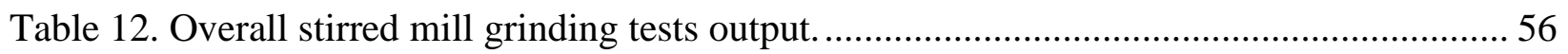

Table 13. Confidence interval and optimum values of selection and breakage functions........... 60

Table 14. Interpretation of Pearson correlation coefficient. ................................................. 65

Table 15. Industrial stirred mills in mineral processing. ................................................. 83

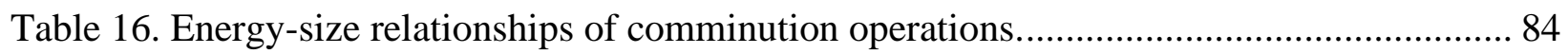

Table 17. Examples of cryogenic grinding for different kinds of materials............................ 85 


\section{LIST OF FIGURES}

Figure 1. Mechanisms of breakage: (a) Impact or compression, (b) chipping or attrition, and (c) Abrasion. 5

Figure 2. Effect of breakage on liberation.

Figure 3. Liberation patterns: (1) and (2) Liberated valuable mineral, (3) and (4) middlings, and

(5) and (6) Liberated gangue mineral. 6

Figure 6. Crushability Index (CI) and $\mathrm{P}_{80}$ values for different types of explosives..................... 7

Figure 7. Bond work index and throughput values for different types of explosives.................. 8

Figure 8. Optimum blasting leads to cost minimization for mining and processing. ................... 9

Figure 9. Example crushing flowsheets feeding a: (a) rod mill, and (b) SAG mill with a "recycle" (pebble) crusher to reduce the "critical size" material size..................................................... 10

Figure 10. Flow diagram of an IsaMill in an open grinding circuit...................................... 11

Figure 11. Applicable size range for comminution unit operations....................................... 11

Figure 12. The general control problem (GCP) framework. ................................................. 12

Figure 13. Sketch of a double-toggle jaw crusher. ............................................................. 13

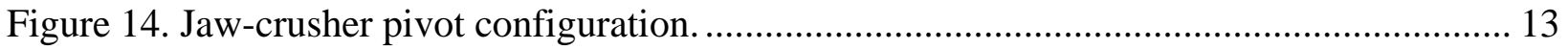

Figure 15. Schematic diagram of a gyratory crusher......................................................... 14

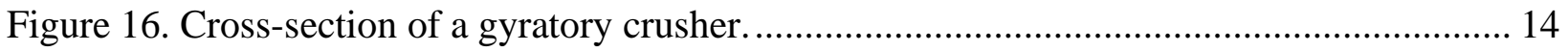

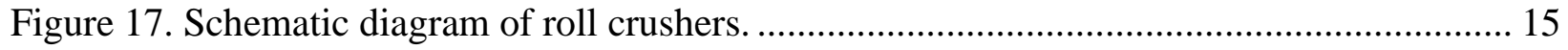

Figure 18. Nip angle and forces acting on a particle during crushing. .................................. 15

Figure 19. Breakage mechanisms in tubular mills................................................................ 16

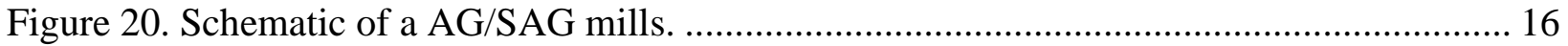

Figure 21. Illustration of a vertical spiral (a) and a vertical pin (b) stirred mills, as well as (c) flow

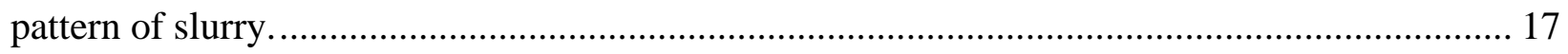

Figure 22. U.S industrial sector energy consumption by type of industry. ............................. 18

Figure 23. The estimated current, best practice, practical minimum, and theoretical minimum energy consumption by mining equipment..................................................................... 19

Figure 24. Specific energy required to produce $-0.15 \mathrm{~mm}$ product ........................................ 20

Figure 25. Specific energy input for size reduction in comminution. ..................................... 22

Figure 26. Union Process cryogenic stirred mill. ............................................................. 24 
Figure 27. View of charge motion from feed end with media shown as light grey and slurry colored

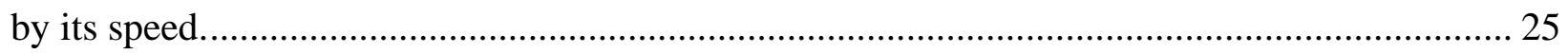

Figure 28. Illustration of the distribution of broken particles after fragmentation. .................... 28

Figure 29. Grinding media materials chosen to study ultrafine grinding behavior................... 30

Figure 30. Laboratory scale stirred mill employed throughout the study................................ 32

Figure 31. Thermogravimetric analysis before and post-grinding ...................................... 38

Figure 32. Power input and specific energy required by each type of media material: (a) Ceramic balls, (b) Alumina beads, (c) Silica beads, and (d) Granular sand.......................................... 40

Figure 33. Specific energy input of each type of media material. ......................................... 40

Figure 34. Particle size distribution of feed and ground products obtained by each type of grinding

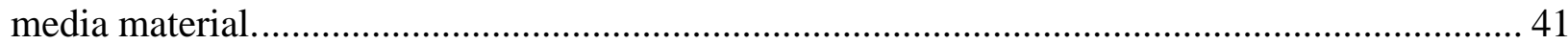

Figure 35. Degradation process of granular sand. Samples taken at the $0.5^{\text {th }}$ and $64^{\text {th }}$ minute during

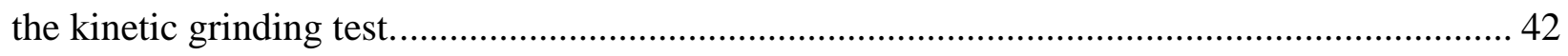

Figure 36. Shape analysis of the grinding media materials before and after stirred mill grinding tests. 43

Figure 37. Image analysis of grinding media materials submitted to grinding stress..... 44

Figure 38. Power input and specific energy required by silica beads with different sizes: (a) Fine silica beads 40 x $210 \mu \mathrm{m}$, and (b) Coarse silica beads 420 x $850 \mu \mathrm{m}$................................... 45

Figure 39. Specific energy input of silica beads with different sizes. 46

Figure 40. Particle size distribution of feed and ground products obtained using regular and coarse silica beads. 47

Figure 41. Shape analysis of silica beads with different size ranges before and after stirred mill grinding tests. 48

Figure 42. Power input and specific energy required by coarse silica beads and ceramic balls with different solids concentrations by weight.

Figure 43. Specific energy input of coarse silica beads and ceramic balls with different solids concentration by weight. 50

Figure 44. Particle size distribution of feed and ground products obtained using coarse silica beads (CSB) and ceramic balls (CB) with different solids concentrations by weight. 51

Figure 45. Power input and specific energy required by coarse silica beads and ceramic balls with different doses of sodium silicate as a viscosity modifier. 53 
Figure 46. Specific energy input of coarse silica beads and ceramic balls employing different doses of sodium silicate as a viscosity modifier.

Figure 47. Particle size distribution of feed and ground products obtained using coarse silica beads with different doses of sodium silicate as a viscosity modifier. ............................................. 55

Figure 48. Overall specific energy input as a function of product size .................................. 58 Figure 49. Trendline of specific energy and product size as a function of various grinding media

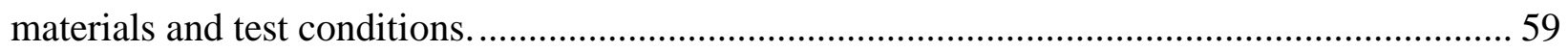
Figure 50. Mean squared error (MSE) minimization on coarse silica beads using particle swarm optimization (PSO). 61

Figure 51. Mean squared error (MSE) minimization on ceramic balls using particle swarm optimization (PSO). 61 Figure 52. Simulation using population balance modeling for various grinding media materials under standard test conditions. 62 Figure 53. Simulation using population balance modeling for coarse silica beads and ceramic balls with different solids concentrations. 63 Figure 54. Simulation using population balance modeling for coarse silica beads and ceramic balls with different dosages of sodium silicate as a viscosity modifier. 64 Figure 55. Correlation analysis between simulated and experimental cumulative percent passing obtained using coarse silica beads. 65 Figure 56. Correlation analysis between simulated and experimental cumulative percent passing obtained using ceramic balls. 66 


\section{CHAPTER 1: INTRODUCTION}

\subsection{BACKGROUND}

Ultrafine grinding has become more critical over the years with the increase of fine-grained ores and the depletion of high-grade deposits (Semsari Parapari et al., 2020). Comminution operations require a continuous development due to the great demand of run-of-mine material to be processed, finer product size required and elevated energy consumption (Fuerstenau, 1995). Ultrafine grinding processes can require up to $4 \%$ of the global electric power on an industrial scale and represent around 50\% of the mine site's total consumption (Jeswiet and Szekeres, 2016). Therefore, developing performance-enhancing mechanisms that make particle size reduction processes economically and energetically viable has the utmost importance.

In the past decades, several studies have been conducted to beneficiate ultrafine coal, which is widely used for the production of high-purity materials, synthetic compounds, or by-products derived from coal, depending upon its particle size and composition (Lewitt, 2011). For instance, Pinchuk et al. (2017) improved coal-water fuel (CWF) combustion behavior using an electromagnetic treatment. The solid component of the fuel was coal with a particle size distribution ranging between 0 to $250 \mu \mathrm{m}$. Moreover, Shukla and his co-workers (2008) used different sizes of coal samples (i.e., $108 \mu \mathrm{m}, 75.7 \mu \mathrm{m}$, and $62.9 \mu \mathrm{m}$ ) to demonstrate the particle size influence on the rheological behavior of multiphase fuels such as coal-oil-water fuel (COW). Novel nanostructures such as polycrystalline nano-graphite are also produced from fine coal powders (Masi et al., 2021). Graphite with a mean size of approximately $1 \mu \mathrm{m}$ is commonly used

for the production of solar stills where nano-particles and porous materials are required (Sharshir et al., 2017a; Sharshir et al., 2017b; Peng et al., 2021). It has also been demonstrated that fine and ultra-fine coal is a source of rare earth elements (REEs) and other critical minerals. Silva and his co-workers (2020) found that the spontaneous combustion of coal produced a significant amount of rare earth elements, carbon nanotubes, and graphene. These minerals can also be released by applying a grinding process followed by a decarbonization step (Huang et al., 2018). 
Nano-sized grinding is an energy-intensive and time-consuming process. Therefore, high-tech equipment is required to produce ultrafine material efficiently (Breitung-Faes \& Kwade, 2019). Stirred mills have been widely used in some specialized industries and now are gaining importance in the mining industry (Gupta and Yan, 2016). Stirred mills are typically classified as vertical mills (VertiMills) and horizontal mills (IsaMills); however, it is not limited to these two main categories (L. Taylor et al., 2020). Although the major difference between the mills is their geometry/shape, their operating principles are the same. Parameters such as stirring speed, feed rate, media filling, media size, pulp density, grinding aids, etc., are continuously studied to improve milling efficiency (Akkaya et al., 2015; Baigereyev and Guryanov, 2019). One common indicator to evaluate grinding performance is the size-energy relationship (Martins, 2020). Table 1 shows detailed information about the feed size, product size, and specific energy required to achieve the corresponding reduction ratio based on previous studies:

Table 1. Size-energy relationship of stirred mills.

\begin{tabular}{ccccc}
\hline Source & $\begin{array}{c}\mathrm{F}_{80} \\
(\mu \mathrm{m})\end{array}$ & $\begin{array}{c}\mathrm{P}_{80} \\
(\mu \mathrm{m})\end{array}$ & $\begin{array}{c}\text { Reduction } \\
\text { Ratio }\end{array}$ & $\begin{array}{c}\text { Spec. Energy } \\
(\mathrm{kWh} / \mathrm{t})\end{array}$ \\
\hline (Huang et al., 2020) & 23.40 & 10.29 & 2.27 & 397.00 \\
& 23.40 & 2.33 & 10.04 & 216.00 \\
& 23.40 & 6.04 & 3.87 & 262.00 \\
(Adeniji, 2018) & 23.40 & 4.42 & 5.29 & 323.00 \\
& 21.60 & 12.80 & 1.69 & 16.10 \\
& 86.40 & 51.20 & 1.69 & 92.90 \\
& 149.20 & 135.00 & 1.11 & 85.10 \\
& 21.60 & 5.70 & 3.79 & 218.40 \\
& 86.40 & 83.40 & 1.04 & 65.20 \\
(Wang et al., 2013) & 149.20 & 137.50 & 1.09 & 218.60 \\
& 21.60 & 4.50 & 4.80 & 270.40 \\
& 86.40 & 84.00 & 1.03 & 416.30 \\
& 149.20 & 102.60 & 1.45 & 128.40 \\
& 341.00 & 75.00 & 4.55 & 5.10 \\
& 66.00 & 36.00 & 1.83 & 6.50 \\
& 66.00 & 39.00 & 1.69 & 5.30 \\
& 62.00 & 36.00 & 1.72 & 5.60 \\
& 62.00 & 35.00 & 1.77 & 8.70 \\
& 2287.00 & 73.00 & 31.33 & 10.60 \\
& 1999.00 & 78.00 & 25.63 & 17.40 \\
\hline
\end{tabular}


Many researchers have explored ultrafine grinding behavior of various materials using stirred mills (Patel et al., 2014; Prziwara et al., 2018; Breitung-Faes and Kwade, 2019; Yao et al., 2019; Zhang et al., 2020). However, there are still many areas, including modeling and simulation, need to be studied to understand the grinding mechanism in detail. Therefore, this study sought to provide a better understanding of the effect of various parameters involved in grinding. Starting from the selection of suitable grinding media to the verification of results by modeling and simulation, this study evaluated the effect of various operating variables that affect the ultrafine coal grinding.

\subsection{OBJECTIVES}

The general objective of this research project was to investigate the influence of various parameters such as grinding media materials, media size, solids concentration and viscosity modifiers on ultrafine grinding of coal, as well as the development of numerical models to predict the particle size distribution of ground products. The optimization of energy consumption and product size along with the corresponding simulation were the main goals. Specific objectives included:

1. Enhance ultra-fine grinding of coal in terms of power consumption, reduction ratio and product particle size through kinetic stirred mill tests and simulation on Matlab.

2. Identify suitable grinding media materials that provide optimal grinding performance under various test conditions.

3. Determine the adequate size range of silica grinding media to produce micronized coal particles at low energy consumption.

4. Evaluate degradation process of grinding media materials by conducting shape analysis and their further recovery through wet screening.

5. Comprehend the effect of operating parameters like solids concentration and grinding aids like viscosity modifiers on the rheological properties of coal slurry.

6. Develop forecasting numerical models of particle size distributions using population balance modeling (PBM) with the corresponding breakage function, selection function and particle swarm optimization (PSO). 


\subsection{THESIS ORGANIZATION}

This thesis consists of six chapters. Chapter one gives a brief introduction, background, and general and specific objectives. The second chapter provides a comprehensive review of the fundamentals of comminution, advances in ultra-fine grinding employing stirred mills, and comminution modeling using population balance modeling. The third chapter shows the laboratory studies and grinding simulation comprised in the experimental work. Coal sample and grinding media characterization, experiment design and setup, specific energy input measurement and particle size, shape, and thermogravimetric tests are part of this chapter. The test results and corresponding discussions are presented in chapter number four. Detailed findings of the effect of grinding media material, media size, solids content and dispersant dosage on grinding performance are discussed in this section. The main conclusions of this research project and recommendations for future studies are presented in chapters five and six, respectively. 


\section{CHAPTER 2: LITERATURE REVIEW}

\subsection{FUNDAMENTALS OF COMMINUTION}

The very first steps in mineral processing are mineral liberation and particle size reduction either by crushing, grinding, or pulverization. These stages before mineral extraction are particularly energy-intensive processes and can be affected by multiple factors related to material properties, type of process, or pre-treatment (Semsari Parapari et al., 2020). Comminution is becoming increasingly important over the years with the increase of fine-grained ores and the depletion of high-grade deposits. It has pushed researchers to develop alternatives that enhance the overall performance of comminution operations due to the large demand of run-of-mine material to be processed, finer product size required, and elevated energy consumption (Fuerstenau, 1995).

\subsubsection{Breakage Mechanisms and Liberation}

Comminution is the particle size reduction stage in which mechanical forces such as compression or shear are applied to generate finer fragments of rock (Figure 1). According to Wills and Finch (2016c), the progressive reduction in the size of run-of-mine ores, either dry or more commonly in a slurry form, is commonly produced by a sequence of multiple breakage mechanisms simultaneously. Since economic-valuable minerals are normally scattered on the mineral matrix and are closely associated with gangue minerals, they first should be released prior to the separation process. Moreover, size reduction eases the transportation of ore throughout the process and increases surface area for subsequent operations (Wills \& Finch, 2016b).

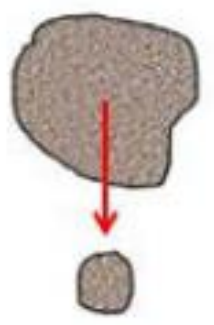

(a)

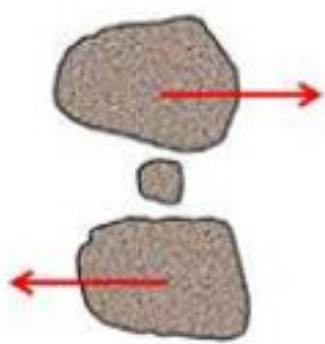

(b)

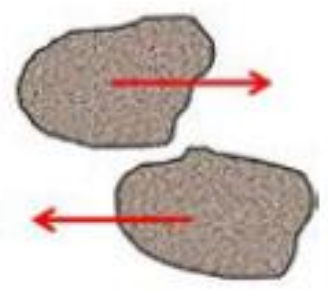

(c)

Figure 1. Mechanisms of breakage: (a) Impact or compression, (b) chipping or attrition, and (c) Abrasion (Wills \& Finch, 2016d). 
Figure 2 represents how mineral particles are commonly locked within a gangue matrix and the pattern of fragments normally obtained after breakage. Fully liberated valuable mineral, locked middlings, and fully liberated gangue are the most common products obtained after applying a crushing and/or grinding stress to lump of ore (Figure 3). Since middlings have not attained a complete liberation, particles are further submitted to a regrinding stage to achieve the desired degree of liberation. Achieving the liberation at the coarsest possible particle size is the primary objective of comminution as this saves energy during grinding and facilitates the subsequent separation and concentration processes. The measures of separation such as grade and recovery can be greatly impacted by the degree of liberation, therefore, it is inherent to study the breakage mechanism based on the rock composition, forming minerals and strength of boundaries (Wills \& Finch, 2016a).
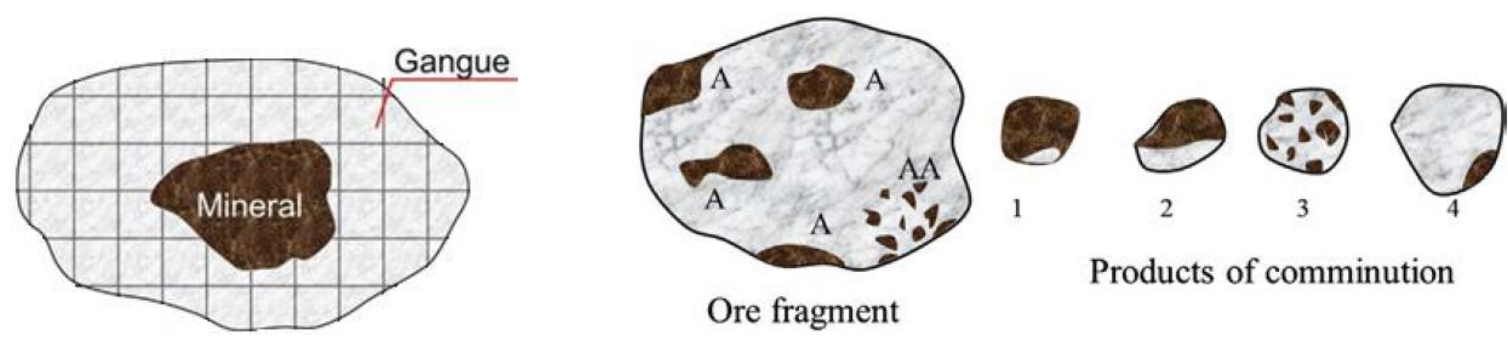

Products of comminution

Figure 2. Effect of breakage on liberation (Wills \& Finch, 2016a).

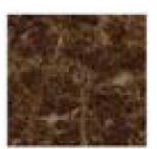

(1)

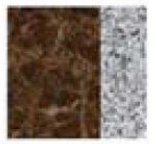

(3)

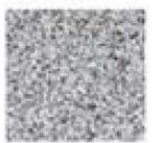

(5)

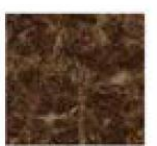

(2)

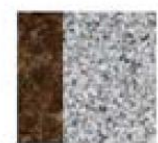

(4)

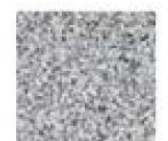

(6)

\section{Liberated mineral A}

\section{Locked middlings}

(3) $2 / 3$ mineral A

(4) $1 / 3$ mineral A

\section{Liberated gangue $B$}

Figure 3. Liberation patterns: (1) and (2) Liberated valuable mineral, (3) and (4) middlings, and (5) and (6) Liberated gangue mineral (Wills \& Finch, 2016a). 
In some cases, blasting is also considered part of the comminution process due to the rock fragmentation by using explosives. As reported by Chi et al. (1996), crack propagation is induced by releasing an enormous quantity of energy transformed into shock pressure, heat, noise, vibration and, gas expansion. The magnitude of the shock wave produced during the denotation is higher than the strength of the surrounding rock, thus producing a deep fragmentation in the material next to the drill hole. For many years, experts have been studying the influence of crack generation by blasting in the efficiency of downstream processes related to particle size reduction. This hypothesis has also been studied for decades and was supported by Revnivtsev (1988), who demonstrated the lower energy required to crush and grind rock samples submitted to explosiveinduced cracking compared to fresh rock. Later on, Chi et al. (1996) confirmed that rock weakening by using explosives substantially enhances both crushing and grinding performance.

The alteration in mineral grindability due to blasting operations has also been studied by Khademian and Bagherpour (2017), where they concluded that using explosives for fragmentation reduces considerably the mechanical strength of rock mass. According to their findings, the crushability index can be up to $12.11 \%$ (Figure 4) and the Bond work index around 18\% (Figure 5) lower than fresh rock depending on the type of explosive employed. The authors stated that "there is a correlation between mechanical strength of rock fragments and their comminution behavior, rocks with higher strength have a higher Bond index and lower crushability index".

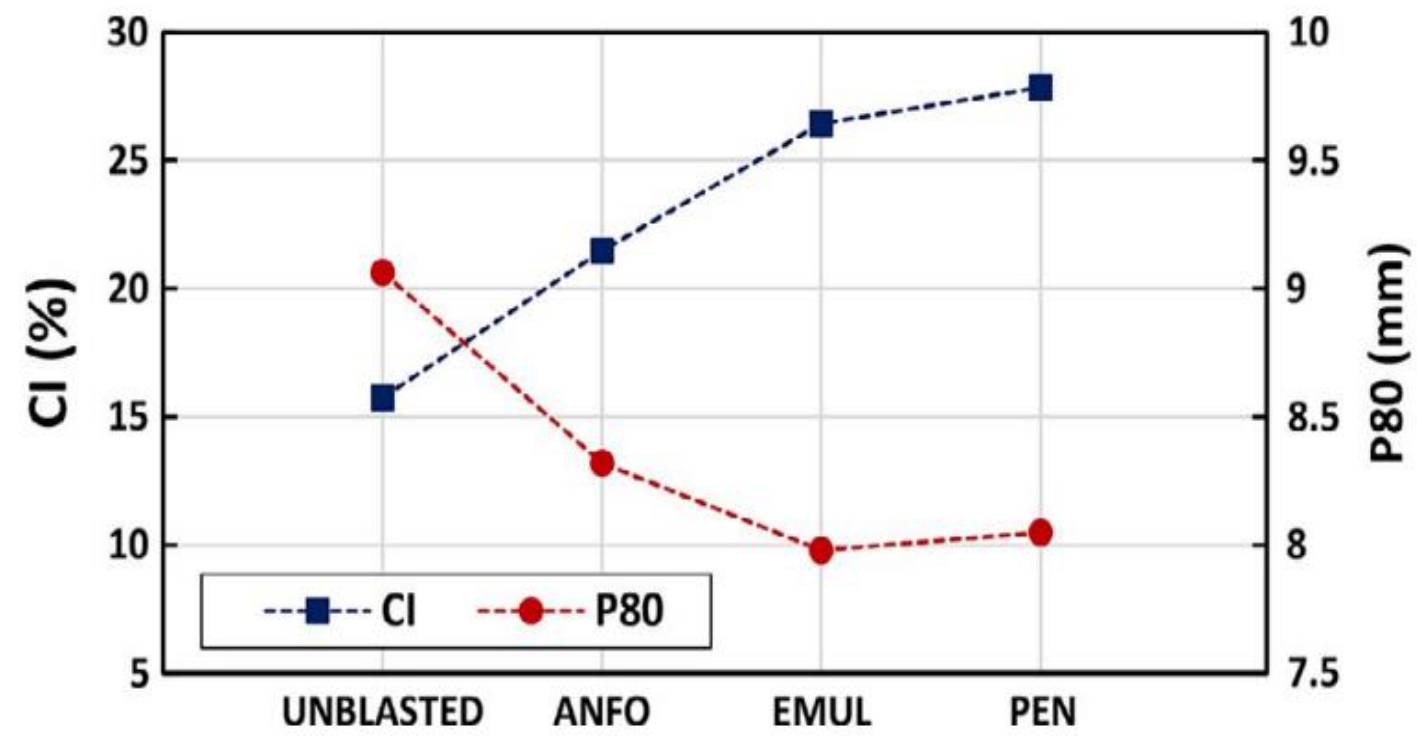

Figure 4. Crushability Index (CI) and $\mathrm{P}_{80}$ values for different types of explosives (Khademian \& Bagherpour, 2017). 


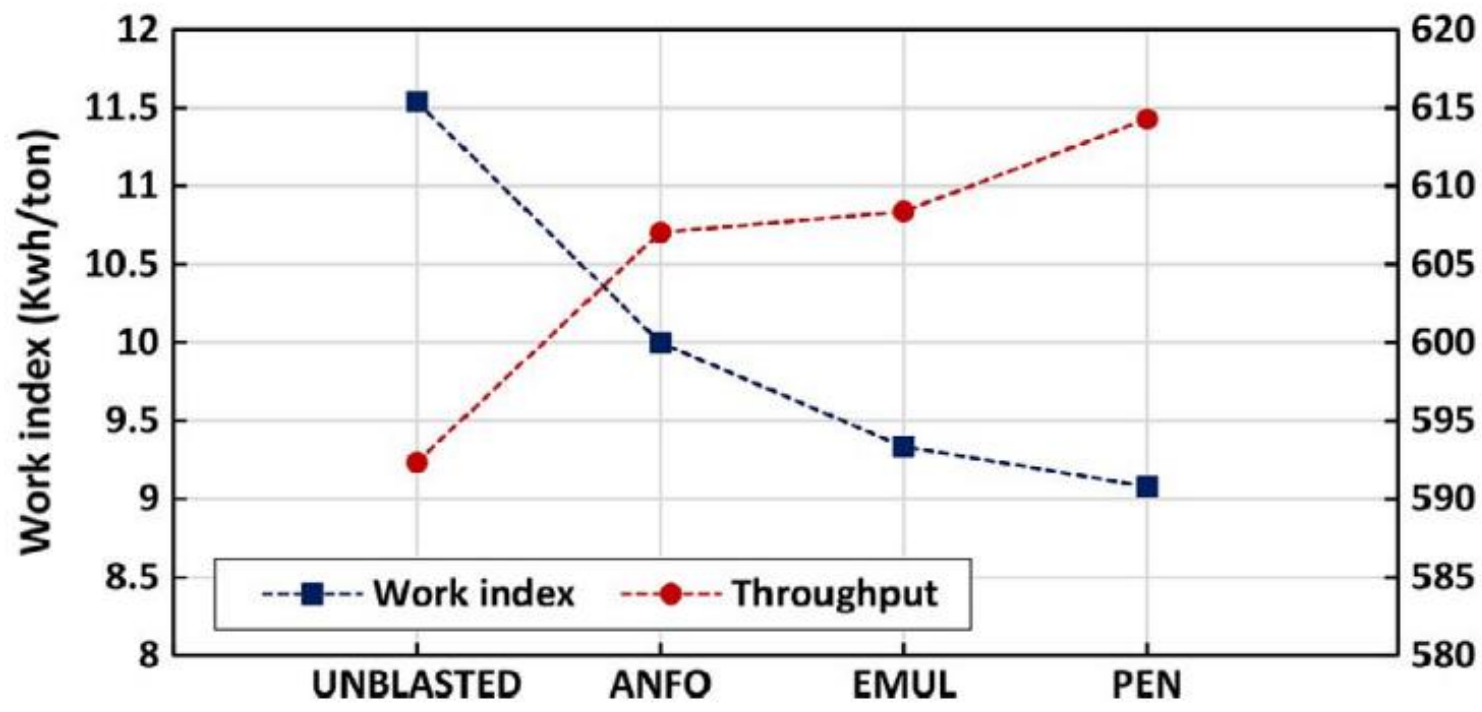

Figure 5. Bond work index and throughput values for different types of explosives (Khademian \& Bagherpour, 2017).

Similar results were obtained by Kai Nielsen and Kristiansen (1996), Kai Nielsen and Mick Lownds (1997), and Nielsen and Malvik (1999) who focused their studies on the variation of fragments' microcrack network induced by blasting. They conducted some experimental blasting and grinding tests on different rock samples including taconite, gabbro, quartz diorite, and monzonite, and found out that changing the blast parameters has a significant influence on the Bond work index of the resulting fragments. As shown in Table 2, the number of small, boundary, and grain cracks registered increased as the level of blasting energy increased.

Table 2. Quantitative assessment of the crack density in thin sections of taconite and ilmenite ores subject to blasting (Nielsen \& Malvik, 1999).

\begin{tabular}{lccc}
\hline Sample & Small cracks & Boundary cracks & Grain cracks \\
\hline Taconite 1 & 98 & 97 & 45 \\
Taconite 2 & 146 & 130 & 72 \\
US taconite 1 & 55 & 48 & 15 \\
US taconite 2 & 73 & 116 & 23 \\
US taconite 3 & 84 & 103 & 35 \\
Ilmenite ore 1 & 40 & 9 & 31 \\
Ilmenite ore 2 & 74 & 15 & 48 \\
Ilmenite ore 3 & 97 & 18 & 80
\end{tabular}


Figure 6 illustrates an economic evaluation of crushing and grinding when including blasting as part of the comminution process. Drilling and blasting not only have a direct influence on crushing and grinding productivity but also in operations like loading, hauling, and subsequent stages of mineral processing. The use of a greater amount of explosives leads to higher operating costs but substantially reduces costs associated with wear and tear of equipment, and lowers the energy needed to achieve a certain level of fragmentation. Usually, mining and processing operations are the responsibility of different departments, so it is inherent that they coordinate their activities in order to optimize the system by scrutinizing the whole production process (Nielsen \& Malvik, 1999).

MINING
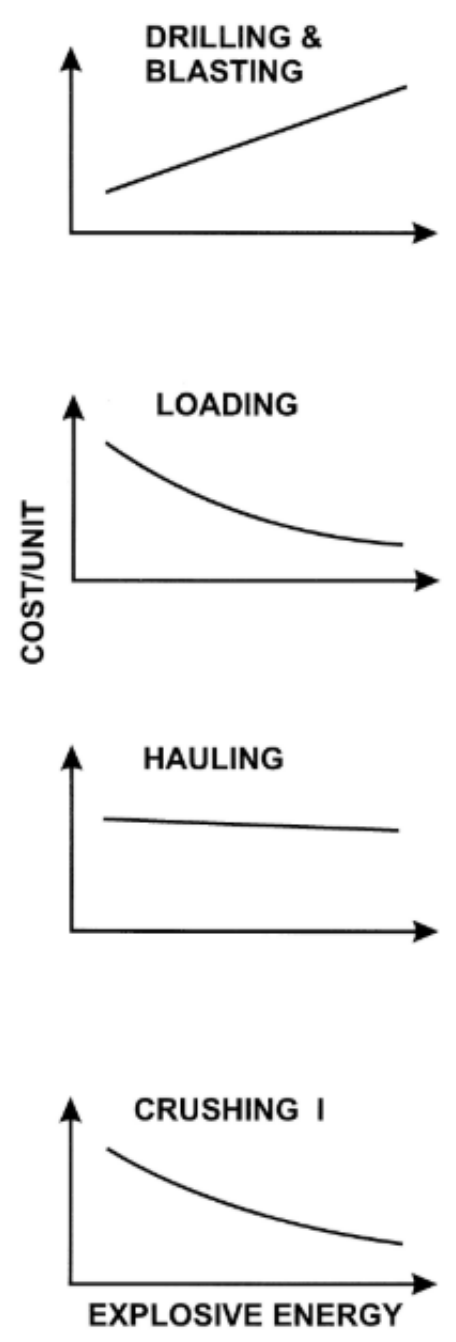

\section{PROCESSING}
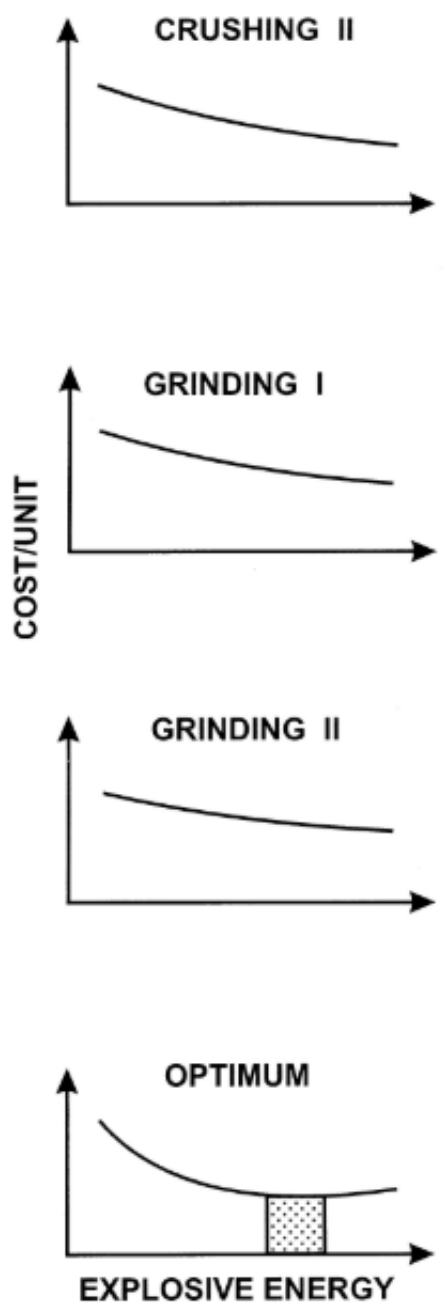

Figure 6. Optimum blasting leads to cost minimization for mining and processing (Nielsen \& Mick Lownds, 1997). 


\subsubsection{Crushing and Grinding Stages}

The comminution process is mainly composed of crushing and grinding stages. Primary, secondary, and tertiary crushers, and primary and/or secondary mills are commonly used in industrial circuits depending on the requirements (Figure 7). The number of unit operations and type of equipment required depend on parameters such as feed size $\left(\mathrm{F}_{80}\right)$, product size $\left(\mathrm{P}_{80}\right)$, ore hardness, ore type, equipment availability, operating costs, maintenance costs, etc. (OrtizLandazuri \& Colay, 2019; Stanujkic et al., 2019). Although many modern coal preparation plants do not include ultra-fine grinding in their grinding circuits (Noble \& Luttrell, 2015), stirred mills are commonly operated in open circuits (Figure 8). One of the largest horizontal stirred mills commercially available was installed in the Kyrgyz Republic. This IsaMill has a volume of $10 \mathrm{~m}^{3}$, an installed power capacity of $3,000 \mathrm{~kW}$, and was installed to increase zinc recovery by enhancing mineral liberation (Burford \& Clark, 2013).

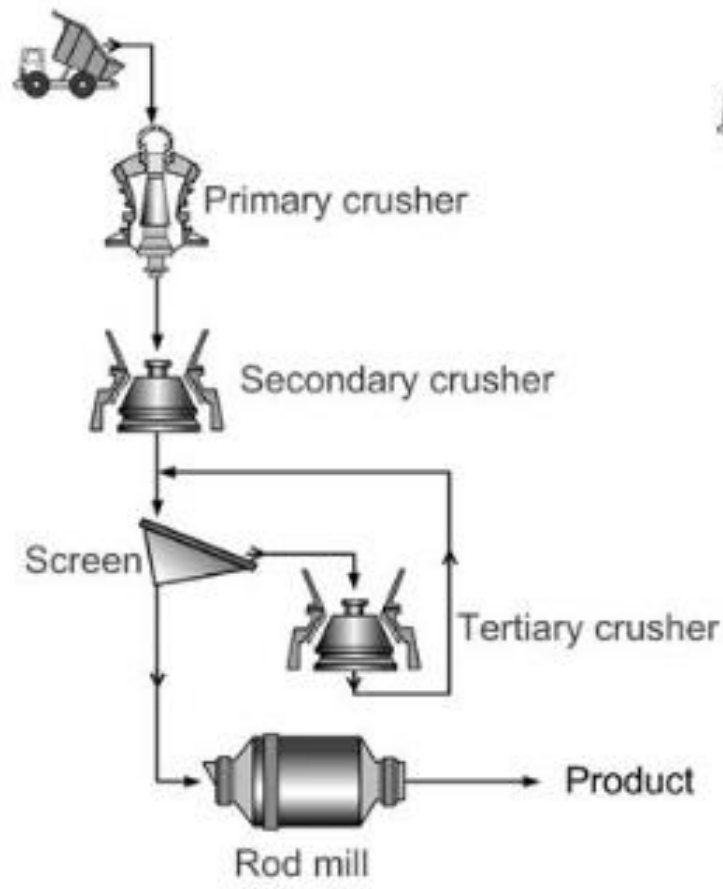

(a)

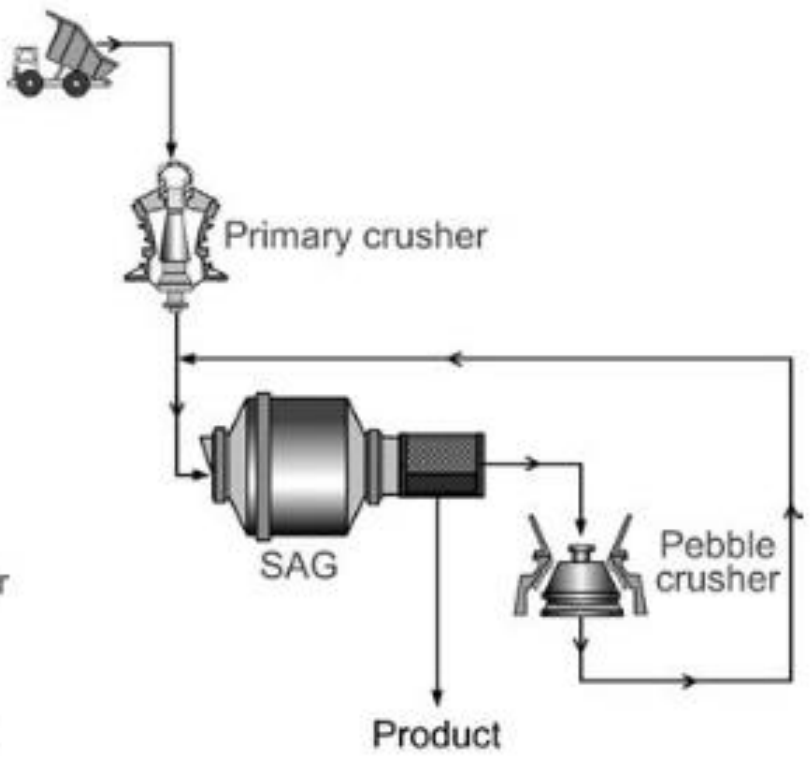

(b)

Figure 7. Example crushing flowsheets feeding a: (a) rod mill, and (b) SAG mill with a "recycle" (pebble) crusher to reduce the "critical size" material size (Wills \& Finch, 2016c). 


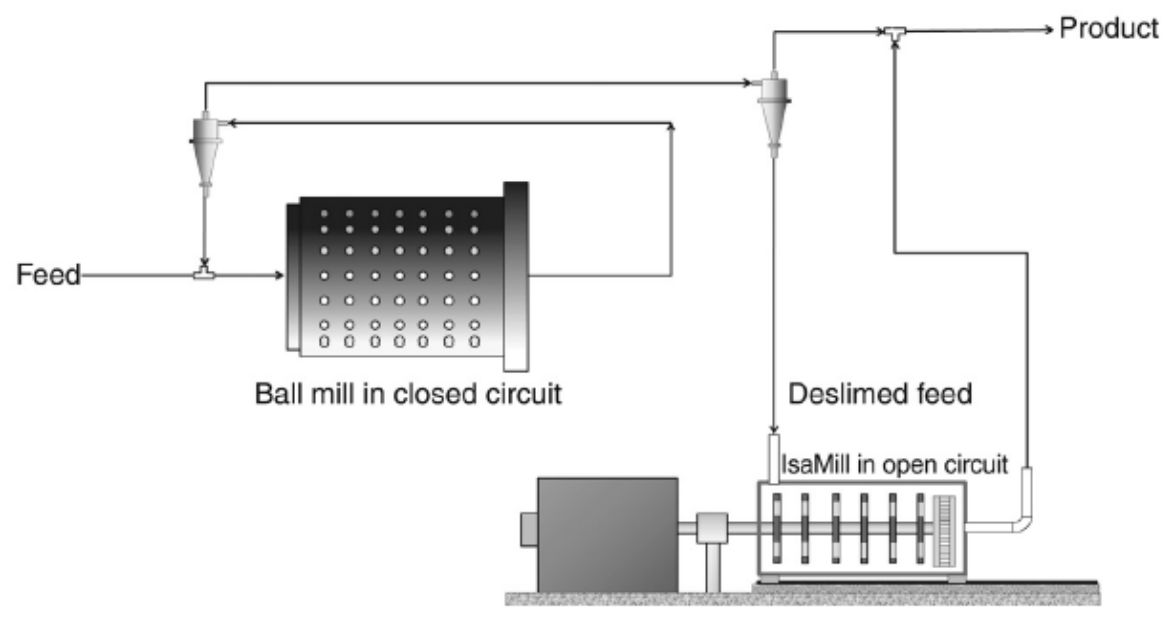

Figure 8. Flow diagram of an IsaMill in an open grinding circuit (Gupta \& Yan, 2016a).

Figure 9 shows the general size range for typical unit operations in crushing and grinding. Autogenous Mills (AG), Semi-autogenous Mills (SAG), and high-pressure grinding rolls (HPGRs) span a broad range of comminution particle size ranges and applications. AG/SAG mills are used in primary milling applications but achieve both coarse particle breakage and fines production relative to conventional crushing circuits, the product of AG/SAG circuits typically generates more fines. HPGRs are most typically used as a stage of comminution but have been broadly employed in many different stages: tertiary crushing, secondary pebble-crushing, and quaternary crushing roles, as well as fine-grinding applications (Mosher, 2016).

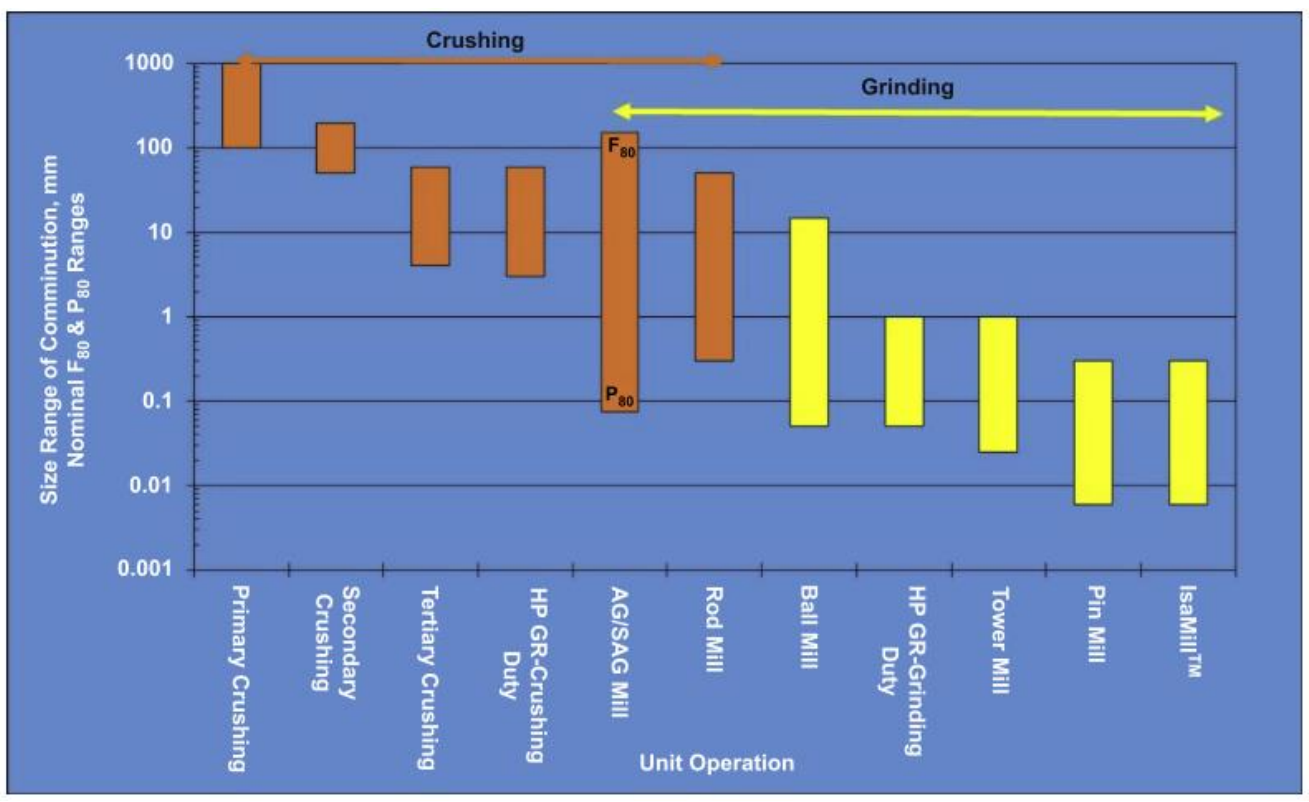

Figure 9. Applicable size range for comminution unit operations (Mosher, 2016). 
Efforts have been continuously devoted to developing models that help optimize comminution circuits. The use of deep neural networks and genetic algorithms are some of the approaches extensively used for design and optimization purposes (Farzanegan \& Vahidipour, 2009; Koh et al., 2021). Several steady-state and dynamic simulation tools such as JKSimMet and MODSIM are available in the market to assist mineral processing engineers (Song et al., 2018). The exploration of different scenarios of efficient comminution operations at low cost is the main goal of simulation (Ureta et al., 2019). Craig and Henning (2000) illustrated the general control problem framework in Figure 10, which represents the plant in the real world versus the plant model in a mathematical world. This model predictive control was successfully implemented in a coal comminution circuit by Meyer et al. (2019), in which the objective function was established to maximize throughput while maintaining bins level.

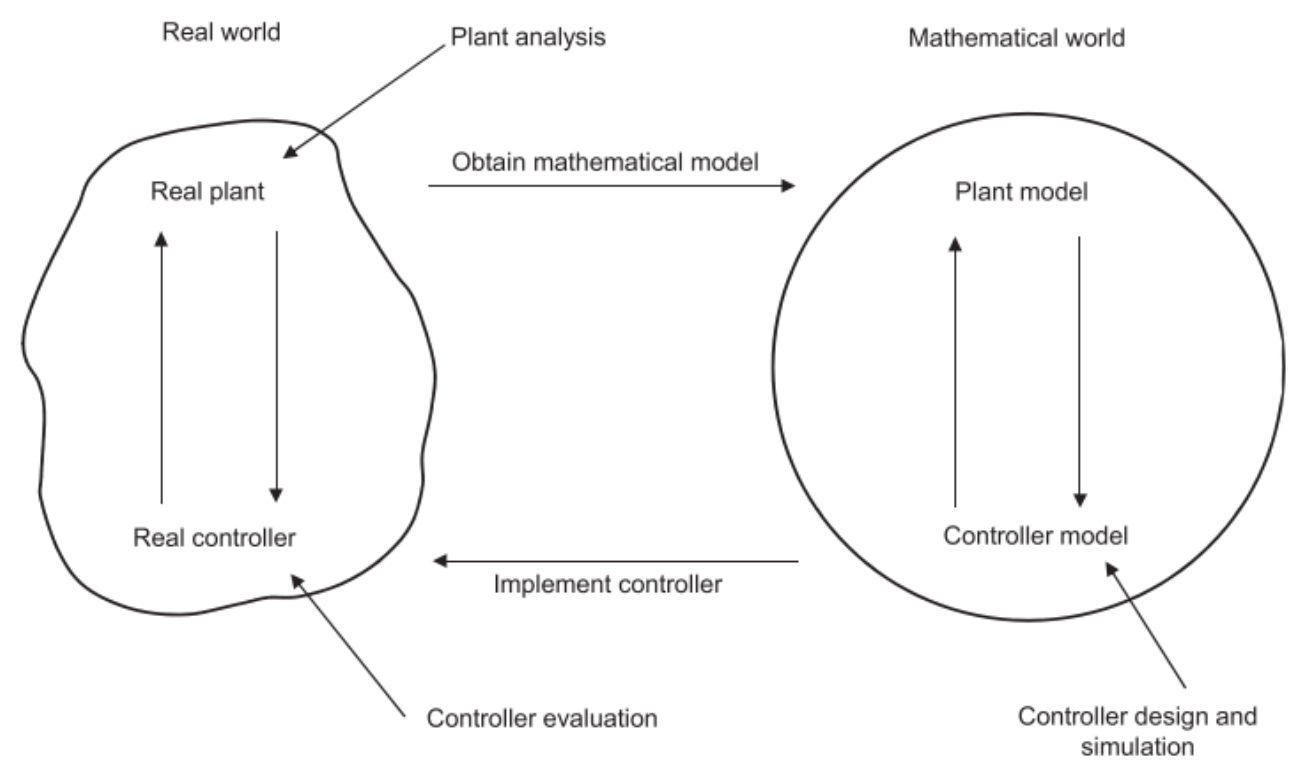

Figure 10. The general control problem (GCP) framework (Craig \& Henning, 2000). 


\subsubsection{Comminution Equipment}

\subsubsection{Crushers}

Crushing is the very first step in mineral processing and can be classified in primary, secondary, and tertiary crushing depending on parameters such as feed size handling capacity and reduction ratio. Figure 11 shows the main parts that make up a double-toggle jaw crusher, which is heavyduty equipment normally used in primary crushing to process ROM material. Breakage is produced when mineral particles are compressed by the force of a movable jaw towards a fixed corrugated plate. Jaw crushers' capacity is mainly determined by design parameters such as the vertical height and width of the jaw, and the pivot can be in different positions resulting in multiple configurations (Figure 12). The maximum feed size is controlled by the gape, which is the distance between the jaws at the feed opening, while the open side set (OSS) determines the discharge size of the material (Wills \& Finch, 2016c).

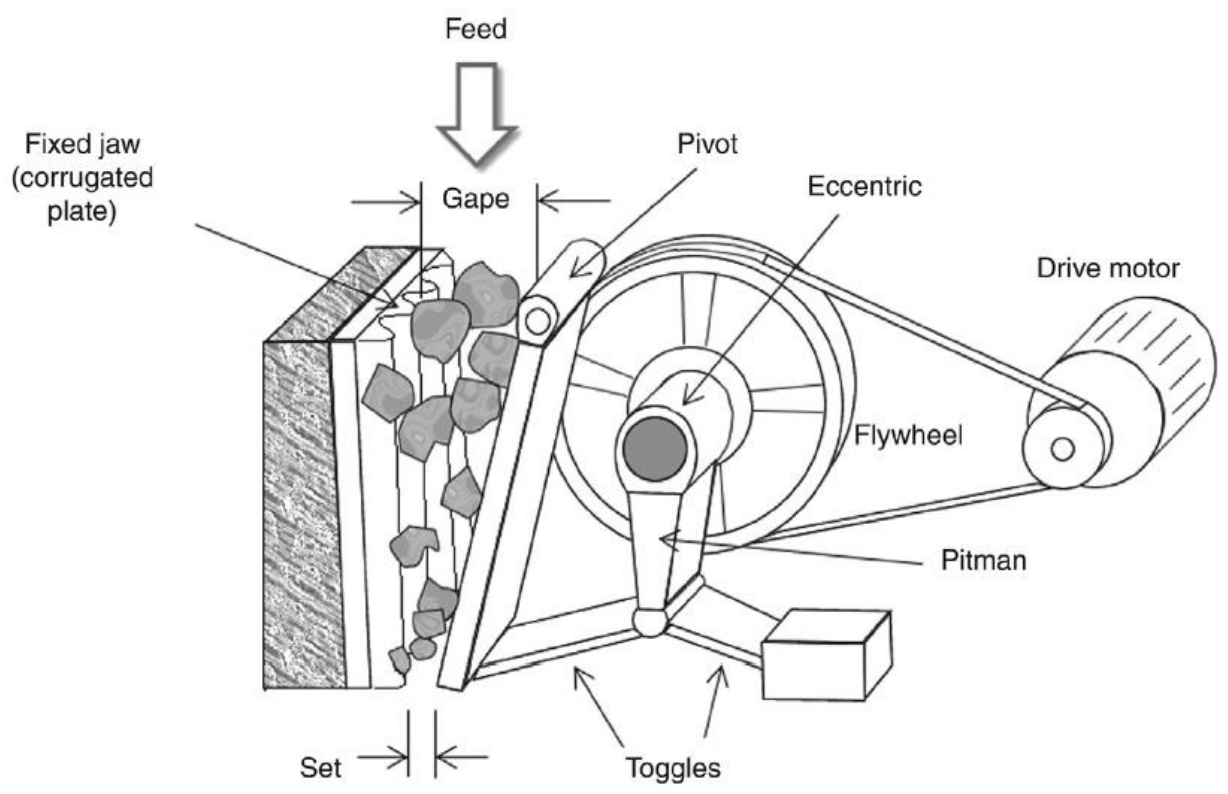

Figure 11. Sketch of a double-toggle jaw crusher (Gupta \& Yan, 2016c).

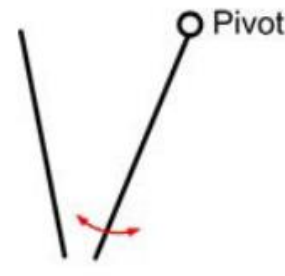

Blake

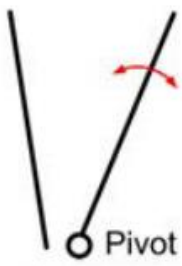

Dodge

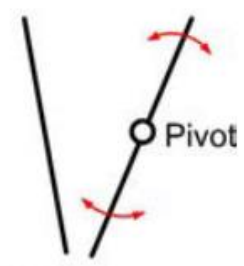

Universal

Figure 12. Jaw-crusher pivot configuration (Wills \& Finch, 2016c). 
Gyratory crushers are frequently used in secondary crushing receiving lumps of rock coming from jaw crushers. Although the design of gyratory crushers is completely different compared to jaw crushers, the breakage mechanism is primarily based on the compression force applied to the mineral particles by two pieces of steel (Figure 13). This type of crusher consists of a fixed conical shell, a long spindle suspended from a "spider" that holds a cone known as mantle or crushing head. The particle size reduction process occurs when rock pieces slip down between the shell and the mantle as it rotates between 85 and $150 \mathrm{rpm}$ (Figure 14). Smaller versions of gyratory crushers are described as cone crushers and are employed in tertiary crushing (Brown, 2016).

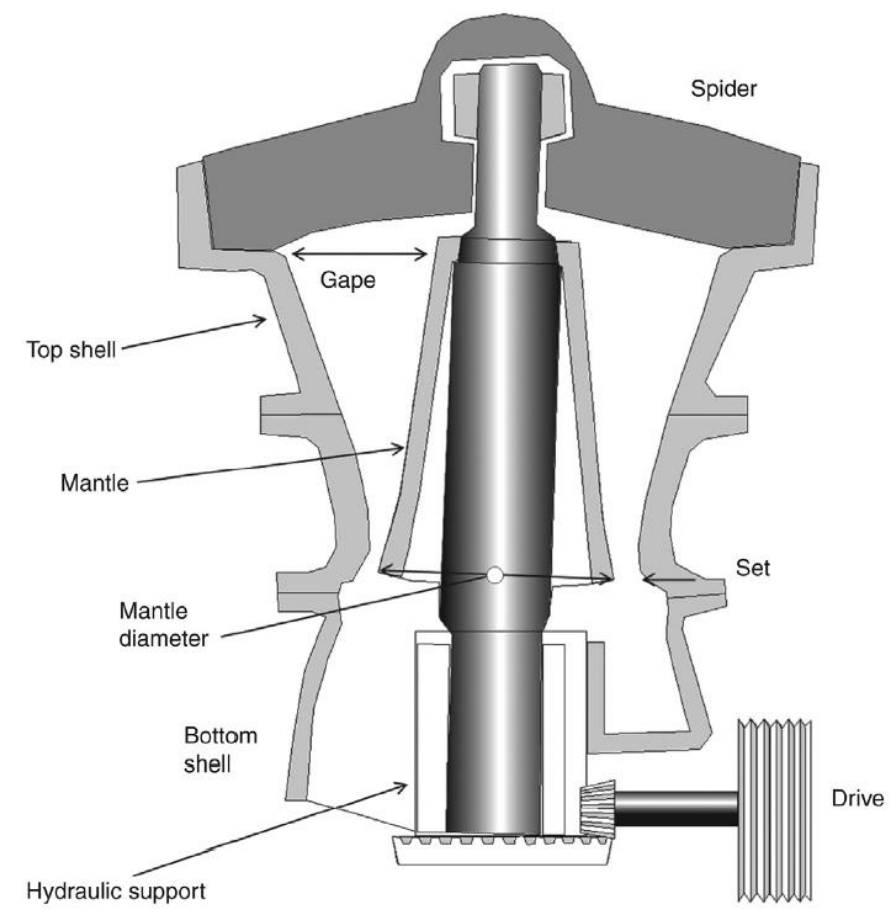

Figure 13. Schematic diagram of a gyratory crusher (Brown, 2016).

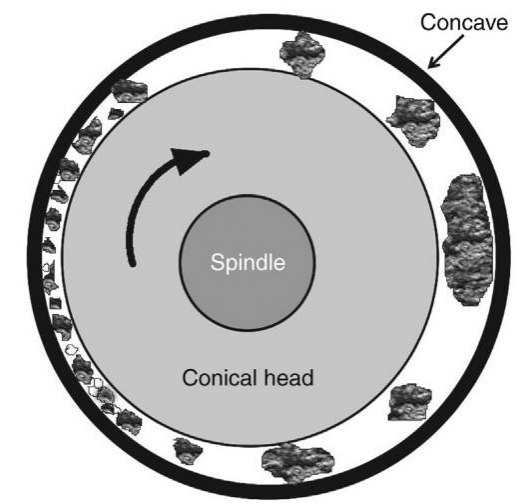

Figure 14. Cross-section of a gyratory crusher (Brown, 2016). 
Roll crushers are another type of crushers whose operating system is relatively straightforward. Basically, two parallel rolls rotate in opposite directions creating large forces of compression (Figure 15). Roll crushers are also known as high-pressure grinding rolls (HPGR) due to this characteristic. The gape or distance between rolls can be adjusted, allowing some degree of freedom to handle different sizes. An important parameter is the nip angle, which is defined as the angle that is tangent to the roll surface at the points of contact between the rolls and the particle (Gupta \& Yan, 2006a), and it is used to determine the maximum size of rock gripped by the rolls based on their diameters and gape (Figure 16).

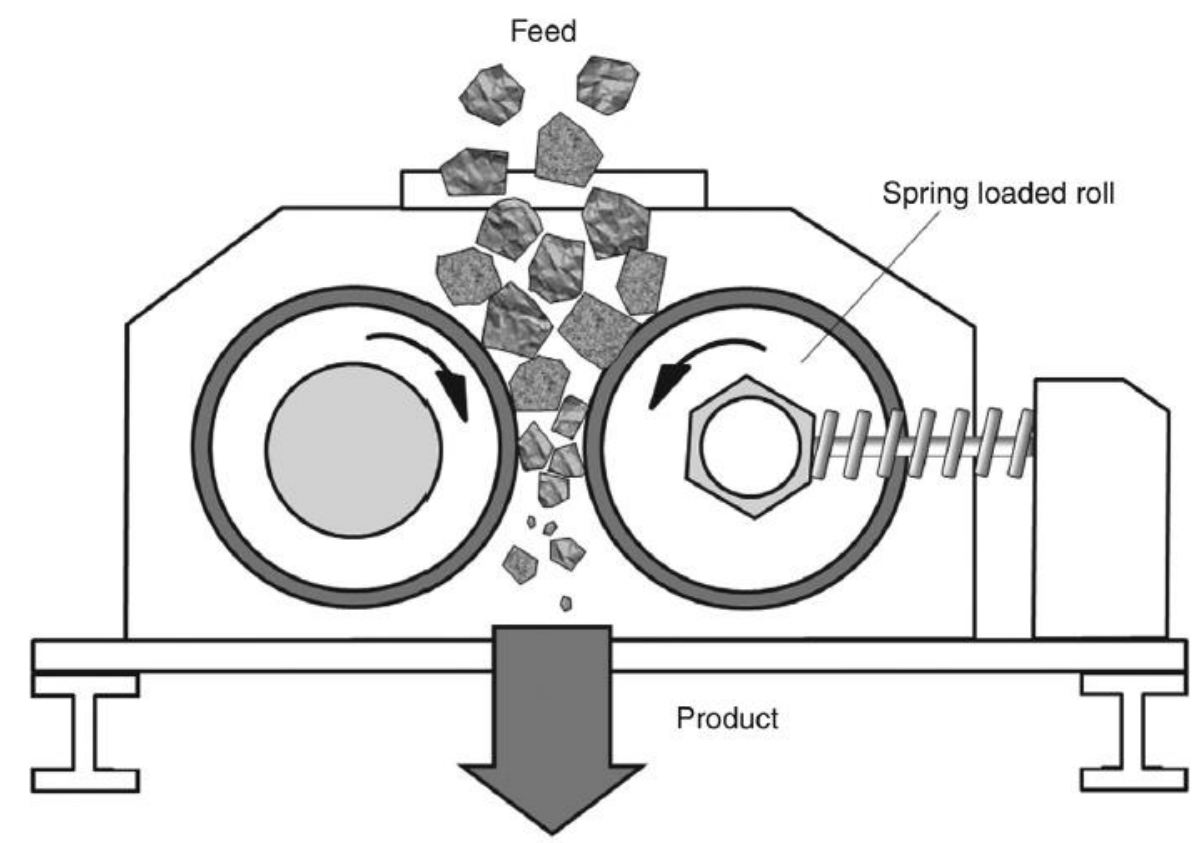

Figure 15. Schematic diagram of roll crushers (Gupta \& Yan, 2006a).

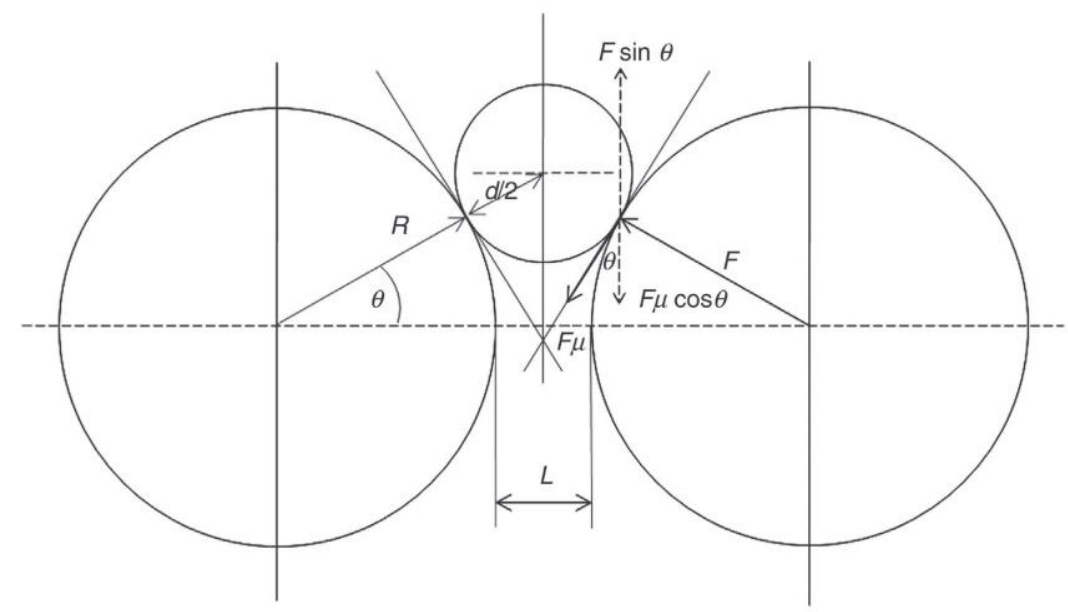

Figure 16. Nip angle and forces acting on a particle during crushing (Gupta \& Yan, 2006a). 


\subsubsection{Mills}

Coarse lumps of rock are initially fractured during crushing primarily by the application of compressive and/or impact forces. However, after crushing, the particulate material is not fine enough to achieve the liberation size, thus grinding stages are needed. Ball mills and rod mills are the most common equipment used in comminution circuits (Figure 17), as well as autogenous (AG) and semi-autogenous (SAG) mills (Figure 18). Both devices consist of a rotating cylinder that contains the charge of crushed material. The major difference between each type of equipment is the lack of grinding media in AG mills, or the small ball charge in SAG mills, and the large diameter-to-length $(\mathrm{D} / \mathrm{L})$ ratio. In tumbling mills, the breakage process is produced by the impact of the grinding media against the mineral particles and perimeter of the mill, whereas in AG/SAG mills the ore breaks mainly due to the impact after falling.

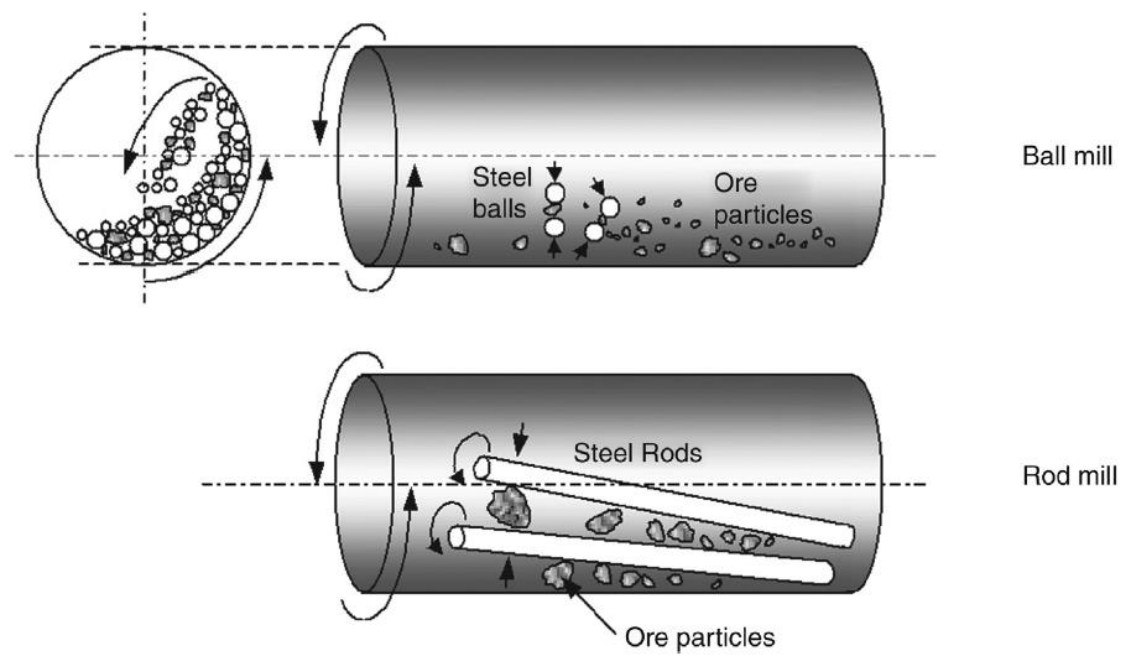

Figure 17. Breakage mechanisms in tubular mills (Gupta \& Yan, 2006b).

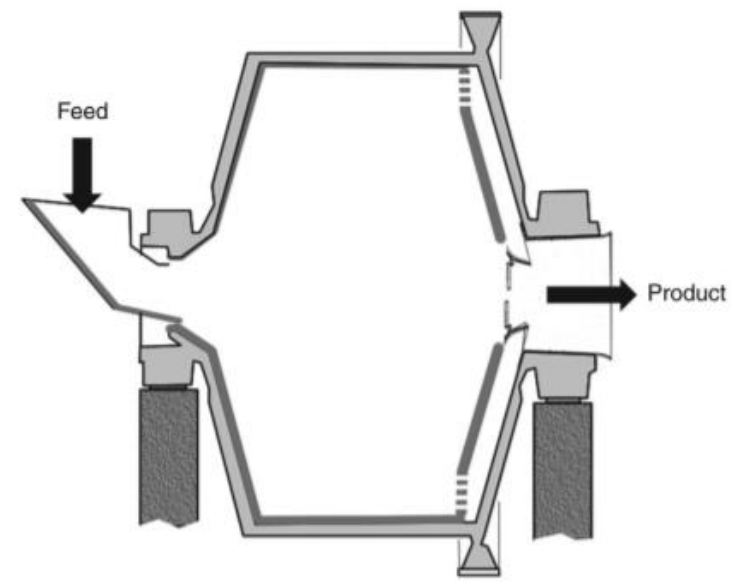

Figure 18. Schematic of a AG/SAG mills (Gupta \& Yan, 2016d). 


\subsubsection{Attrition Mills}

Also known as attrition mills, stirred mills consist of a vertical drum with a stirrer connected on the top end of the cylinder. The shaft is driven by an external motor and the speed is controlled by a variable speed drive system. The impeller and shell surface can have different geometries, Figure 19 illustrates a vertical spiral and a vertical pin stirred mills. Table 15 in Appendix A displays detailed specifications of the stirred mills commercially available produced by industry-leading companies such as Glencore, Metso, Eirich, FLSmidth, and Outotec.
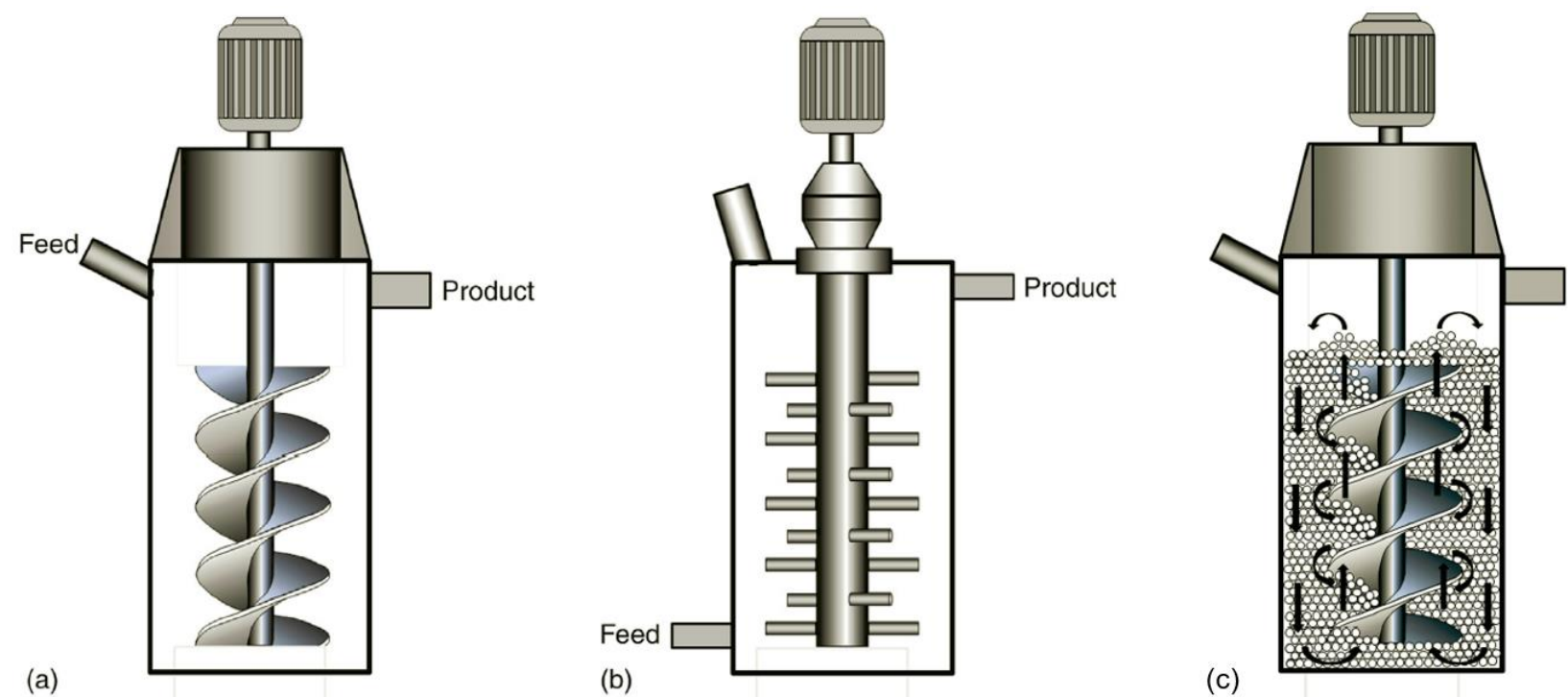

Figure 19. Illustration of a vertical spiral (a) and a vertical pin (b) stirred mills, as well as (c) flow pattern of slurry (Gupta \& Yan, 2016a).

Unlike tumbling mills, stirred mills use predominantly shear energy to produce the breakage. Shearing forces are more effective in fine grinding when the product $\mathrm{P}_{80}$ is less than $100 \mu \mathrm{m}$, and make stirred mills more energy-efficient due to the use of less energy per ton (Nesset et al., 2006). The utilization of small grinding media increases the probability of collision due to the higher surface area. Thus, tiny grinding beads coupled with high power densities delivered by the impeller result in an environment of elevated collision intensities (L. Taylor et al., 2020). Nevertheless, there is evidence of the existence of "grind limits" according to the conclusions drawn by Cho et al. (1996) during their investigation. Under specific controlled test conditions and using a slurry consisting of quartz and water, the minimum particle size achieved was about $30 \mathrm{~nm}$. 


\subsubsection{Energy-Size Relationship}

It is well-known that comminution is a high energy-consuming process, demanding up to $4 \%$ of the global electric power and representing around $50 \%$ of the total consumption in the mine site (Jeswiet \& Szekeres, 2016). According to the U.S Energy Information Administration (2020), the mining industry is in the top 3 most energy-intensive industrial sectors in the United States, accounting for $11 \%$ of the total sector's energy consumption (Figure 20). The bulk chemical and refining industries are the largest consumers accounting for $29 \%$ and $18 \%$ respectively.

Table 3. Energy production and consumption in the U.S in 2019 (U.S EIA, 2021).

\begin{tabular}{lc}
\hline Category & $\mathrm{x} 10^{15}$ Btu/year \\
\hline Total primary energy production & 101.04 \\
Total energy consumption & 100.17 \\
Total industrial sector energy consumption & 32.78 \\
Total mining industry consumption & 3.61 \\
\hline
\end{tabular}

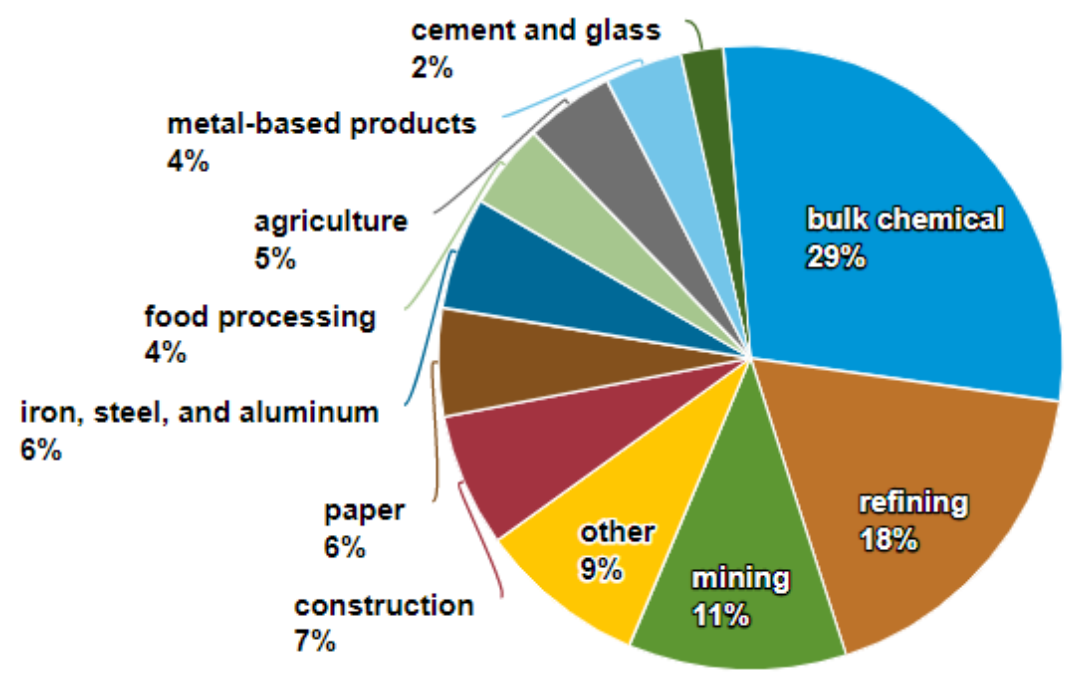

Figure 20. U.S industrial sector energy consumption by type of industry (U.S EIA, 2020).

A study carried out in 2007 found that grinding was the most energy-consuming operation in the U.S mining industry of coal, metals, and industrial minerals, accounting for $40 \%$ of the energy required in the mining project (Figure 21). Evidently, the energy needed in grinding far exceeds the energy needed to execute other operations in the mine, and both grinding and crushing consume 
approximately half of the total power (44\%). The study also showed that it is possible to save up to $258 \mathrm{Tbtu}(21 \%)$ per year by implementing best practices in all the operations, or also, to lower the energy consumption up to $54 \%$ by using cutting-edge technology that increases the effectiveness of the processes. This is an exceptional opportunity for saving money by reducing operating costs, but it also exposes the tremendous gap between the actual and theoretical performance of the mining practices (BCS, 2007).

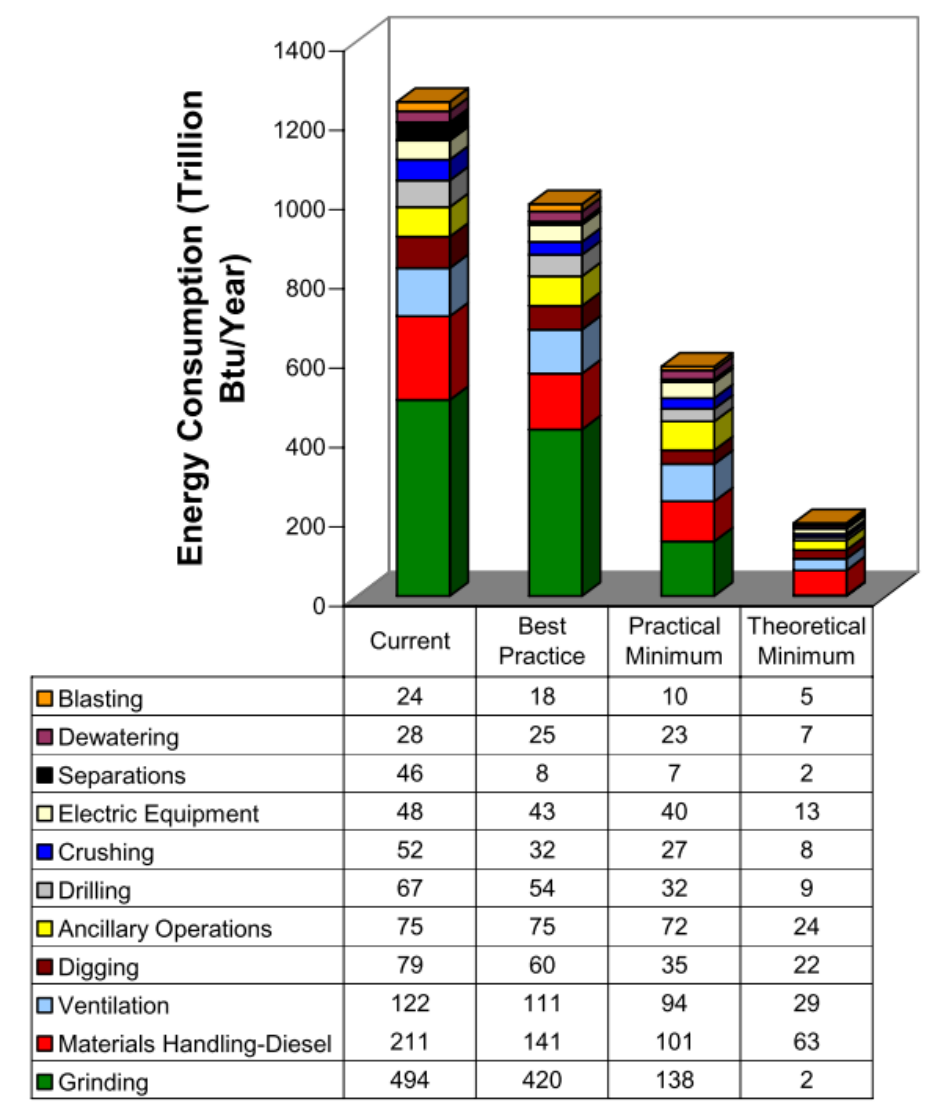

Figure 21. The estimated current, best practice, practical minimum, and theoretical minimum energy consumption by mining equipment (BCS, 2007).

The relationship between product particle size and energy consumption for both crushing and grinding is inversely proportional. It means, the finer the product the more energy is needed to comminute, although, there are multiple parameters involved that can change the behavior of comminution. Foggiatto (2017) evaluated different scenarios of the comminution circuit for various case studies in order to develop a multi-component model that responds to variable stream properties (Table 4). The results obtained in the base case of case study number 2 show the 
increasing trend of the energy consumption of different unit operations in the comminution circuit to produce a $-0.15 \mathrm{~mm}$ product size (Figure 22). On this occasion, the SAG mill was counted as part of the crushing stage due to its capability to handle a wide range of particle sizes, but it can be considered as grinding equipment as well according to the situation.

Table 4. Operating parameters of crushing and grinding operations (Foggiatto, 2017).

\begin{tabular}{|c|c|c|c|c|c|c|c|}
\hline \multirow{5}{*}{ 号 } & Circuit & $\begin{array}{l}\text { Solids } \\
\text { (t/h) }\end{array}$ & $\begin{array}{c}F_{80} \\
(\mathrm{~mm})\end{array}$ & $\begin{array}{c}P_{80} \\
(\mathrm{~mm})\end{array}$ & $\begin{array}{c}\text { Power } \\
\text { draw (MW) }\end{array}$ & $\begin{array}{c}\text { Specific energy } \\
\text { (kWh/t) }\end{array}$ & $\begin{array}{l}\text { Circulating } \\
\text { load (\%) }\end{array}$ \\
\hline & Secondary crushers & 1148 & 124.1 & 58.6 & 0.44 & 0.38 & - \\
\hline & HPGR circuit & 2204 & 40.0 & 17.1 & 3.35 & 1.52 & $11 \%$ \\
\hline & SAG mill (M1) & 2612 & 23.6 & 2.77 & 15.3 & 5.87 & $4 \%$ \\
\hline & $\begin{array}{l}\text { SAG mill, sec. crushers } \\
\text { and HPGR circuit }\end{array}$ & 2500 & 98.5 & 2.19 & 19.1 & 7.65 & - \\
\hline \multirow{5}{*}{ 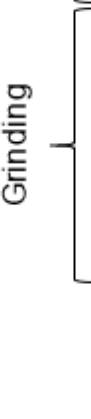 } & $\begin{array}{l}\text { Ball mill (M2) and } \\
\text { cyclone (C1) circuit }\end{array}$ & 628 & 2.19 & 0.13 & 9.7 & 15.41 & $462 \%$ \\
\hline & $\begin{array}{l}\text { Ball mill (M3) and } \\
\text { cyclone (C2) circuit }\end{array}$ & 553 & 2.19 & 0.10 & 9.7 & 17.50 & $579 \%$ \\
\hline & $\begin{array}{l}\text { Ball mill (M4) and } \\
\text { cyclone (C3) circuit }\end{array}$ & 1319 & 2.40 & 0.18 & 15.6 & 11.82 & $293 \%$ \\
\hline & $\begin{array}{l}\text { Combined ball mill } \\
\text { circuit }\end{array}$ & 2500 & 2.30 & 0.15 & 35.0 & 13.98 & - \\
\hline & Whole circuit & 2500 & 98.5 & 0.15 & 54.1 & 21.63 & - \\
\hline
\end{tabular}

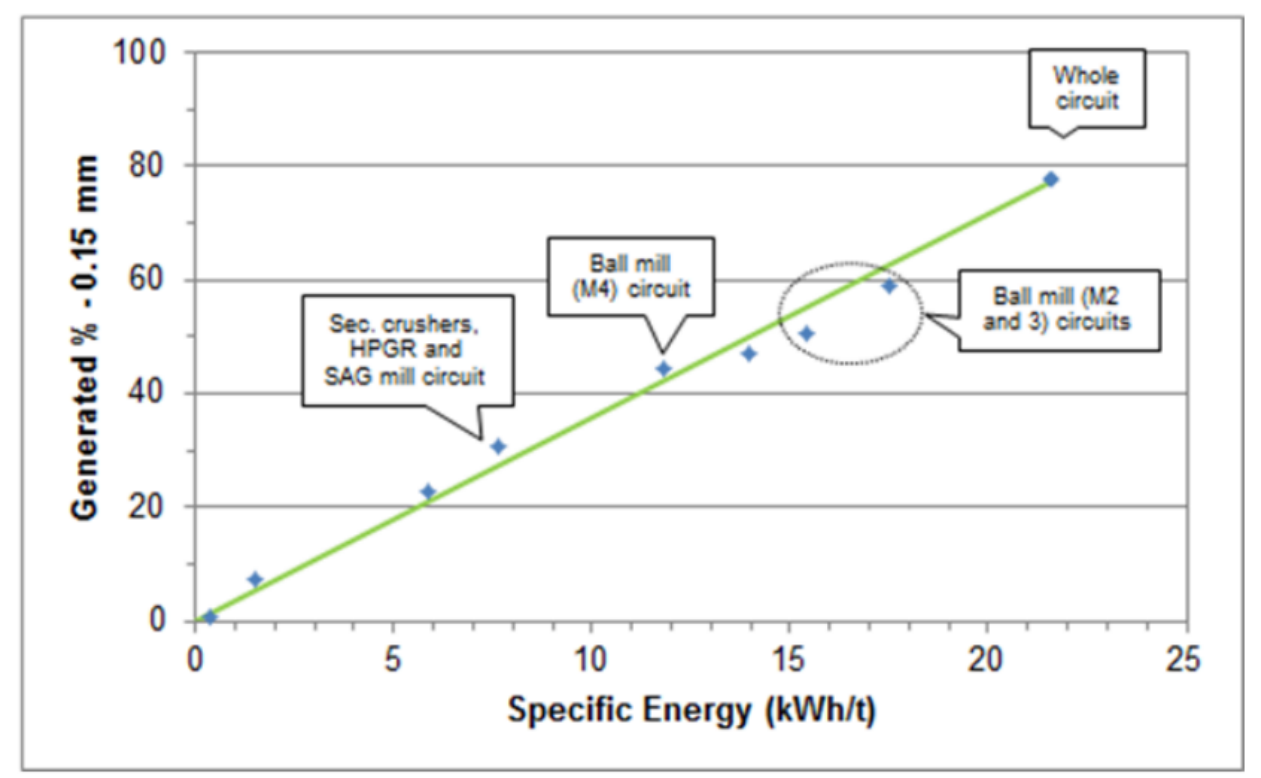

Figure 22. Specific energy required to produce $-0.15 \mathrm{~mm}$ product (Foggiatto, 2017). 
The comminution process can be classified depending upon the level of fragmentation and the energy consumption varies accordingly. For example, grinding is classified by de Bakker (2014) into 3 different levels: a) Coarse; employing AG/SAG mill and producing a product size that ranges between 500 to 10,000 microns, b) Intermediate; using ball/rod mills and generating particle sizes between 40 to 400 microns and, c) Fine; employing stirred mills and obtaining particles under 40 microns in size is increasing. Although many authors propose different classifications systems for comminution, the increasing trend of the energy consumption versus particle size is common among scientific findings. For instance, Martins (2020) studied the correlation between the energy required to produce changes in the size of the particles and the product size obtained after applying that amount of energy. His findings support this theory by demonstrating that the Hukki relationship describes properly the relationship between particle size and specific energy, even though it does not provide truthful information about the size-energy relationship exponents. Liu et al. (2016) developed a model to address the energy consumption in the comminution of coal specifically, and they found that the lower the size modulus and distribution modulus, the higher comminution energy. This behavior is also common using HPGR, as reported by Djordjevic (2010) while studying the thermal losses.

From the literature, experimental data of size-energy relationship exponents can be found. Table 16 in Appendix B shows detailed information on the feed size $\left(\mathrm{F}_{80}\right)$, product size $\left(\mathrm{P}_{80}\right)$, and power consumption collected from multiple operations. The state of the art of comminution circuits presented include various particle size reduction equipment such as SAG mills, pebble crushers, ball mills, AG mills, HPGR, etc. along with different configurations. 


\subsection{ADVANCES IN ULTRAFINE GRINDING}

Stirred milling is a power-efficient process to produce fine and ultra-fine particles. This concept was first developed back in 1928 when Klein and Szegvari performed the first wet grinding test using an agitator and spherical grinding media (Stehr, 1988). Since then, it has been widely used in several industries such as pharmaceutical, materials, cement, chemical, cosmetic, metallurgical, and biomass powders industries (Kwade \& Schwedes, 2007; Mucsi et al., 2013; Rajaonarivony et al., 2021). Throughout the years, several advances have been achieved in terms of energy efficiency, operating conditions, design parameters, grinding media materials, and applications in a broad range of fields. The need to create energy-efficient systems is due to the high costs associated with specific energy consumption. By its nature, ultra-fine grinding is an energyintensive process. The production of nano-sized particles demands a significant power input compared to coarse grinding or other metallurgical processes. Figure 23 represents the relationship between specific energy $(\mathrm{kWh} / \mathrm{t})$ as a function of product size $(\mu \mathrm{m})$, where ultrafine grinding is clearly on the order of hundreds of kilowatts-hour per ton. The reported deviation in specific energy consumption is caused by variations in circuit configuration, ore hardness, and operating conditions (Y. Wang \& Forssberg, 2007).

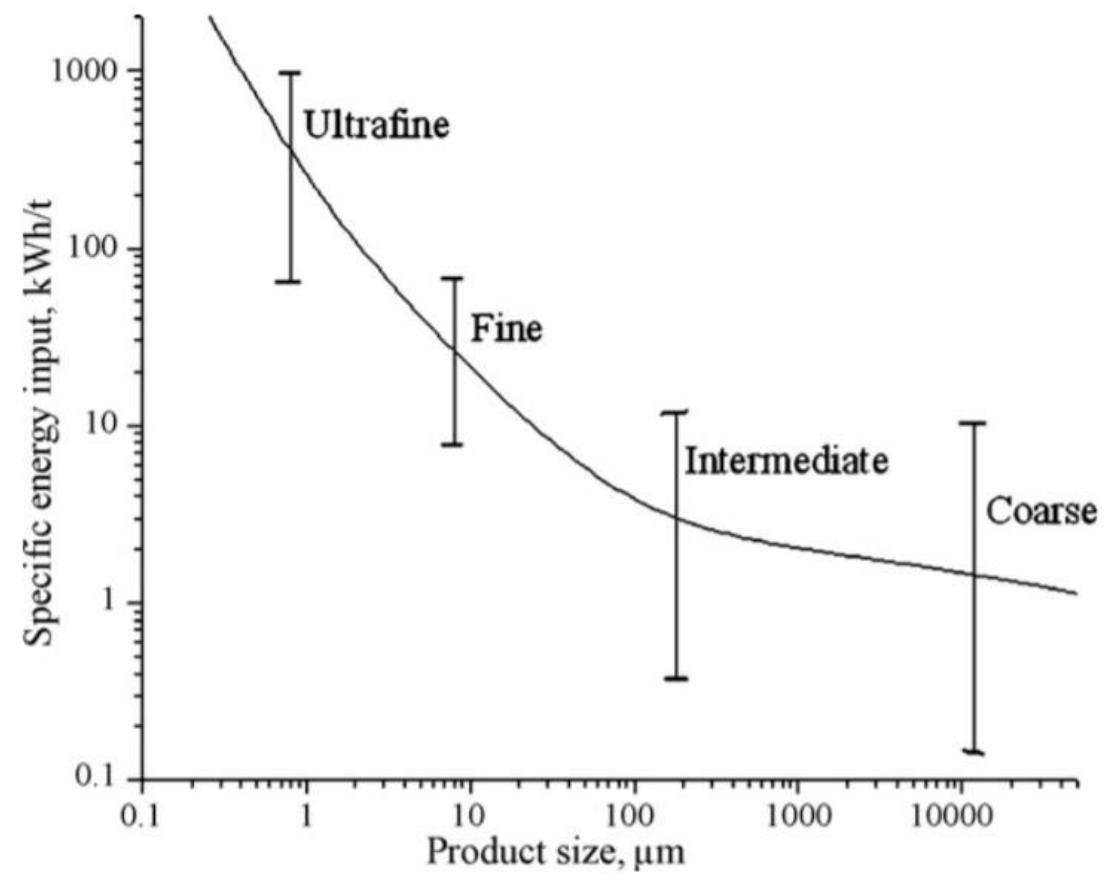

Figure 23. Specific energy input for size reduction in comminution (Silverman, 1981). 
Most of the efforts to optimize stirred milling have been dedicated to the operating conditions and design parameters. Research projects have been carried out to understand the effect of parameters such as ball diameter, grinding time, ball charge ratio, stirrer speed, solids concentration of slurry, dispersants, pH, and so forth. For instance, Celep et al. (2011) used a three-level Box-Behnken factorial design to study the impact of ball diameter, grinding time, ball charge, and stirrer speed on the product size $\left(\mathrm{P}_{80}\right)$ using refractory $\mathrm{Au} / \mathrm{Ag}$ ore. A response surface methodology $(\mathrm{RSM})$ and quadratic programming (QP) were employed for modeling and optimization purposes as well. Compared to the results in terms of ball size obtained in the previous case study, Chetan M. Patel et al. (2012) determined that a finer bead size $(0.5 \mathrm{~mm})$ was more suitable for the production of barium sulfate nanoparticles. Therefore, it can be inferred that the optimum diameter of grinding media is highly dependent on particle size, strength, and density regardless of the breakage mechanism (Tanaka, 1995).

The use of novel grinding media materials in ultra-fine grinding is another alternative widely explored. Grinding media types such as glass balls $\left(\mathrm{SiO}_{2}\right)$, ceramic balls $\left(\mathrm{Al}_{2} \mathrm{O}_{3}\right)$, zirconium oxide balls $\left(\mathrm{ZrO}_{2}\right)$, and stainless-steel balls are commonly used in grinding (Guo et al., 2021). Ceramic grinding media gained importance in processes such as the production of high-purity materials or froth flotation of pyrite and chalcopyrite due to the low levels of contamination post grinding. According to Zhang et al. (2021), the separation index is better when ceramic balls are used instead of steel balls. Table 5 shows several ceramic mineral composites along with their chemical composition and properties.

Table 5. Properties of various types of ceramic grinding media (Gupta \& Yan, 2016a).

\begin{tabular}{|c|c|c|c|c|}
\hline Ceramic Mineral Composite & Chemical Composition & $\begin{array}{l}\text { Hardness } \\
\text { (HV) }\end{array}$ & $\begin{array}{l}\text { Hardness } \\
\text { (Mohs) }\end{array}$ & $\begin{array}{l}\text { Fracture } \\
\text { Toughness }\end{array}$ \\
\hline Alumina & $\mathrm{Al}_{2} \mathrm{O}_{3}\left(\mathrm{Al}_{2} \mathrm{O}_{3}>85 \%\right)$ & $1500-1700$ & $7.8-8.3$ & $3-5$ \\
\hline $\begin{array}{l}\text { Yttrium Stabilised Zirconium } \\
\text { Oxide }\end{array}$ & $\mathrm{ZrO}_{2}-95 \%, \mathrm{Y}_{2} \mathrm{O}_{3}-5 \%$ & $1300-1400$ & $7.4-7.6$ & 13 \\
\hline $\begin{array}{l}\text { Cerium Stabilised } \\
\text { Zirconium Oxide }\end{array}$ & $\mathrm{ZrO}_{2}-80 \%, \mathrm{CeO}_{2}-20 \%$ & $1100-1200$ & $6.8-7.1$ & 13 \\
\hline $\begin{array}{l}\text { Magnesium Stabilised } \\
\text { Zirconium Oxide }\end{array}$ & $\mathrm{ZrO}_{2}-97 \%, \mathrm{MgO}-3 \%$ & $900-1100$ & $6.3-6.8$ & 6 \\
\hline Zirconium Silicate & $\mathrm{ZrO}_{2}-69 \%, \mathrm{SiO}_{2}-31 \%$ & $600-800$ & $5.3-5.9$ & 3 \\
\hline Aluminium Silicate & $\mathrm{Al}_{2} \mathrm{O}_{3}(34 \%)-\mathrm{SiO}_{2}(62 \%)$ & $800-900$ & $5.9-6.3$ & 3 \\
\hline Keramax®MT1 & $\begin{array}{l}\mathrm{Al}_{2} \mathrm{O}_{3}(79 \%)-\mathrm{SiO}_{2}(6.5 \%)- \\
\mathrm{ZrO}_{2}(14 \%)\end{array}$ & $1300-1400$ & 7.4-7.6 & $5-6$ \\
\hline
\end{tabular}


Manufacturing companies of particle size reduction equipment such as Union Processes are developing cutting-edge technologies to take grinding a step forward (Figure 24). In the past few years, the concept of cryogenic grinding has gained great importance and remarkable advances were achieved. The fundamentals of "cryomilling" are based on embrittling mineral particles by inducing temperatures below $275 \mathrm{~K}$ during grinding (J. Liu et al., 2021). Usually, liquid nitrogen is used to prepare the cryogen slurry (Process, 2008). This method promotes the production of nanosized particles and provides important advantages particularly for heat-sensitive materials such as coal (Yokoyama \& Inoue, 2007). Table 17 in Appendix C shows various examples of cryogenic grinding applications for different types of materials.
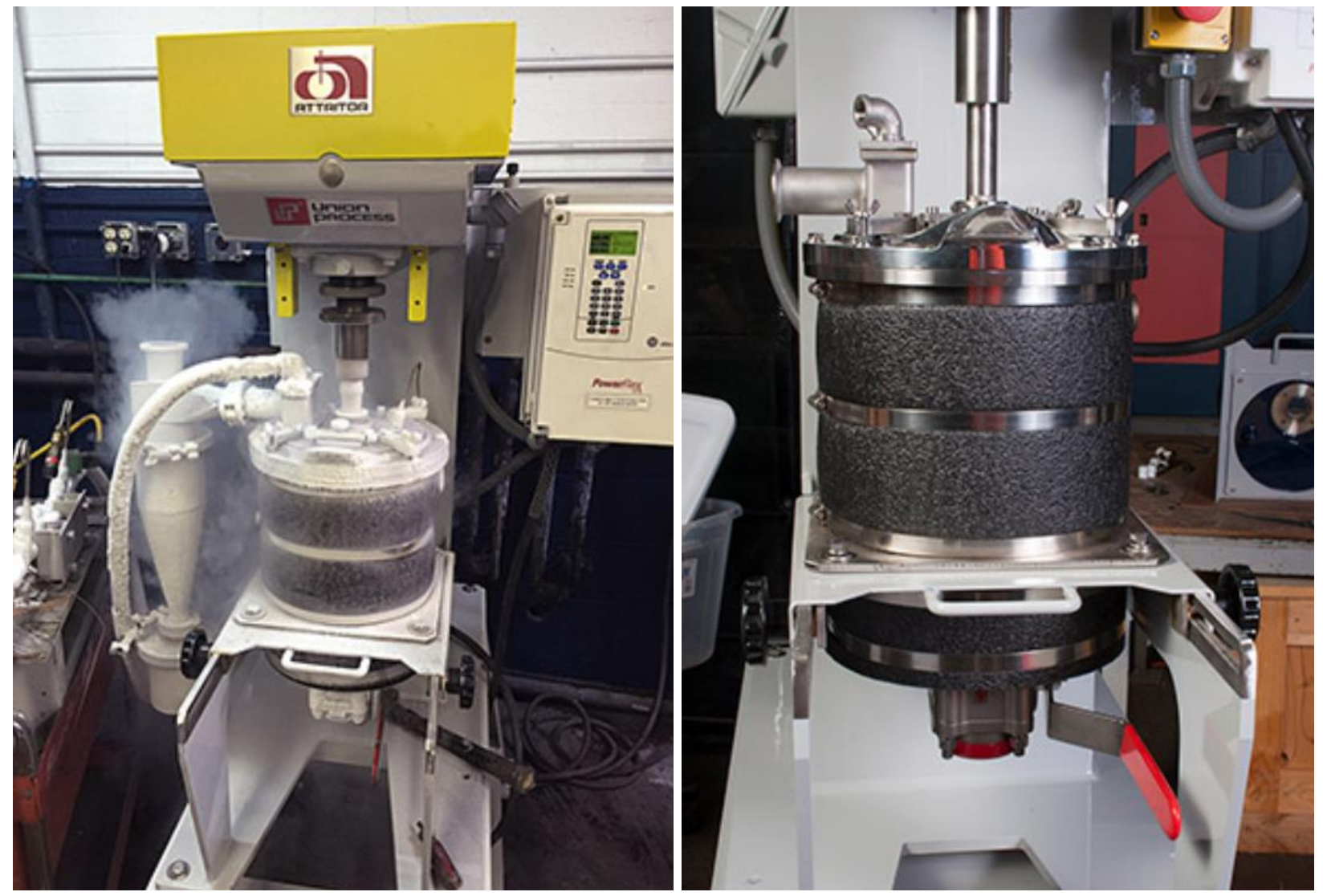

Figure 24. Union Process cryogenic stirred mill (Process, 2017). 


\subsection{COMMINUTION MODELING}

The energy-particle size relationship is an important aspect of the minerals comminution process and a lot of experimental and theoretical efforts have been devoted to it (Stamboliadis, 2007). In previous studies, Portnikov and Kalman (2019) developed an experimental procedure to determine the material comminution functions of wet insoluble particles immersed in liquid. These functions play an important role in particle breakage modeling for various wet industrial systems such as hydraulic conveying and wet-milling processes. Cleary et al. (2020) have been working on advanced particle-based comminution modeling of various types of crushers and mills. This modeling can provide significant insight into the flow of particles, their breakage, the effect of slurry wear, and energy consumption in the equipment.

An example of modeling in grinding mills developed by Cleary, Cummins, et al. (2020) is shown in Figure 25. It shows a nearly axial view from the discharge end of the mill. This velocity distribution within the slurry can be seen, as well as the full shape of the slurry pool. The key drivers of slurry pool motion are:

1. The slurry in the cascading region and immediately adjacent is dragged down and to the left parallel to the media surface.

2. The mill liner is moving down vertically into the slurry pool above the toe and strongly entrains fluid dragging it down towards the solid toe.

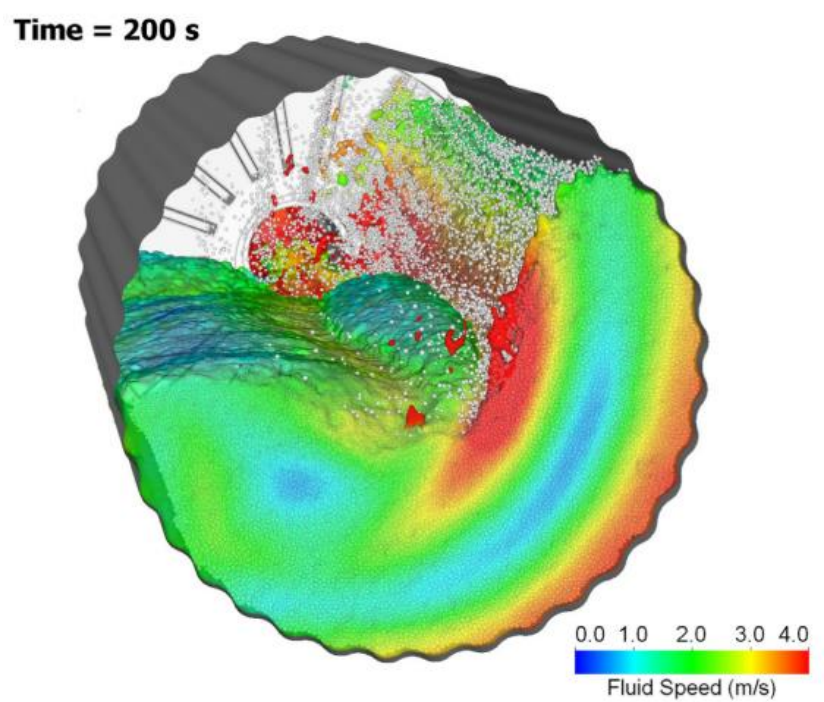

Figure 25. View of charge motion from feed end with media shown as light grey and slurry colored by its speed (Cleary, Cummins, et al., 2020). 
Prediction of size and liberation distribution of mineral particles and energy consumption in comminution can also be approached by studying the mineralogical properties of minerals. According to Mwanga et al. (2017), properties such as modal mineralogy (mineral composition), hardness, grain size, and bulk density of iron ores can be used to predict the patterns of mineral breakage distribution, which are the attributes used in comminution and geo-metallurgical modeling.

\subsubsection{Energy-based Models}

Models in comminution processes are used in preliminary and detailed design, for assessing comminution performance, and for geo-metallurgy. The energy-based models were the first empirical models developed in this field and continue to find widespread use. As well as empirical models, phenomenological and fundamental models are widely used in unit and circuit simulators. Phenomenological models include population balance models and fundamental models include those based on discrete element method (DEM), computational fluid dynamics (CFD), and statistical physics (Wills \& Finch, 2016b).

Energy-based models assume a relationship between the energy input of the comminution device and the resultant effective particle size of the product. The energy input is for net power, that is, after correcting for motor efficiency and drive train mechanical losses. Typically, energy is measured as $\mathrm{kWh} \mathrm{t}^{-1}$ or Joules, depending on the model (Wills \& Finch, 2016b).

The first general energy-based comminution equation is the one developed by Walker et al. (1937). In differential form it is:

$$
d E=-K x^{-n} d x
$$

where $\mathrm{dE}$ is the increment in energy to affect an incremental decrease $\mathrm{dx}$ in particle size $\mathrm{x}$, and $\mathrm{n}$ and $\mathrm{K}$ are constants ( $\mathrm{K}$ also converts units). In integral form it is:

$$
E=-K \int_{F}^{P} x^{-n} d x
$$

where $\mathrm{F}$ and $\mathrm{P}$ are the measures of feed and product particle size (usually a diameter). Letting $\mathrm{n}=$ 2, 1, or 3/2 gives the "three comminution laws" according to Von Rittinger, Kick, and Bond. 
Von Rittinger (1867) was the first scientist who proposed an equation to explain the relationship of parameters in comminution. In his theory, he stated that the energy consumed in size reduction is proportional to the area of new surface produced. The surface area of a known weight of particles of uniform diameter is inversely proportional to the diameter, hence Von Rittinger's law equates to:

$$
E_{V R}=K\left(\frac{1}{P}-\frac{1}{F}\right)
$$

This equation is obtained by solving equation 2 for $\mathrm{n}=2$.

Kick (1885) proposed the second oldest theory, but this time he stated that the energy required is proportional to the reduction in volume of the particles, instead of the area of new surface produced as Von Rittinger affirmed initially. Kick equation is obtained by solving equation 2 for $\mathrm{n}=1$ :

$$
E_{K}=K\left(\ln \frac{F}{P}\right)
$$

where F/P is the reduction ratio. Kick's theory states that the energy requirement depends only on the reduction ratio, and not the original size of the particles.

A couple of decades later, Bond (1952) proposed his theory known as "The third theory of comminution" which stated that the energy input is proportional to the new crack tip length produced in particle breakage. Later on, Bond redefined his theory by stating that the specific work input is an empirical relationship between the work index, and product and feed passing sizes (Bond, 1985). The equation shown below is obtained by solving equation 2 for $n=3 / 2$ :

$$
W=10 \times W i\left(\frac{1}{\sqrt{P_{80}}}-\frac{1}{\sqrt{F_{80}}}\right)
$$

where $\mathrm{W}$ is the work-energy input in kilowatt-hours per short ton, Wi is the work index (Bond work index) in kilowatt-hours per short ton, which indicates the energy required to reduce from theoretically infinite size to $80 \%$ percentage passing 100 microns, and $\mathrm{P}_{80}$ and $\mathrm{F}_{80}$ are the $80 \%$ product and feed passing sizes. 


\subsubsection{Population Balance Modeling}

The energy-based models covered in the previous section are convenient to predict any desired percent passing size based on the specific energy input, however, they do not deliver the complete particle size distribution. For this reason, population balance modeling is widely used to simulate the behavior of the product in equipment such as HPGR and vertical mills. Moreover, it allows the design, control, and optimization of comminution circuits (Esnault et al., 2015). For a better understanding of population balance modeling, it is necessary to comprehend the breakage process and the distribution of broken particles (Figure 26). Column 1 shows the size distribution of the feed sample, along with $N$ size fractions colored grey. Column 3 represents the breakage function, which is the product obtained after a single breakage event. Lastly, column 4 shows the product obtained after $N$ breakage events with the corresponding number of progenies of each size fraction.

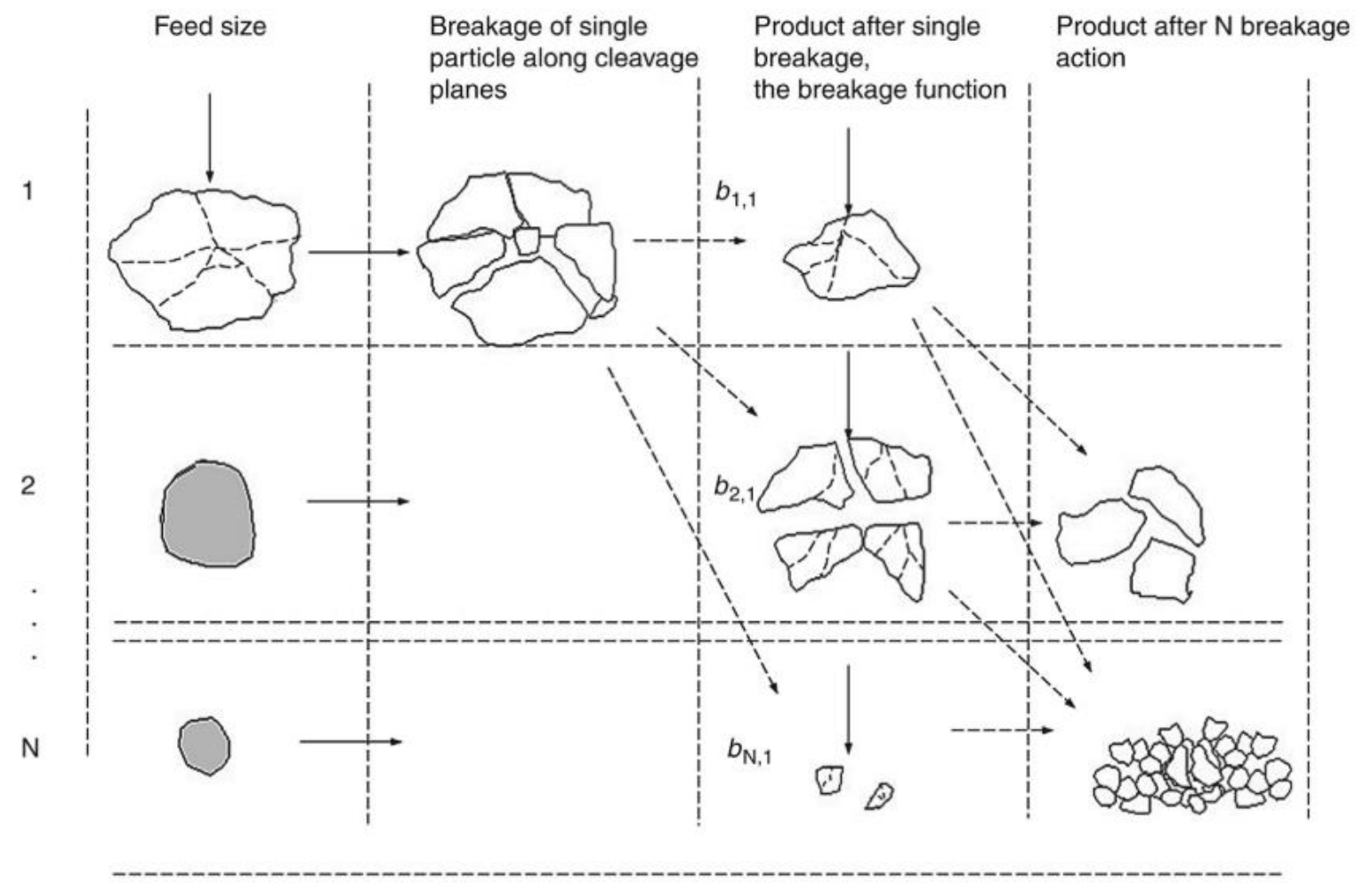

Figure 26. Illustration of the distribution of broken particles after fragmentation (Gupta \& Yan, 2016b). 
A range of successful applications of population balance modeling can be found in the literature. For instance, Lee et al. (2019) analyzed the grinding kinetics not only using population balance modeling, but also a discrete element method. PBM was used to determine the grinding parameters and DEM to further understand the internal phenomenon occurring in the mill. In addition, they developed an expression to relate the grinding rate parameters with the acting normal force.

Population balance modeling is also applicable to crushing processes. The use of high-pressure grinding rolls (HPGR) gained relevance in the mineral processing industry due to their demonstrated energy efficiency. Therefore, the need arose to determine the breakage rate of crushing equipment in order to subsequently optimize coarse size reduction circuits. According to Dundar et al. (2013), the breakage rate in HPGRs strongly depends on equipment parameters, material characteristics, and particle size. The machine constant $(k)$ is mainly determined by the operating pressure, while the material constant $(\alpha)$ is associated with the specific surface area. 


\section{CHAPTER 3: EXPERIMENTAL WORK}

\subsection{LABORATORY STUDIES}

\subsubsection{Sample and Grinding Media Materials}

\section{Coal Sample}

Feedstock material used throughout the study was provided by an active coal preparation plant located in the core of the Appalachian Coal Basin, approximately 50 minutes south of Morgantown, WV. Samples of Middle Kittanning coal in slurry form were collected from the thickener underflow and the solids concentration was adjusted by dilution or decantation. Later, representative samples were taken and were subjected to particle size and thermogravimetric analysis to determine the particle size distribution and the ash content of the feed samples, respectively.

\section{Grinding Media}

Four low- to moderate-cost grinding media (i.e., ceramic balls, alumina beads, silica beads, and granular sand) were chosen to evaluate their performance on ultrafine grinding (Figure 27). To ensure the commensurability and reliability of the results, similar size ranges were selected to analyze the effect of the type and size of grinding media on ultrafine grinding performance. Based on the test results, three different size ranges of silica beads were chosen to study the effect of fine, regular, and coarse silica beads on the product size. Moreover, according to the initial test results, the effects of solids concentration and sodium silicate as a viscosity modifier on the ultrafine grinding were addressed using coarse silica beads only.

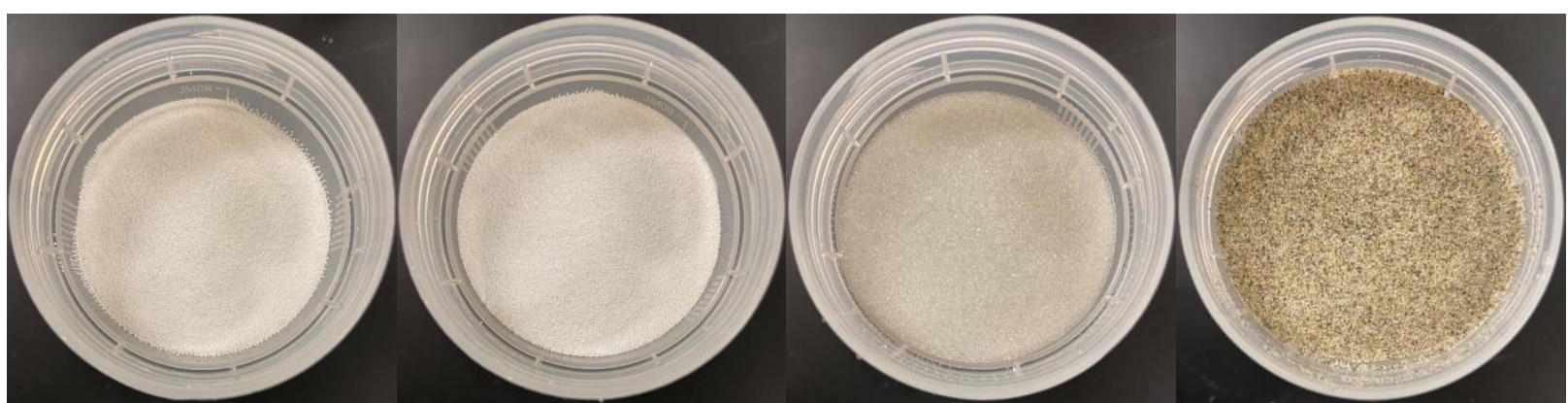
(a) Ceramic Balls
(b) Alumina Beads
(c) Silica Beads
(d) Granular Sand

Figure 27. Grinding media materials chosen to study ultrafine grinding behavior. 
The alumina beads (Union Process, Akron, OH) and ceramic balls (Carbo Ceramics, Houston, TX) correspond to the moderate-cost grinding media. Both have the same particle size range $(250 \mathrm{x}$ $340 \mu \mathrm{m}$ ), similar mechanical properties, density, and uniform size and sphericity. On the other hand, the Potters glass beads (Kleen Blast, Hayward, CA) and granular sand (Lowes, Morgantown, WV) are the low-cost grinding media. The granular sand has almost the same particle size range $(250 \times 350 \mu \mathrm{m})$ as alumina and ceramic media, but the silica beads span a broader size range (Fine: 40 x $210 \mu \mathrm{m}$; Regular: 250 x $420 \mu \mathrm{m}$; Coarse: 420 x $850 \mu \mathrm{m}$ ). Both silica beads and sand have similar properties and density since they are silica-based materials, even though the glass beads have a perfect roundness while granular sand particles are angular. Table 6 shows detailed information on the grinding media materials employed in this study.

Table 6. Grinding media material specifications.

\begin{tabular}{lccccc}
\hline \multicolumn{1}{c}{ Media Type } & $\begin{array}{c}\text { Size Range } \\
(\mathbf{m m})\end{array}$ & $\begin{array}{c}\text { Specific } \\
\text { Gravity }\end{array}$ & Hardness & $\begin{array}{c}\text { Relative } \\
\text { Cost }\end{array}$ & Vendor \\
\hline Ceramic Balls & $0.25-0.34$ & 3.75 & NA & Moderate & Carbo Ceramics \\
Alumina Beads & $0.25-0.34$ & 3.80 & Mohs 9 & Moderate & Union Process \\
Granular Sand & $0.25-0.35$ & 2.65 & NA & Low & Lowes \\
Silica Beads & $0.25-0.42$ & 2.50 & Mohs 6 & Low & Kleen Blast \\
Fine Silica Beads & $0.04-0.21$ & 2.50 & Mohs 6 & Low & Kleen Blast \\
Coarse Silica Beads & $0.42-0.85$ & 2.50 & Mohs 6 & Low & Kleen Blast \\
\hline
\end{tabular}

All the grinding media types were screened using a Sweco Round Separator (Sweco, Florence, KY) to guarantee that the media particles were within the specified size range. This pre-screening process eases the recovery of the media material after grinding tests and avoids the alteration of the coal particle size analysis due to the presence of media particles.

\subsubsection{Experiment Design and Stirred Mill Grinding Tests}

Kinetic grinding tests were conducted using a laboratory-scale stirred mill (Figure 28), Union Process, Akron, $\mathrm{OH})$. Also known as Attritor, this versatile mill provides reproducible results from batch to batch and can be used for wet or dry grinding processes under controlled operating conditions. The mill is equipped with a 2.5-gallon tank which provides a working capacity of 4.2 L. The adjustable shaft accommodates different-sized grinding media, and the electronic variable speed drive system controls the shaft rotation speed in RPM. It also has a bottom discharge grid 
for sampling and discharge, water-cooled jackets for cooling or heating, and a liquid crystal display (LCD) that shows the agitator's rotational speed (rpm), motor frequency $(\mathrm{Hz})$, and kilowatts $(\mathrm{kW})$ being used.

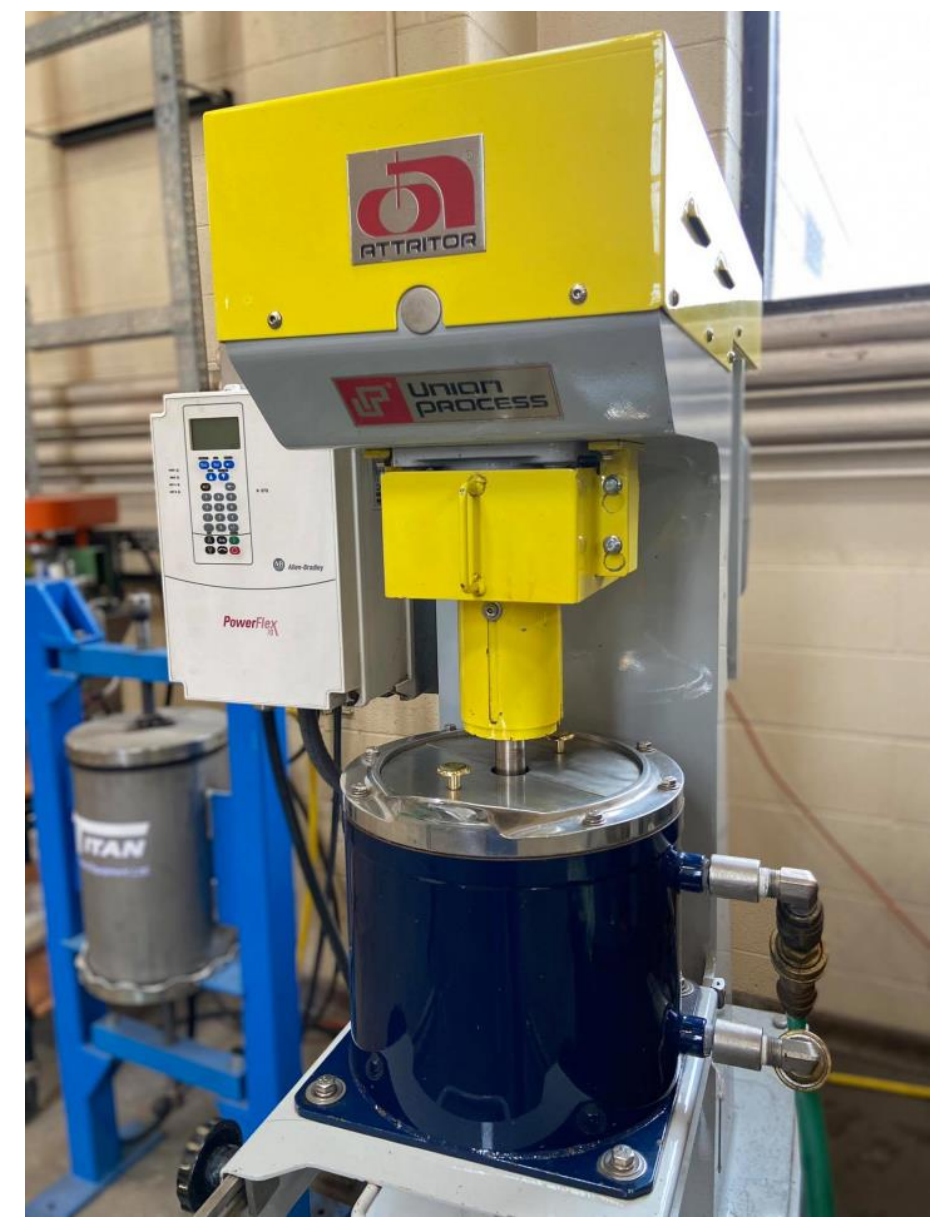

Figure 28. Laboratory scale stirred mill employed throughout the study.

The ultrafine grinding tests followed a similar procedure undertaken by Adeniji (2018) and Huang et al. (2020). In this study, standard tests were designed to provide replicable results and ease the analysis of variation in product size and energy consumption when one parameter is changed, and the others are held constant. The four main parameters assessed in this study are: (a) grinding media material, (b) media size, (c) solids concentration, and (d) dispersant dosage. Detailed test conditions, including solids concentration, shaft speed, the dose of dispersant, and grinding media parameters, were presented in Table 7. 
Table 7. Detailed test conditions for stirred mill grinding tests.

\begin{tabular}{lc|ccccc}
\hline \multicolumn{1}{c|}{ Parameter } & Unit & $\begin{array}{c}\text { Standard } \\
\text { Conditions }\end{array}$ & $\begin{array}{c}\text { Alumina } \\
\text { Beads }\end{array}$ & $\begin{array}{c}\text { Granular } \\
\text { Sand }\end{array}$ & $\begin{array}{c}\text { Ceramic } \\
\text { Balls }\end{array}$ & $\begin{array}{c}\text { Silica } \\
\text { Beads }\end{array}$ \\
\hline Slurry/Pulp Mass & $\mathrm{g}$ & 1,360 & 1,360 & 1,360 & 1,360 & 1,360 \\
Solids Concentration & $\%$ & 30 & 30 & 30 & $20,30,40$ & $20,30,40$ \\
Dispersant & $\mathrm{kg} / \mathrm{ton}$ & - & $\mathrm{NA}$ & $\mathrm{NA}$ & $2,8,14$ & $2,8,14$ \\
Stirrer Speed & $\mathrm{RPM}$ & 340 & 340 & 340 & 340 & 340 \\
Grind Time & $\mathrm{min}$ & 64 & 64 & 64 & 64 & 64 \\
& & & & & & $40 \times 210$ \\
Media Size & $\mu \mathrm{m}$ & - & $250 \times 340$ & $250 \times 350$ & $250 \times 340$ & $250 \times 420$ \\
& & & & & & $420 \times 850$ \\
Media Mass & $\mathrm{g}$ & 5,194 & 5,194 & 5,194 & 5,194 & 5,194 \\
Feed Size, F80 & $\mu \mathrm{m}$ & 24.36 & 24.36 & 24.36 & 24.36 & 24.36 \\
\hline
\end{tabular}

The grinding media was introduced into the vessel with the coal sample in a slurry form. The shaft was slightly jogged to mix both materials homogenously and ensure voids were fully covered with pulp. The slurry holdup volume and media load were selected based on the mill capacity. The coal pulp filled the remaining volume not occupied by grinding media. A freeboard was maintained to avoid overflowing due to the vortex produced by shaft rotation. Kinetic grinding tests were completed in 64 minutes. During this period, power input was constantly monitored, and eight representative samples were taken at $0.5,1,2,4,8,16,32$, and 64 minutes for post-grinding particle size analysis. Once the tests were finished, the material was discharged and screened with the Sweco round separator to separate the coal material from the grinding media. The sieve aperture size employed during the screening process equals the grinding media's bottom size so that the grinding media was retained on top while the coal sample passed through the openings.

\subsubsection{Specific Energy Input Measurement}

Power consumption at the $0.5,1,2,4,8,16,32$, and $64^{\text {th }}$ minute was recorded during the kinetic grinding tests. Subsequently, the specific energy (SE) was calculated based on power input readings obtained from the tests and the unloaded power input, which was determined while operating under "free-load" conditions. This no-load power draw represents the energy required to run the shaft; therefore, it should be deducted to calculate the specific energy required to produce the reduction in particle size. Equation 6 was used to calculate the specific energy (Ouattara \& Frances, 2014): 


$$
S E=\frac{\int_{0}^{t}\left(N(\tau)-N_{0}\right) d \tau}{m_{p}}
$$

where $m_{p}$ is the mass of solids in the pulp, $N(\tau)$ is the power at the time $\tau$, and $N_{0}$ is the no-load power. Specific energy is commonly expressed in kilowatts-hour per short ton.

\subsubsection{Particle Size, Shape, and Surface Morphology Analyses}

Particle size distributions of feed and product samples were obtained using a CILAS 1190 Particle Size Analyzer (CPS US, Inc., Madison, WI). Multiple replicate tests per sample were conducted to ensure the results were statistically reliable. On the other hand, the wear performance of the grinding media was evaluated through a shape analysis before and after the grinding tests using a CILAS Microscope attached to the CILAS 1190 Particle Size Analyzer.

The shape descriptors chosen to analyze the morphological variation are the circularity ratio, sphericity, and aspect ratio. These parameters seek to measure a particle's degree of roundness compared to a perfect sphere based on its dimensions, perimeter, area, and volume. The circularity ratio was calculated with the following equation defined by (Cox, 1927):

$$
\text { Cicularity Ratio }(C R)=\frac{4 \pi A}{P^{2}}
$$

where $\mathrm{A}$ is the area and $\mathrm{P}$ is the perimeter of the particle. According to Grace \& Ebneyamini (2021), sphericity is defined as the quotient of the surface area of a sphere of the same volume as the particle over the actual exterior surface of the particle:

$$
\text { Sphericity }(\phi)=\frac{\text { Surface area of a sphere of the same volume as the particle }}{\text { Actual exterior surface of the particle }}
$$

The aspect ratio measures the relationship between a particle's width and height. For ellipses, the aspect ratio would be the relationship between the major and minor axis, and it would be equal to one when both axes are the same (Takashimizu \& Iiyoshi, 2016). Equation 9 represents the aspect ratio:

$$
\text { Aspect Ratio }(A R)=\frac{\text { Major axis lenght of approximate ellipse }}{\text { Minor axis lenght of approximate ellipse }}
$$




\subsection{GRINDING SIMULATION}

The comminution process was simulated in Matlab using Population Balance Modeling (PBM), which is governed by two main functions: Breakage Function (BF) and Selection Function or Breakage Probability (BP). While the selection function is the probability of a particle to fragment under a certain impact velocity (King, 2012), the breakage function describes the mass of the broken fragments that achieves the desired size range (Rozenblat et al., 2012).

\subsubsection{Population Balance Modeling (PBM)}

Different population balance models (PBMs) for batch grinding can be developed based on the definition of breakage rate and breakage distribution (Bilgili et al., 2006). Equation 10 is the general energy-based differential equation in vector notation (Klimpel \& Austin, 1977):

$$
\frac{d m(\bar{E})}{d \bar{E}}=-(I-B) \operatorname{Sm}(\bar{E})
$$

The solution of equation 10 is shown as follow:

$$
m(\bar{E})=\exp (-[I-B] S \bar{E}) m(0)
$$

where,

$\mathrm{m}_{\mathrm{i}}$ : Mass fraction of size class $i$

$\mathrm{m}(\overline{\mathrm{E}})$ : Matrix (n x 1) of mass fractions resulting from a specific energy input $\bar{E}$

I: Identity matrix ( $\mathrm{n} \times \mathrm{n})$

B: Breakage function matrix ( $\mathrm{n} \times \mathrm{n})$ with elements $b_{i j}$

$\mathrm{S}$ : Selection function matrix ( $\mathrm{n} \times \mathrm{n})$ with diagonal $S_{i}{ }^{E}$

$\overline{\mathrm{E}}$ : Specific energy input

$\mathrm{m}(0)$ : Matrix ( $\mathrm{n} \times 1$ ) of mass fraction of feed, and

$\mathrm{n}$ : Number of size intervals 


\subsubsection{Breakage Function $(\mathrm{BF})$}

Several researchers developed mathematical equations to describe the breakage function (Broadbent and Callcott, 1956; Gaudin and Meloy, 1962; Kelsall and Reid, 1965; Klimpel and Austin, 1977; Lynch, 1977; Austin et al., 1984). Klimpel and Austin's formula comprises a general expression (Gupta \& Yan, 2016b):

$$
B\left(d_{i}\right)=1-\left[1-\left(\frac{d_{i}}{d_{j}}\right)\right]^{n_{1}}\left[1-\left(\frac{d_{i}}{d_{j}}\right)^{2}\right]^{n_{2}}\left[1-\left(\frac{d_{i}}{d_{j}}\right)^{3}\right]^{n_{3}}
$$

where,

$\mathrm{d}_{\mathrm{j}}$ : Original size being broken

$\mathrm{d}_{\mathrm{i}}$ : Size of the progeny fragment of breakage

$\mathrm{n}_{1}-\mathrm{n}_{3}$ : Constants depending on the particle shape and flaw density within the particles and $B\left(d_{i}\right)$ : Cumulative mass fraction finer than $d_{i}$ where $d_{j}>d_{i}>0$.

\subsubsection{Selection Function/Breakage Probability (BP)}

Particle breakage is a random process never exactly predictable as it is strongly governed by many factors that contribute to the fracture. However, the capacity of particles to absorb a certain amount of energy is related to the probability of fracture (King, 2012). Mathematically the selection function can be expressed as the diagonal matrix in which each element represents the proportion of particles that have the probability of breakage (Gupta \& Yan, 2016b). Equation 13 represents the selection function when the total mass is constant in a batch mill:

$$
m_{i}(t)=m_{i}(0) \exp \left(-S_{i} t\right)
$$

where,

$\mathrm{m}_{\mathrm{i}}(\mathrm{t})$ : Mass fraction of size $i$ after a grinding time, $t$

$\mathrm{S}_{\mathrm{i}}$ : Proportionality constant, and

$t$ : Grind time 


\subsubsection{Particle Swarm Optimization (PSO)}

This method for the optimization of non-linear functions was first developed by Kennedy and Eberhart (1995). Its fundamentals are based on artificial life (A-life), and bird flocking, fish schooling, and swarming theories. The following steps provide an overall understanding of the application of particle swarm optimization (Coelho and Sierakowski, 2008):

i. Initialize a population of particles with random positions and velocities in the $n$ dimensional space using a uniform probability distribution.

ii. Evaluate the fitness value (the number that represents the goodness of a given solution) of each particle in the swarm.

iii. Compare each particle's fitness value with the current pbest (position in parameter space of the best fitness returned for a specific particle). If the current value is better than pbest, then set the current value as the new pbest with its corresponding location.

iv. Compare the fitness evaluation with the population's overall previous best. If the current value is better than gbest (position in parameter space of the best fitness returned for the entire swarm), then reset gbest to the current particle's array index.

v. Change the particle's velocity and position.

vi. Loop to step ii. until a stopping criterion is met, which is the maximum number of iterations.

In this study, the objective function shown in Equation 14 was used to determine the best parameter, which corresponds to the parameter that returned the minimum objective function.

$$
\theta(\vec{x})=\frac{1}{M}\left(m(\bar{E})_{m o d e l}-m(\bar{E})_{t e s t}\right)^{T}\left(m(\bar{E})_{\text {model }}-m(\bar{E})_{\text {test }}\right)
$$

where,

$\theta$ : Objective function

$\vec{x}$ : Parameter vector

$m(\bar{E})_{\text {model }}$ : Vector of the product size distribution from the simulation

$m(\bar{E})_{\text {test }}$ : Vector of the product size distribution from the test, and

M: Number of predictions/elements in $m(\bar{E})$ 


\section{CHAPTER 4: RESULTS AND DISCUSSION}

\subsection{LABORATORY TEST RESULTS}

\subsubsection{Coal Sample Characterization}

According to the particle size distribution and thermogravimetric analysis, the feedstock coal sample had an initial cumulative passing size $\left(\mathrm{P}_{80}\right)$ of $24.4 \mu \mathrm{m}$, and ash content of $47.99 \%$, respectively. Post grinding the ash content reported was $48.11 \%$ representing an unimportant variation of inorganic residues produced by stirred milling, with coarse silica beads as the grinding media (Figure 29). These results correspond to the mean values obtained from multiple replicate tests.

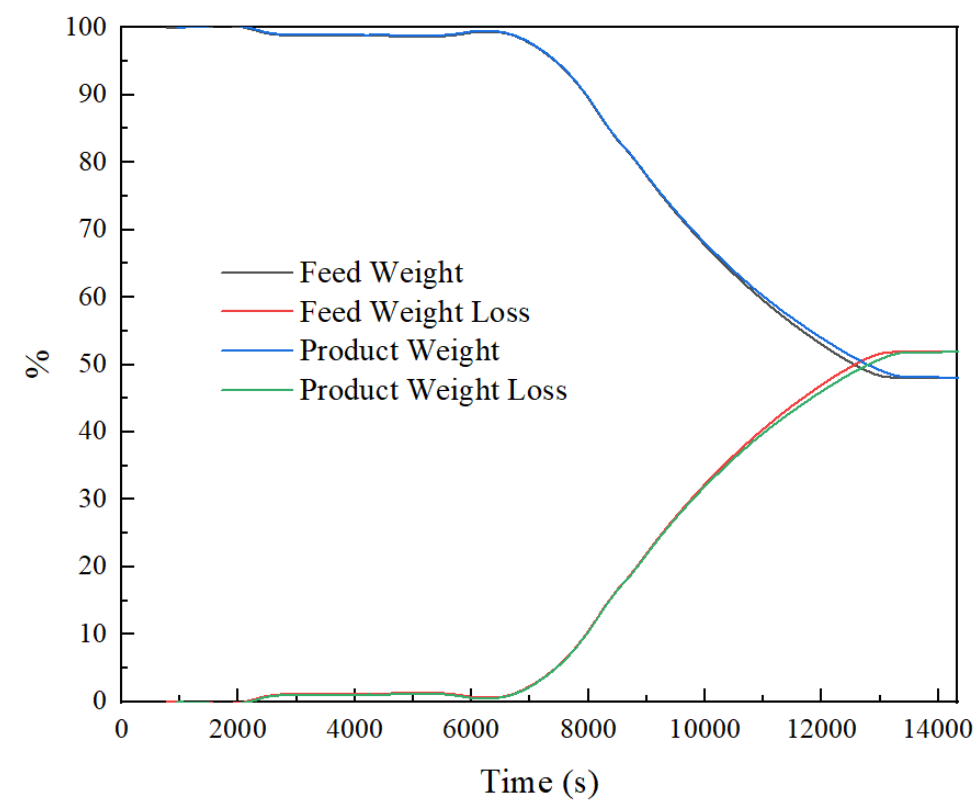

Figure 29. Thermogravimetric analysis before and post-grinding using coarse silica beads under standard test conditions.

\subsubsection{Stirred Mill Grinding Tests}

\subsubsection{1. $\quad$ Effect of Grinding Media Material}

The effect of grinding media material on the product size distribution was studied by conducting a series of kinetic grinding tests with various media materials under the same test conditions. Table 8 shows the detailed experimental parameters considered during the ultrafine grinding study. 
Table 8. Test conditions for kinetic grinding tests employing various grinding media materials.

\begin{tabular}{lc|cccc}
\hline \multicolumn{1}{c}{ Parameter } & Unit & $\begin{array}{c}\text { Ceramic Balls } \\
\text { (CB) }\end{array}$ & $\begin{array}{c}\text { Alumina Beads } \\
(\mathbf{A B})\end{array}$ & $\begin{array}{c}\text { Silica Beads } \\
(\text { SB })\end{array}$ & $\begin{array}{c}\text { Granular Sand } \\
(\text { GS })\end{array}$ \\
\hline Slurry/Pulp Mass & $\mathrm{g}$ & 1,360 & 1,360 & 1,360 & 1,360 \\
Solid Feed Mass & $\mathrm{g}$ & 408 & 408 & 408 & 408 \\
Water Mass & $\mathrm{g}$ & 952 & 952 & 952 & 952 \\
Solids Concentration & $\mathrm{wt} \%$ & 30 & 30 & 30 & 30 \\
Stirrer Speed & $\mathrm{RPM}$ & 340 & 340 & 340 & 340 \\
Grind Time & $\mathrm{min}$. & 64 & 64 & 64 & 64 \\
Media Size & $\mu \mathrm{m}$ & $250 \times 340$ & $250 \times 340$ & $250 \times 420$ & $250 \times 350$ \\
Media Mass & $\mathrm{g}$ & 5,194 & 5,194 & 5,194 & 5,194 \\
Feed Size, $\mathrm{F}_{80}$ & $\mu \mathrm{m}$ & 24.36 & 24.36 & 24.36 & 24.36 \\
\hline
\end{tabular}

Figure 30 represents the power readings and corresponding specific energy values obtained for each test. The highest energy consumption was shown by granular sand, followed by silica beads, alumina beads, and ceramic balls, respectively. Specific energy values of 579 and $309 \mathrm{kWh} / \mathrm{ton}$ were obtained for granular sand and silica beads, and values of 109 and $129 \mathrm{kWh} /$ ton were attained for alumina beads and ceramic balls, separately (Figure 31). The latter two materials demand around $65 \%$ less energy than silica beads and show a second-order polynomial trendline. Differently, silica beads and granular sand demonstrate a logarithmic trendline and similarity in energy consumption.
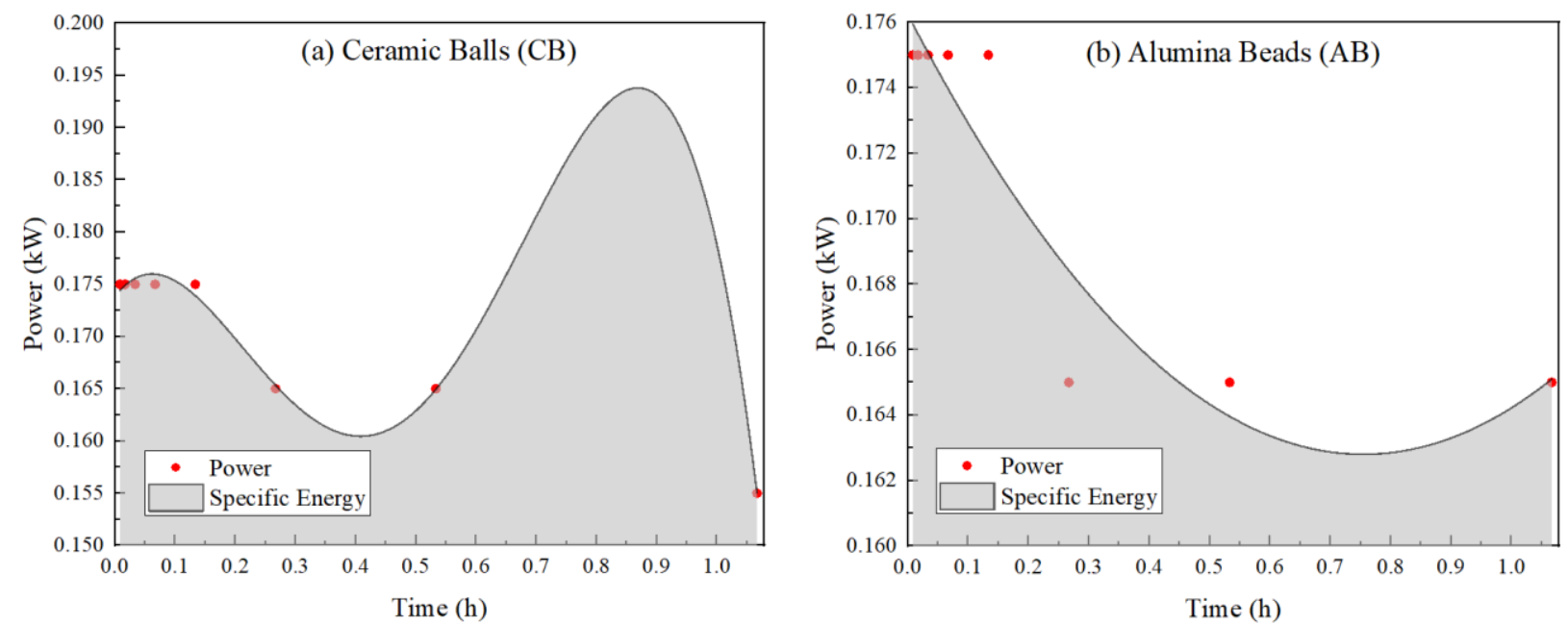

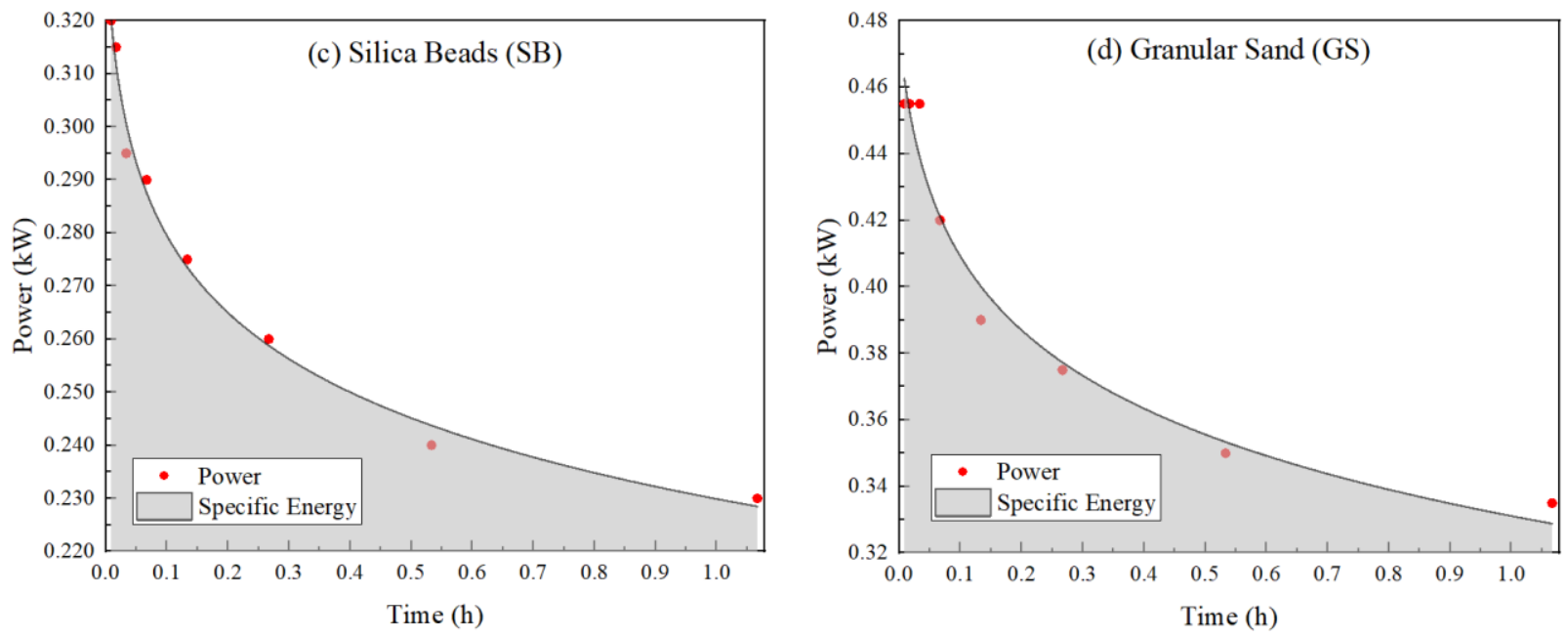

Figure 30. Power input and specific energy required by each type of media material: (a) Ceramic balls, (b) Alumina beads, (c) Silica beads, and (d) Granular sand.

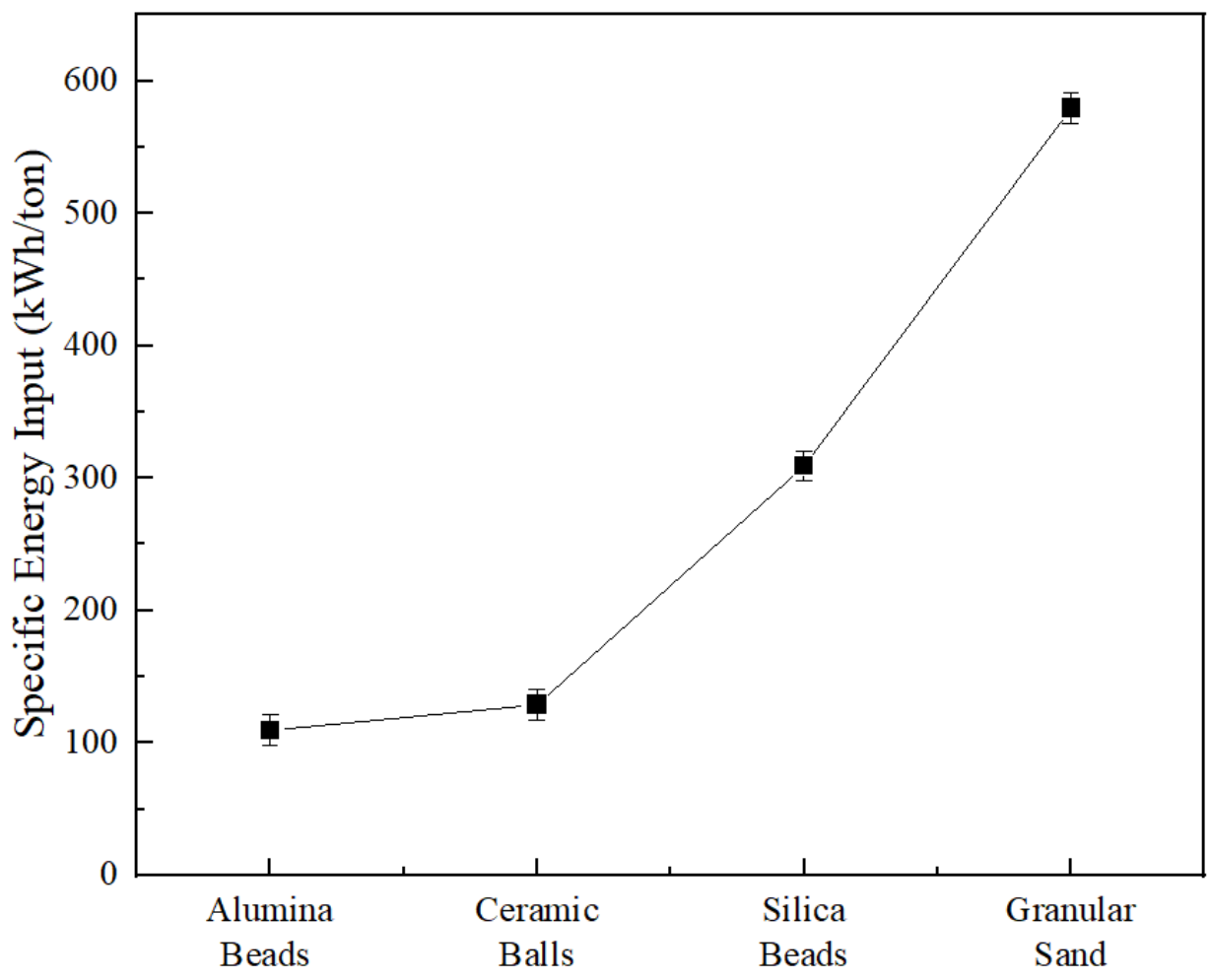

Figure 31. Specific energy input of each type of media material. Error bars represent one standard deviation of three replicate tests. 
According to the particle size distribution shown in Figure 32, the finest product size was obtained by silica beads, achieving a product size $\left(\mathrm{P}_{80}\right)$ of $5.9 \mu \mathrm{m}$. It represents a reduction ratio of 4.2:1 considering the feed size of $24.4 \mu \mathrm{m}$. Similar to the specific energy consumption, again, ceramic balls and alumina beads showed a similar distribution achieving a $\mathrm{P}_{80}$ of 12.8 and $15.5 \mu \mathrm{m}$, respectively, with a corresponding reduction ratio of 1.9:1 and 1.6:1. Due to the grinding media degradation of granular sand, separation of the coal sample from the grinding media was unachievable. Therefore, it was not possible to obtain the particle size distribution for the test conducted with granular sand.

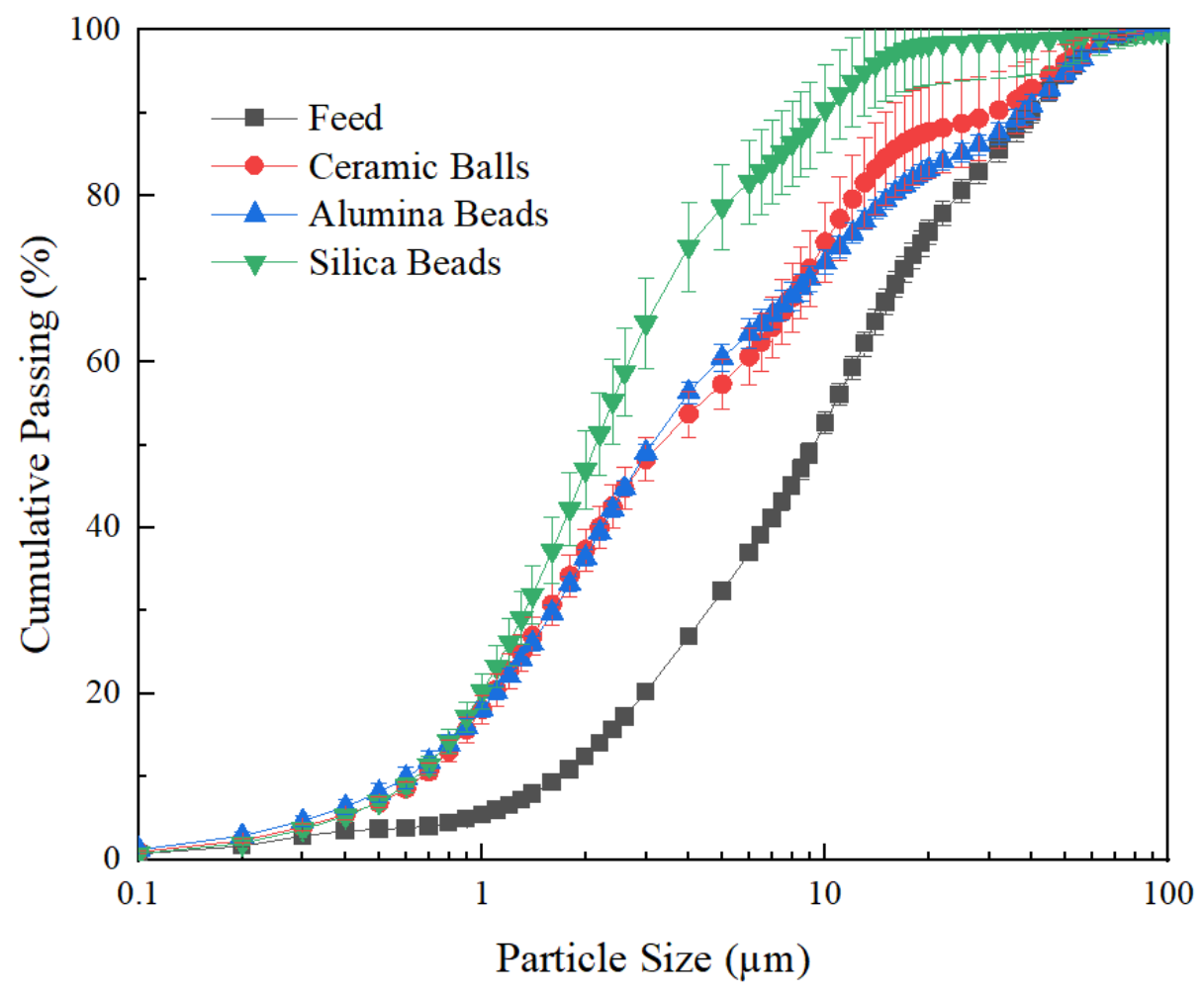

Figure 32. Particle size distribution of feed and ground products obtained by each type of grinding media material. Error bars represent one standard deviation of twelve replicate tests.

Figure 33 further illustrates the wear process of granular sand throughout the kinetic grinding test. According to the samples taken at the 0.5 and $64^{\text {th }}$ minute, this phenomenon started from the very beginning of the grinding process and rendered a physical separation by screening unfeasible. High energy consumption and rheological changes were also noticed at the end of the test, revealing the 
over-grinding of granular sand throughout the grinding test. During comminution, a specific surface area (SSA) generation process occurs, modifying the pulp rheology due to the adsorption of water on the particles' surface (Blanc et al., 2020). This phenomenon explains the significant increase in pulp density, viscosity, and heat generation that turned the coal pulp into a solid paste.

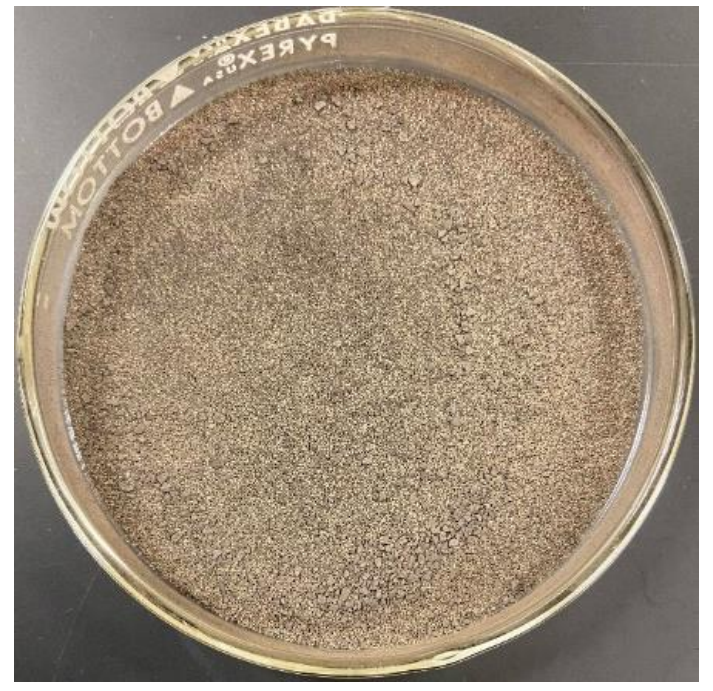

(a) $0.5^{\text {th }}$ minute

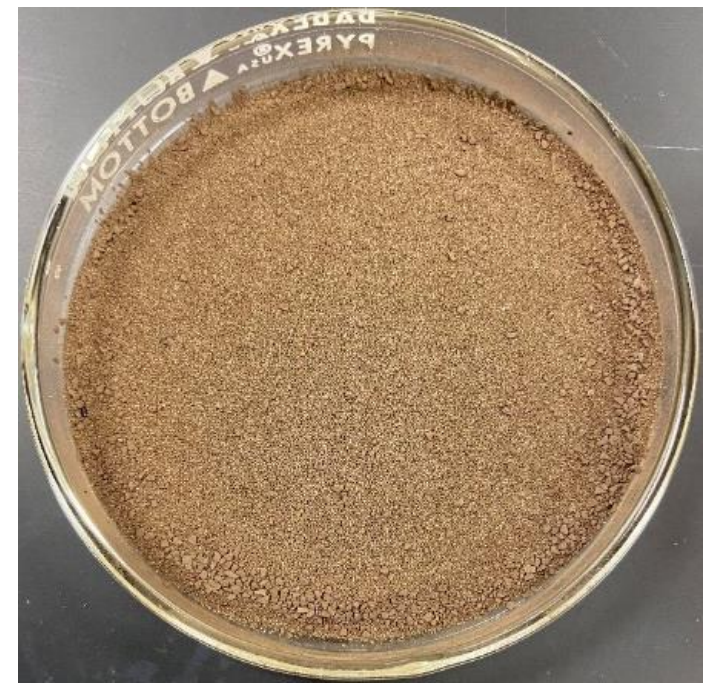

(b) $64^{\text {th }}$ minute

Figure 33. Degradation process of granular sand. Samples taken at the $0.5^{\text {th }}$ and $64^{\text {th }}$ minute during the kinetic grinding test.

A shape analysis was performed in the media beads to determine the wear rate of each material after being submitted to grinding stress. The initial values of circularity ratio, sphericity, and aspect ratio were $0.90,0.97$, and 0.98 for ceramic balls and alumina beads, separately (Figure 34a and Figure 34b). For silica beads, these indicators were around 0.90, 0.98, and 0.99, respectively (Figure 34c). This indicates that grinding media particles were quasi-perfect spheres. Post grinding ceramic balls and alumina beads present a similar trend. The sphericity and aspect ratio dropped by less than $0.30 \%$, while the circularity ratio slightly increased. On the other hand, silica beads show a higher variation in shape compared to the other materials, accounting for up to $0.63 \%$ in sphericity and $0.23 \%$ in aspect ratio. Unlike ceramic balls and alumina beads, the circularity ratio for silica beads also dropped by $0.19 \%$. All these variations observed are within one standard deviation of the replicate tests, indicating minimum or no degradation of all media materials after performing the grinding tests. 
(a) Ceramic Balls (CB)

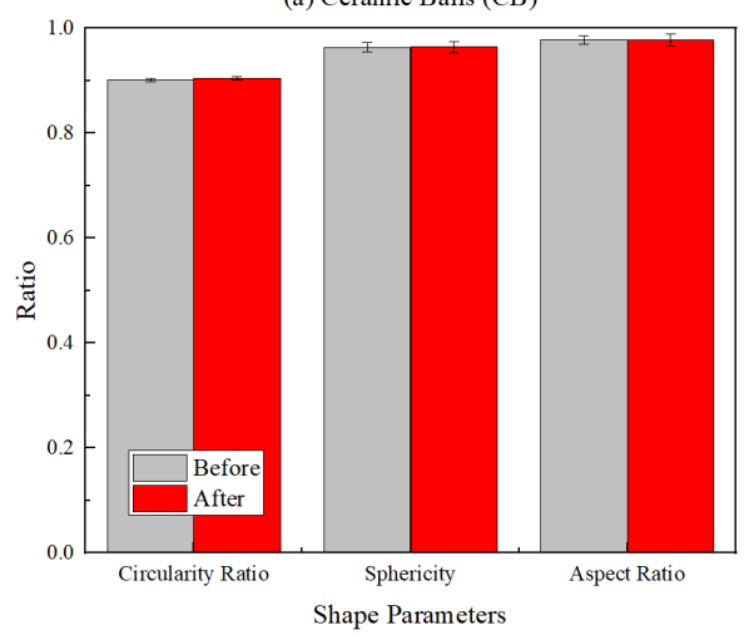

(b) Alumina Beads (AB)

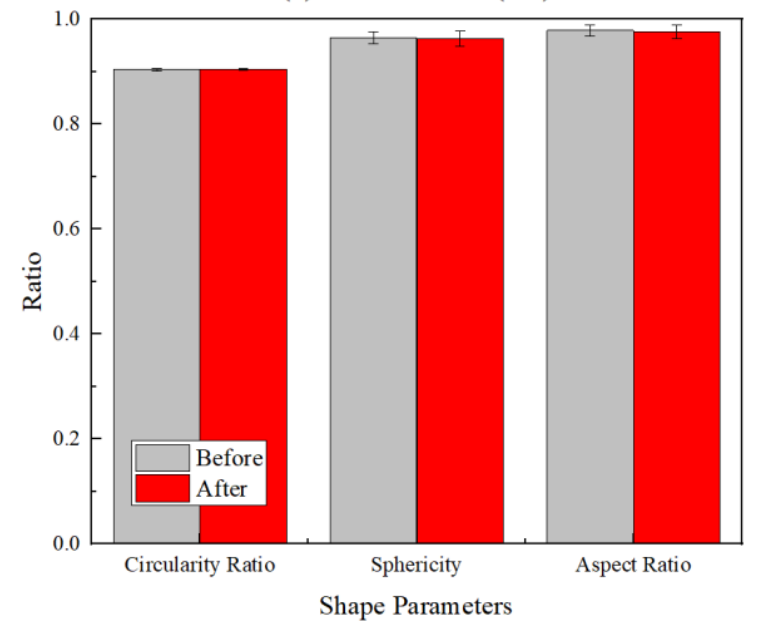

(c) Silica Beads (SB)

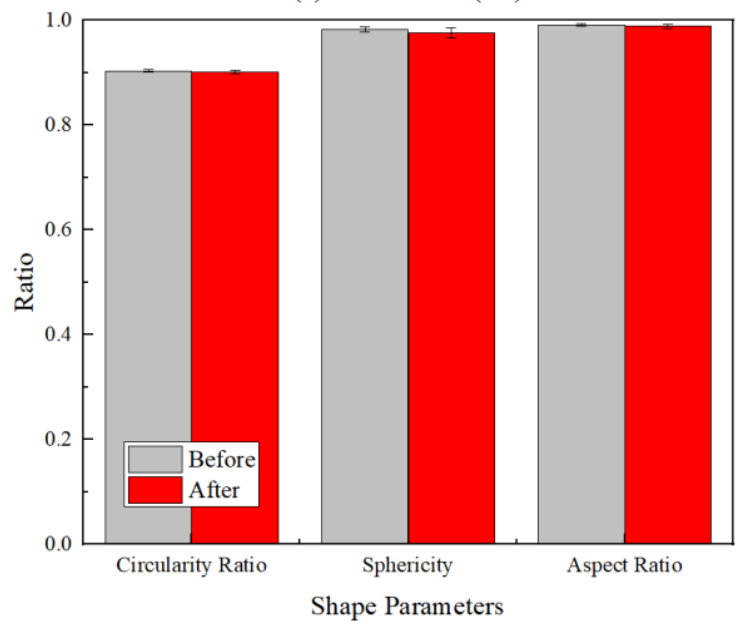

Figure 34. Shape analysis of the grinding media materials before and after stirred mill grinding tests. Error bars represent the standard deviation of multiple measurements.

Moreover, no media degradation was visually observed, as shown in Figure 35. Grinding media wear is a normal process produced by the physical interaction of media grains with themselves, mineral particles, and mill chamber. Becker and Schwedes (1999) state that the wear rate depends primarily on the hardness of the beads, explaining the relatively higher wear rate obtained using silica beads since its hardness is 6 on the Mohs scale, while ceramic balls and alumina beads' hardness is 9 . 


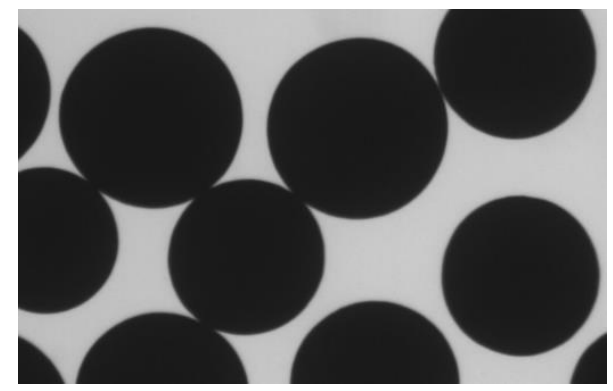

(a) Ceramic balls - Before grinding

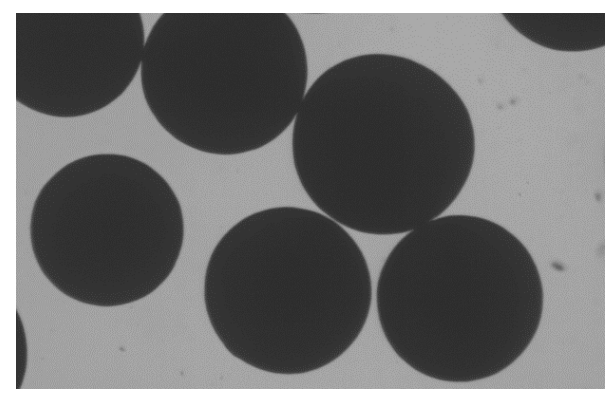

(c) Alumina beads - Before grinding

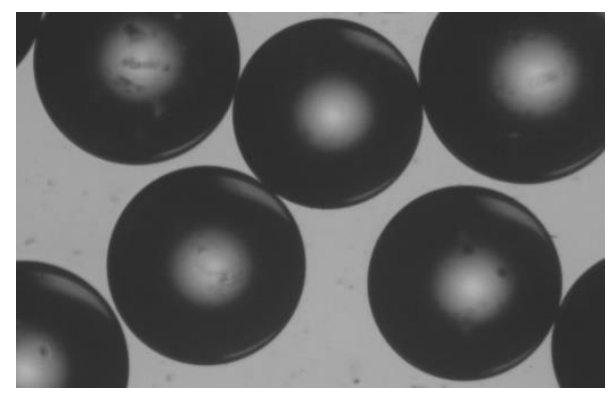

(e) Silica beads - Before grinding

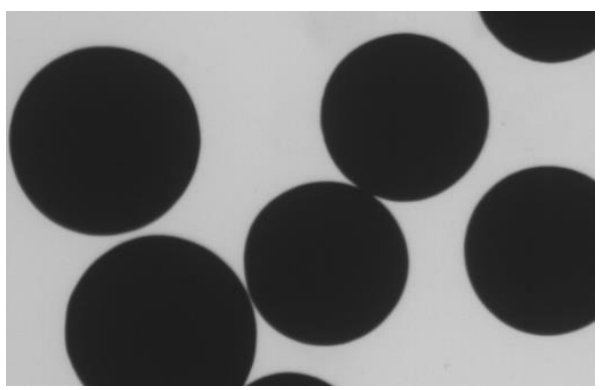

(b) Ceramic balls - Post grinding

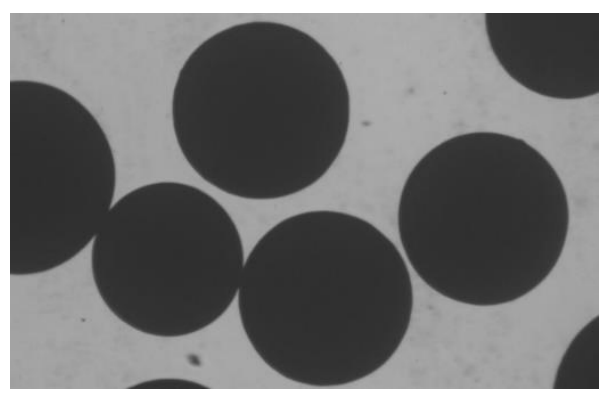

(d) Alumina beads - Post grinding

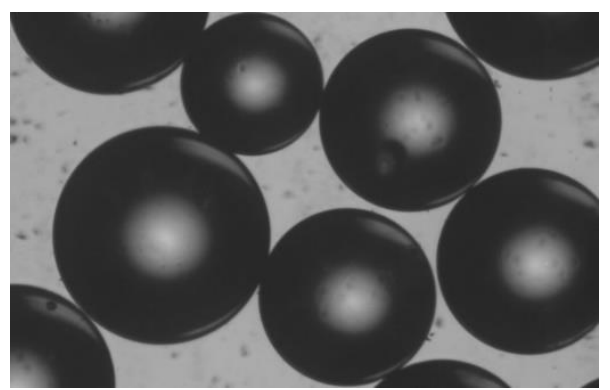

(f) Silica beads - Post grinding

Figure 35. Image analysis of grinding media materials submitted to grinding stress

\subsubsection{2. $\quad$ Effect of Media Size Range}

Given the results obtained for specific energy, particle size, and shape analyses, silica beads provided the optimum grinding performance in terms of product size and energy consumption. Therefore, the study of the effect of the grinding media size range was addressed using only silica beads. Table 9 shows the detailed test conditions followed to study the effect of grinding media size. 
Table 9. Test conditions for kinetic grinding tests employing different size ranges of silica beads.

\begin{tabular}{lc|ccc}
\hline \multicolumn{1}{c}{ Parameter } & Unit & $\begin{array}{c}\text { Fine } \\
\text { Silica Beads }\end{array}$ & $\begin{array}{c}\text { Regular } \\
\text { Silica Beads }\end{array}$ & $\begin{array}{c}\text { Coarse } \\
\text { Silica Beads }\end{array}$ \\
\hline Slurry/Pulp Mass & $\mathrm{g}$ & 1,360 & 1,360 & 1,360 \\
Solid Feed Mass & $\mathrm{g}$ & 408 & 408 & 408 \\
Water Mass & $\mathrm{g}$ & 952 & 952 & 952 \\
Solids Concentration & $\mathrm{wt} \%$ & 30 & 30 & 30 \\
Stirrer Speed & $\mathrm{RPM}$ & 340 & 340 & 340 \\
Grind Time & $\mathrm{min}$. & 64 & 64 & 64 \\
Media Size & $\mu \mathrm{m}$ & $40 \times 210$ & $250 \times 420$ & $420 \times 850$ \\
Media Mass & $\mathrm{g}$ & 5,194 & 5,194 & 5,194 \\
Feed Size, F80 & $\mu \mathrm{m}$ & 24.36 & 24.36 & 24.36 \\
\hline
\end{tabular}

The influence of media size on ultrafine coal grinding performance was analyzed with two additional size ranges of silica beads. Denoted as fine silica beads and coarse silica beads, their size range spans $40 \times 210 \mu \mathrm{m}$ and $420 \times 850 \mu \mathrm{m}$, respectively. As shown in Figure 36, both size ranges exhibit a similar trend in power consumption and specific energy; however, coarse silica beads (Figure 36b) require less energy than fine beads.
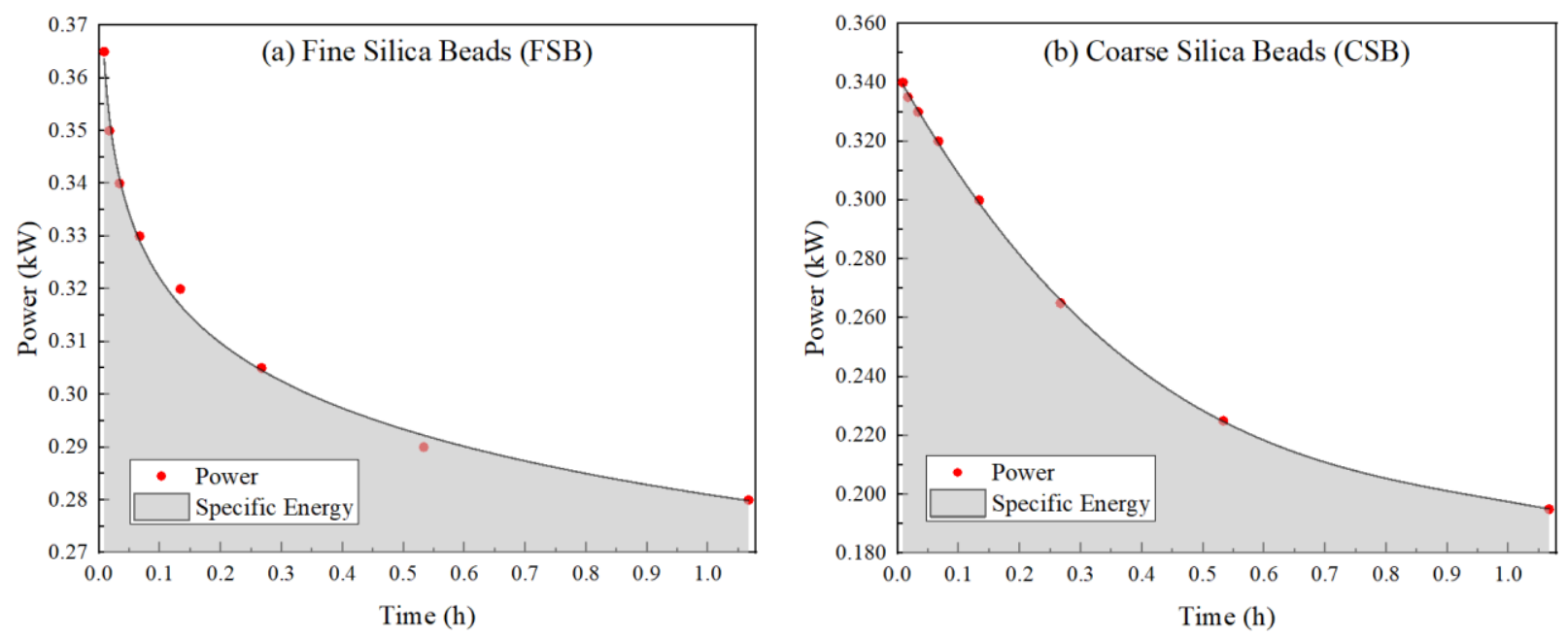

Figure 36. Power input and specific energy required by silica beads with different sizes: (a) Fine silica beads 40 × $210 \mu \mathrm{m}$, and (b) Coarse silica beads $420 \times 850 \mu \mathrm{m}$.

The specific energy input of $283 \mathrm{kWh} /$ ton for coarse silica beads represents around two-thirds of the $421 \mathrm{kWh} /$ ton required by fine beads. These results present a similar trend as those obtained in the previous section. The specific energy decreased as the bead size increased, as shown in Figure 37. A significant saving of $33 \%$ can be achieved by increasing the grinding media size from $+40 /-$ 
210 to $+420 /-850 \mu \mathrm{m}$. According to Altun et al. (2013), the grinding media size plays an important role in grinding operations, and its proper selection can have a positive impact on energy efficiency. Likewise, unsuitable grinding media sizes might dramatically increase the power draw (Jayasundara et al., 2012).

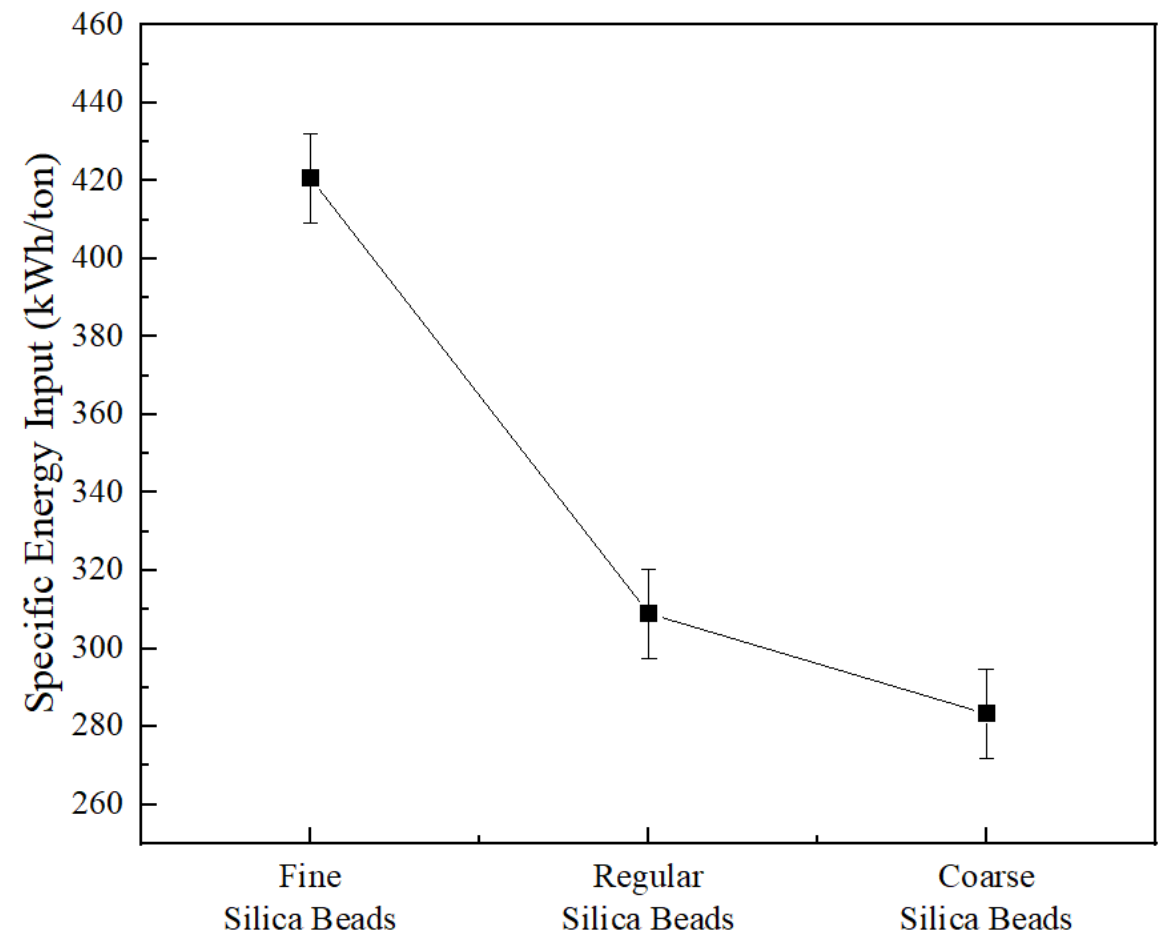

Figure 37. Specific energy input of silica beads with different sizes. Error bars represent one standard deviation of three replicate tests.

The coal product size and grinding media size range displayed an inverse relationship in this study. That is, the coarser the media size, the finer the product material. Coarse silica beads reached a product size of $3.3 \mu \mathrm{m}$, representing a reduction ratio of 7.3:1. Compared to regular-sized silica beads $\left(\mathrm{P}_{80}=5.9 \mu \mathrm{m}\right)$, finer product size and lower energy consumption were achieved by employing a larger media size range. These findings are consistent with the results obtained by Mankosa et al. (1986) and Guo et al. (2021), who also observed an improvement in the yield of the ground product by increasing the size of the grinding media. The particle size distribution for fine silica beads is not shown in Figure 38 because it was not possible to achieve a clear separation of the coal sample from the grinding media material due to its fineness. Although all media materials were pre-screened before each grinding test to ensure the nominal size range provided by the vendor matches the actual size range, a significant amount of fine silica beads were reported to the underflow which altered the results of the particle size analysis. In addition to this, a 
considerable amount of unground coal particles was retained on top of the sieve with the grinding media, implying the necessity of an additional separation process to recover coarse coal material. Hence, it was concluded that fine silica beads are not suitable for ultrafine grinding mainly due to the complexity of separation and the additional steps required to separate the coal sample from the grinding media fully.

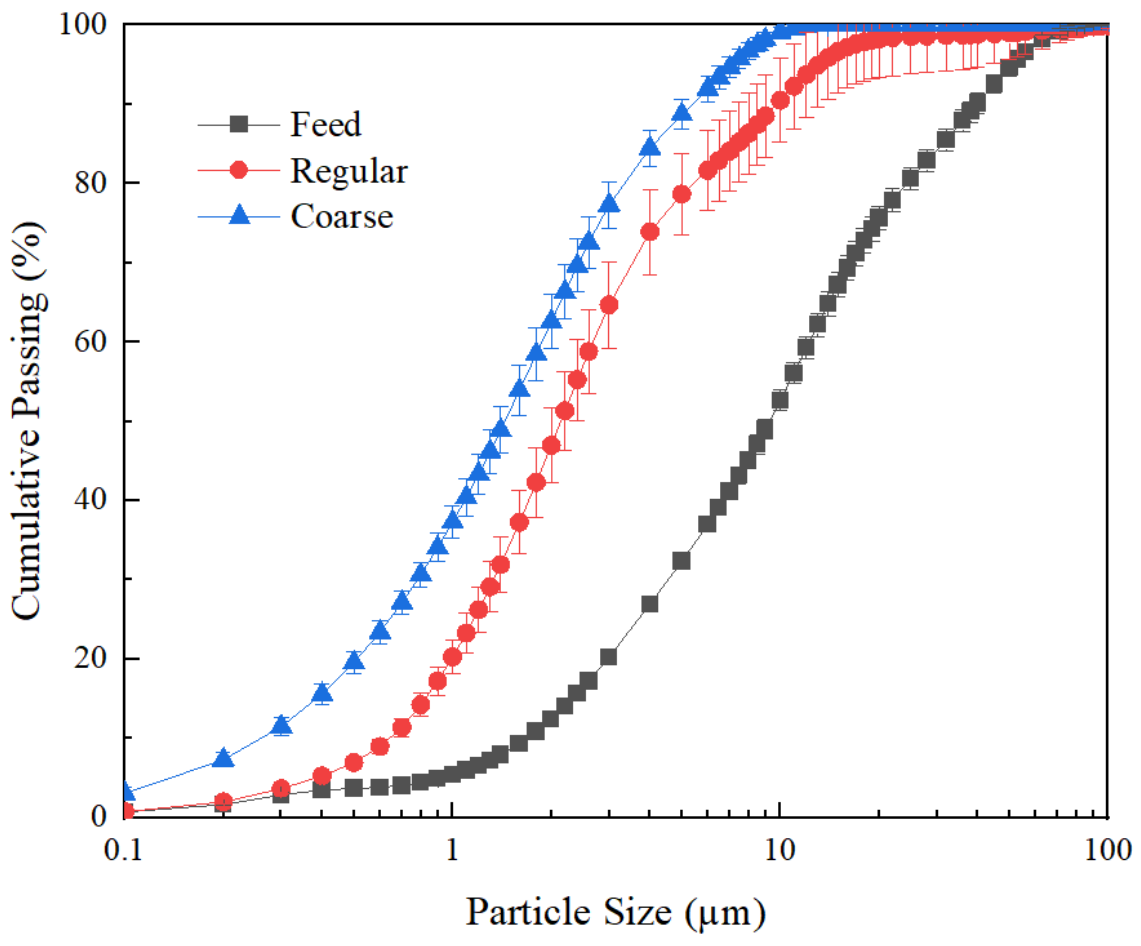

Figure 38. Particle size distribution of feed and ground products obtained using regular and coarse silica beads. It was not possible to obtain the distribution for fine beads due to media degradation and the complexity of separation. Error bars represent one standard deviation of twelve replicate tests.

Shape analysis shows minimum or no degradation expected after grinding for both additional silica bead sizes (Figure 39). Fine silica beads had initial circularity ratio, sphericity, and aspect ratio values of around 0.93,0.92, and 0.95, respectively. After grinding, the circularity ratio remained almost constant while the sphericity and aspect ratio dropped to 0.90 and 0.94 , which accounts for $2.40 \%$ and $1.51 \%$ reduction, separately. On the other hand, coarse silica beads had initial circularity ratio, sphericity, and aspect ratio values of around 0.89, 0.95, and 0.96. After grinding, they decreased by $0.26 \%, 0.85 \%$ and $0.30 \%$, respectively. It seemed that fine silica beads have higher media wear rates than coarse beads; however, all the variations are within the standard deviations generated from the replicate tests. 

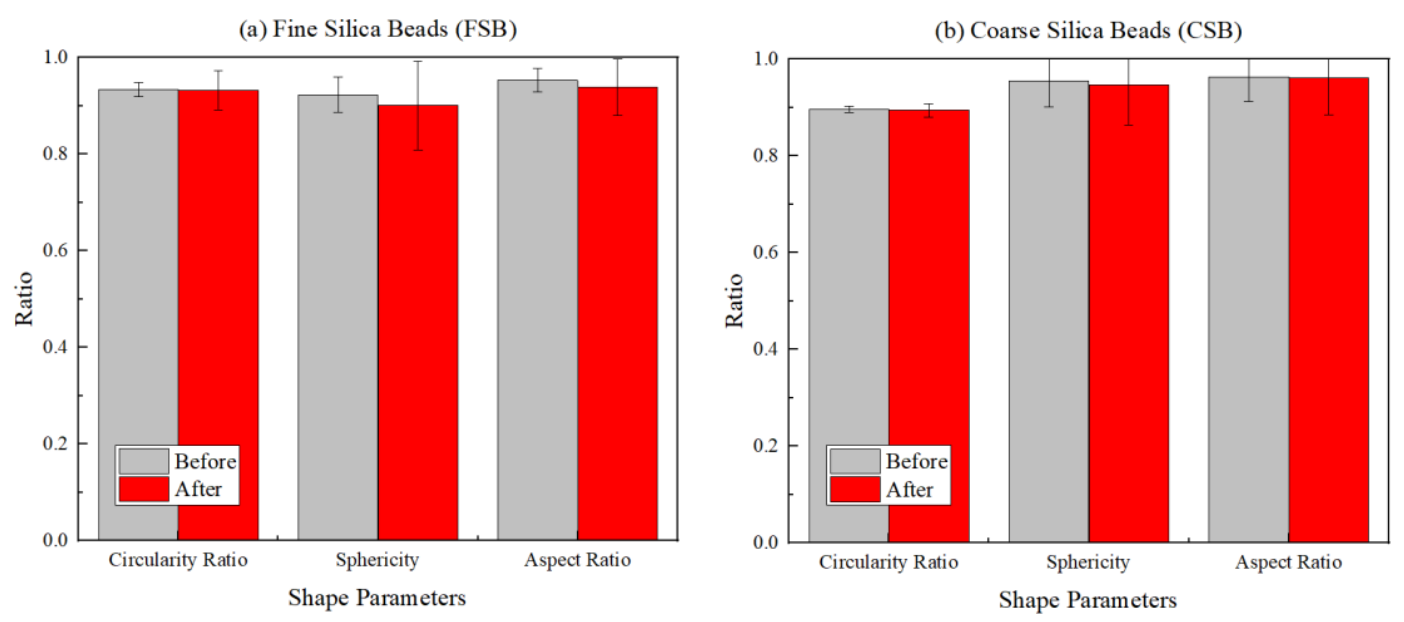

Figure 39. Shape analysis of silica beads with different size ranges before and after stirred mill grinding tests. Error bars represent the standard deviation of multiple measurements.

\subsubsection{3. $\quad$ Effect of Solids Concentration}

The influence of solids concentration on ultrafine grinding of coal was studied using coarse silica beads as well as ceramic balls. Six kinetic grinding tests were performed with varying solids concentrations ranging from $20 \mathrm{wt} \%$ to $40 \mathrm{wt} \%$. The detailed test conditions for both grinding media materials are shown in Table 10.

Table 10. Test conditions for kinetic grinding tests employing coarse silica beads and ceramic balls to analyze the effect of solids concentration.

\begin{tabular}{lc|cccccc}
\hline \multicolumn{1}{c|}{ Parameter } & Unit & \multicolumn{3}{|c}{ Coarse Silica Beads (CSB) } & \multicolumn{3}{c}{ Ceramic Balls (CB) } \\
\hline Slurry/Pulp Mass & $\mathrm{g}$ & 1,360 & 1,360 & 1,360 & 1,360 & 1,360 & 1,360 \\
Solid Feed Mass & $\mathrm{g}$ & 272 & 408 & 544 & 272 & 408 & 544 \\
Water Mass & $\mathrm{g}$ & 1088 & 952 & 816 & 1088 & 952 & 816 \\
Solids Concentration & $\mathrm{wt} \%$ & 20 & 30 & 40 & 20 & 30 & 40 \\
Stirrer Speed & $\mathrm{RPM}$ & 340 & 340 & 340 & 340 & 340 & 340 \\
Grind Time & $\mathrm{min}$ & 64 & 64 & 64 & 64 & 64 & 64 \\
Media Size & $\mu \mathrm{m}$ & $420 \times 850$ & $420 \times 850$ & $420 \times 850$ & $250 \times 340$ & $250 \times 340$ & $250 \times 340$ \\
Media Mass & $\mathrm{g}$ & 5,194 & 5,194 & 5,194 & 5,194 & 5,194 & 5,194 \\
Feed Size, F80 & $\mu \mathrm{m}$ & 24.36 & 24.36 & 24.36 & 24.36 & 24.36 & 24.36 \\
\hline
\end{tabular}

The graphs representing the power draw and specific energy are shown in Figure 40. The displayed characteristic trend for silica beads is consistent with the results obtained previously (Figure 40a, Figure 40c, and Figure 40e). Nevertheless, ceramic balls present either an order 3 or order 4 polynomial trend. These types of trendlines generally present one or multiple hills or valleys (Henke, 2020). 

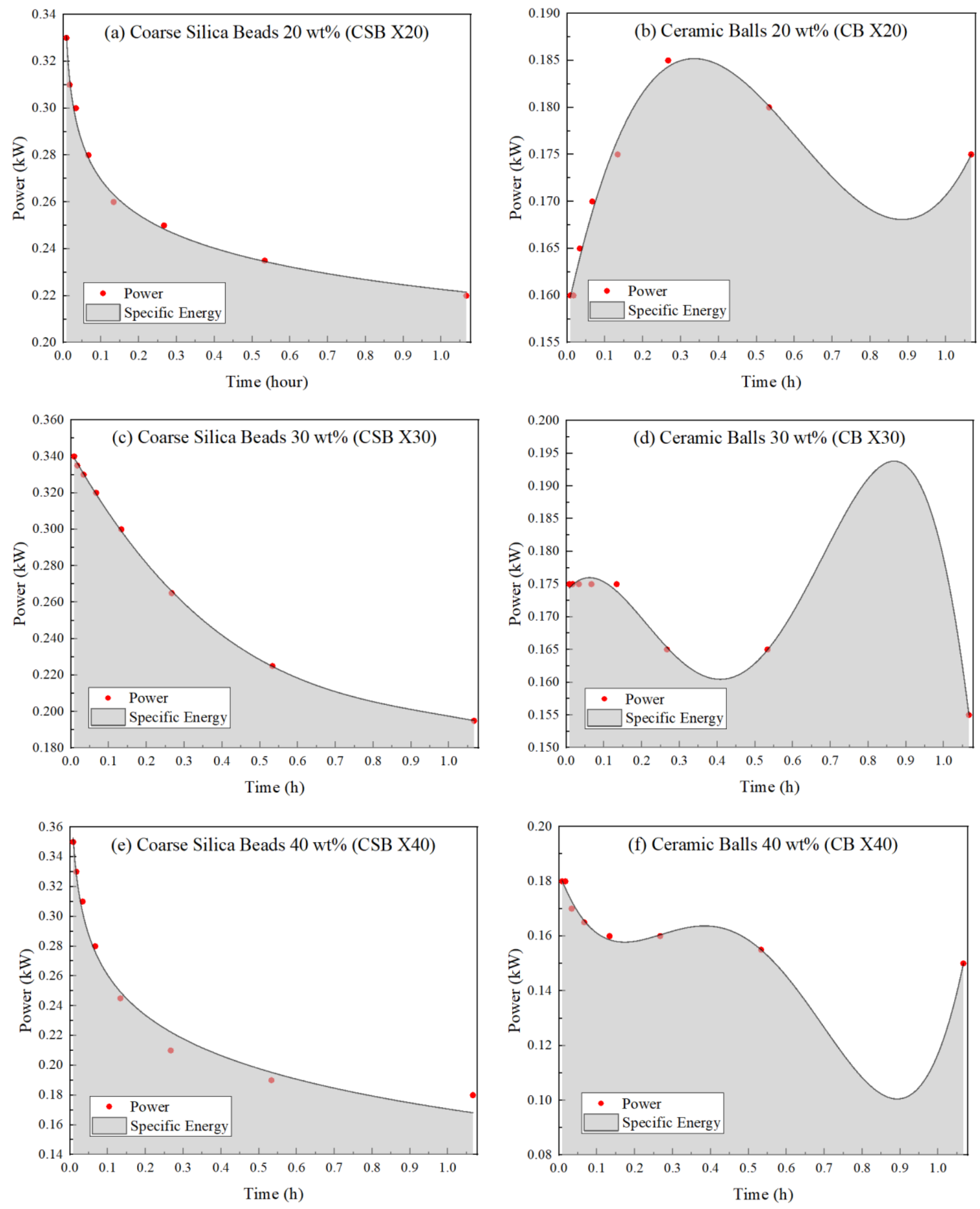

Figure 40. Power input and specific energy required by coarse silica beads and ceramic balls with different solids concentrations by weight. 
As reported in Figure 41, specific energy input considerably increased as the percent of solids was reduced. Lowering this concentration by half (from $40 \mathrm{wt} \%$ to $20 \mathrm{wt} \%$ ) resulted in tripling energy consumption from $155 \mathrm{kWh} /$ ton to $432 \mathrm{kWh} /$ ton using silica beads. For ceramic balls, the energy consumption increased by 5 times, going from 39 to $198 \mathrm{kWh} / \mathrm{ton}$. Under the standard test conditions $(\mathrm{X}=30 \mathrm{wt} \%)$, the specific energy input was around 283 and $129 \mathrm{kWh} /$ ton for silica beads ceramic balls, respectively. Although both grinding media materials showed a decreasing trendline, ceramic balls required significantly less energy than silica beads. However, this power saving is reflected in the lower reduction ratio due to the coarser product size. Similar results were found by Simpson et al. (2015) during the study of the effect of solids concentration on the particle size distribution of deagglomerated barium titanate in stirred media mills. In addition, the researchers found peaks of specific energy at low $(<30 \mathrm{wt} \%)$ and very high $(>80 \mathrm{wt} \%)$ concentrations as a result of de-agglomeration events and increased density and viscosity, respectively.

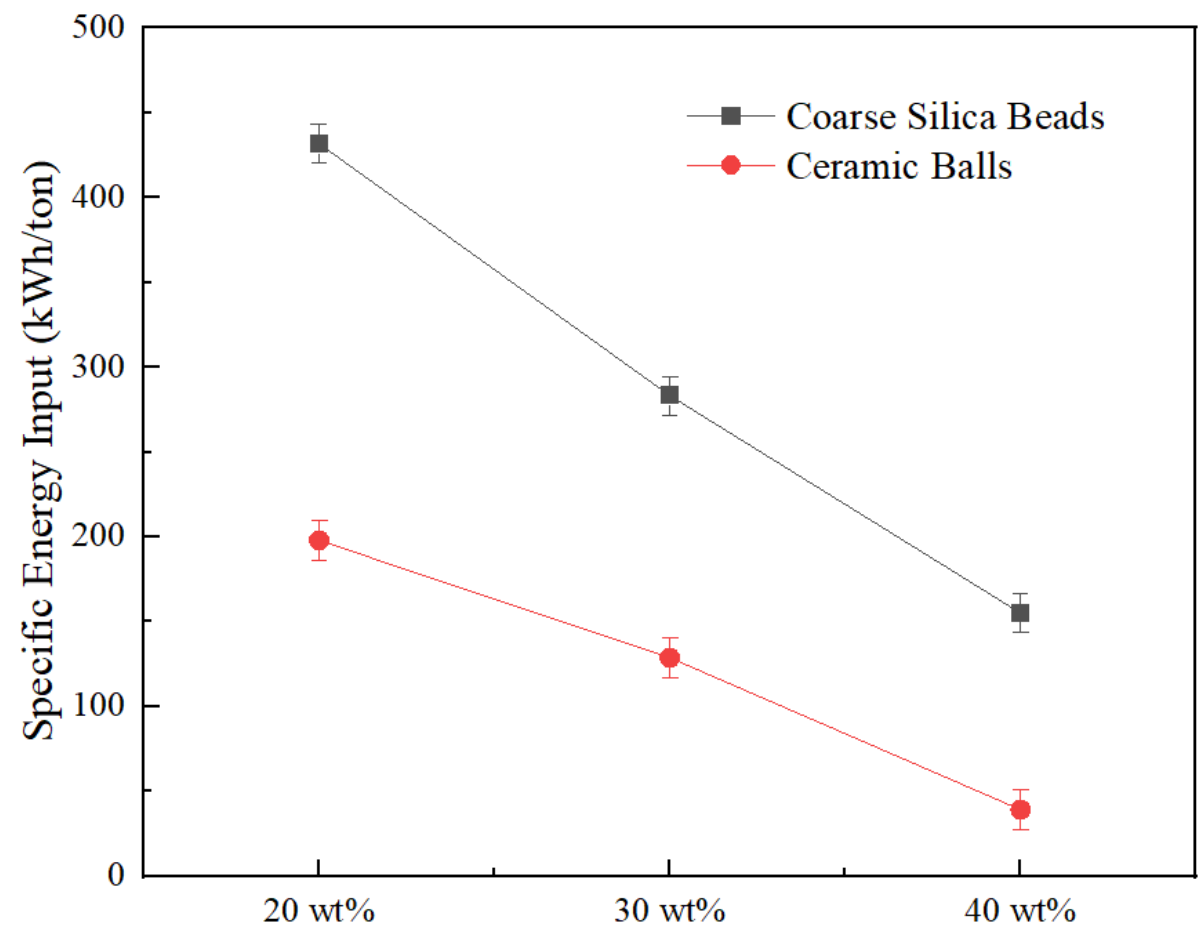

Solids Concentration

Figure 41. Specific energy input of coarse silica beads and ceramic balls with different solids concentration by weight. Error bars represent one standard deviation of three replicate tests. 
According to the results generated, the reduction of solids concentration enhanced the ultrafine grinding performance. The $\mathrm{P}_{80}$ values achieved for 20,30 , and $40 \mathrm{wt} \%$ concentrations using silica beads are 2.8, 3.3, and $4.1 \mu \mathrm{m}$, respectively. Similarly, the cumulative passing sizes $\left(\mathrm{P}_{80}\right)$ are 9.9, 12.8, and $13.0 \mu \mathrm{m}$ for ceramic balls, separately, as shown in Figure 42. Considering the feed size of $24.4 \mu \mathrm{m}$ and the product sizes obtained, the reduction ratio ranges between 5.9:1 and 8.6:1 using coarse silica beads, or 1.9:1 and 2.5:1 when ceramic grinding media is employed. These findings are supported by Bernhardt et al. (1999), who studied the effect of suspension properties on ultrafine grinding. It was found that the solids concentration has a strong influence on the energy utilization and final particle size. Suspensions with low solids concentrations provide the low fluid resistance needed to achieve finer product sizes while requiring higher power consumption. Partyka and Yan (2007) also reported the same grind curves during their experimental work using a horizontal ball mill and quartz andesite rock as a feedstock.

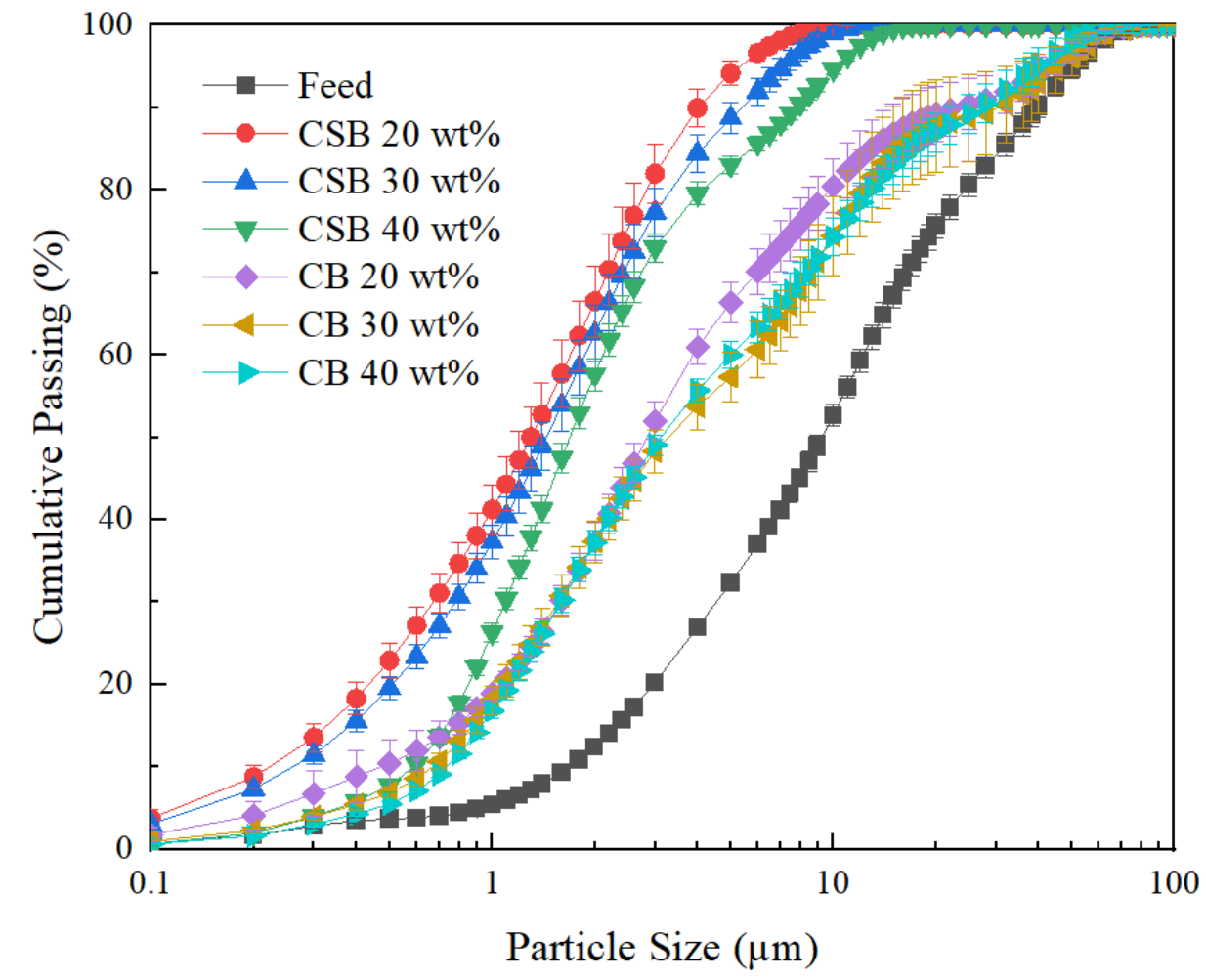

Figure 42. Particle size distribution of feed and ground products obtained using coarse silica beads (CSB) and ceramic balls (CB) with different solids concentrations by weight. Error bars represent one standard deviation of twelve replicate tests. 


\subsubsection{Effect of Viscosity Modifier}

Three different dosages of sodium silicate (i.e., 2, 8, and $14 \mathrm{~kg} /$ ton) were employed to modify the rheological behavior of the pulp and study its effect on ultrafine grinding performance. Detailed tests conditions are shown in Table 11.

Table 11. Test conditions for kinetic grinding tests employing coarse silica beads and ceramic balls to analyze the effect of different doses of dispersant.

\begin{tabular}{lc|cccccc}
\hline \multicolumn{1}{c|}{ Parameter } & Unit & \multicolumn{3}{c}{ Coarse Silica Beads } & \multicolumn{3}{c}{ Ceramic Balls } \\
\hline Slurry/Pulp Mass & $\mathrm{g}$ & 1,360 & 1,360 & 1,360 & 1,360 & 1,360 & 1,360 \\
Solid Feed Mass & $\mathrm{g}$ & 408 & 408 & 408 & 408 & 408 & 408 \\
Water Mass & $\mathrm{g}$ & 952 & 952 & 952 & 952 & 952 & 952 \\
Solids Concentration & $\mathrm{wt} \%$ & 30 & 30 & 30 & 30 & 30 & 30 \\
Dispersant Dosing & $\mathrm{kg} / \mathrm{ton}$ & 2 & 8 & 14 & 2 & 8 & 14 \\
Stirrer Speed & $\mathrm{RPM}$ & 340 & 340 & 340 & 340 & 340 & 340 \\
Grind Time & $\mathrm{min}$ & 64 & 64 & 64 & 64 & 64 & 64 \\
Media Size & $\mu \mathrm{m}$ & $420 \times 850$ & $420 \times 850$ & $420 \times 850$ & $250 \times 340$ & $250 \times 340$ & $250 \times 340$ \\
Media Mass & $\mathrm{g}$ & 5,194 & 5,194 & 5,194 & 5,194 & 5,194 & 5,194 \\
Feed Size, F80 & $\mu \mathrm{m}$ & 24.36 & 24.36 & 24.36 & 24.36 & 24.36 & 24.36 \\
\hline
\end{tabular}

The power draw readings and specific energy obtained during the study of the influence of viscosity modifiers on stirred milling are shown in Figure 43. Both grinding media materials show their characteristic trend line that resembles that obtained previously in the study of the effect of solids concentration. 

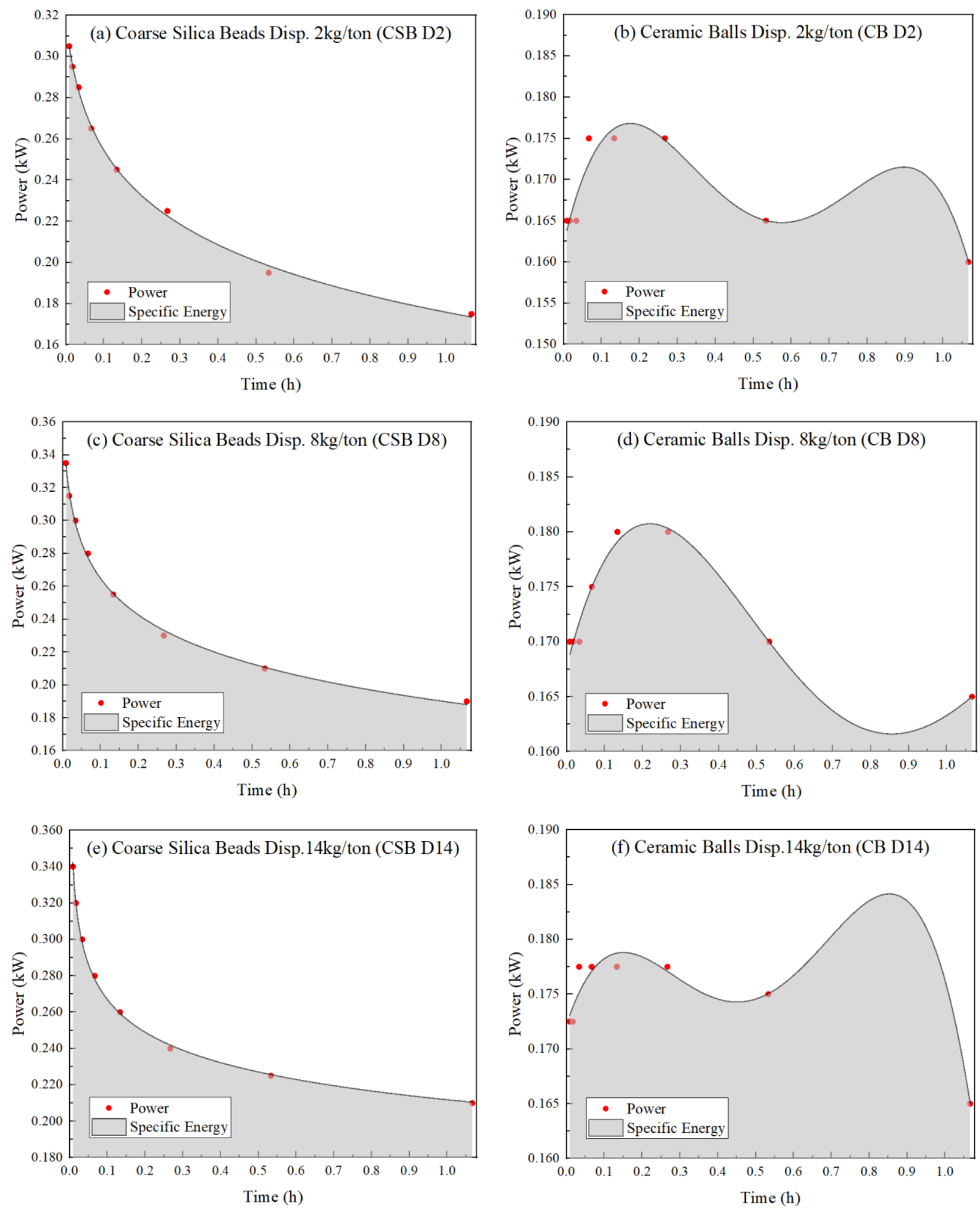

Figure 43. Power input and specific energy required by coarse silica beads and ceramic balls with different doses of sodium silicate as a viscosity modifier. 
As expected, the power consumption and specific energy increased as the dispersant dosage increased (Figure 44). Under standard conditions, the power demand using coarse silica beads with $14 \mathrm{~kg} /$ ton of sodium silicate was $270 \mathrm{kWh} /$ ton and dropped almost linearly to 238 and $213 \mathrm{kWh} / \mathrm{ton}$ when employing 8 and $2 \mathrm{~kg} /$ ton of dispersant, respectively. A linear trend was also observed employing ceramic balls, in which the specific energy dropped from $137 \mathrm{kWh} /$ ton to 119 and 117 $\mathrm{kWh} /$ ton, respectively. The higher efficiency provided by dispersants is due to a lower viscosity maintained during the comminution process (Kapur et al., 1996). Therefore, the breakage rate increases and demands more energy to achieve a finer product size (He et al., 2005). Although the gap between the higher and lower specific energy obtained seems insignificant, it may represent an important difference when dealing with very high energy consumptions for more extended periods.

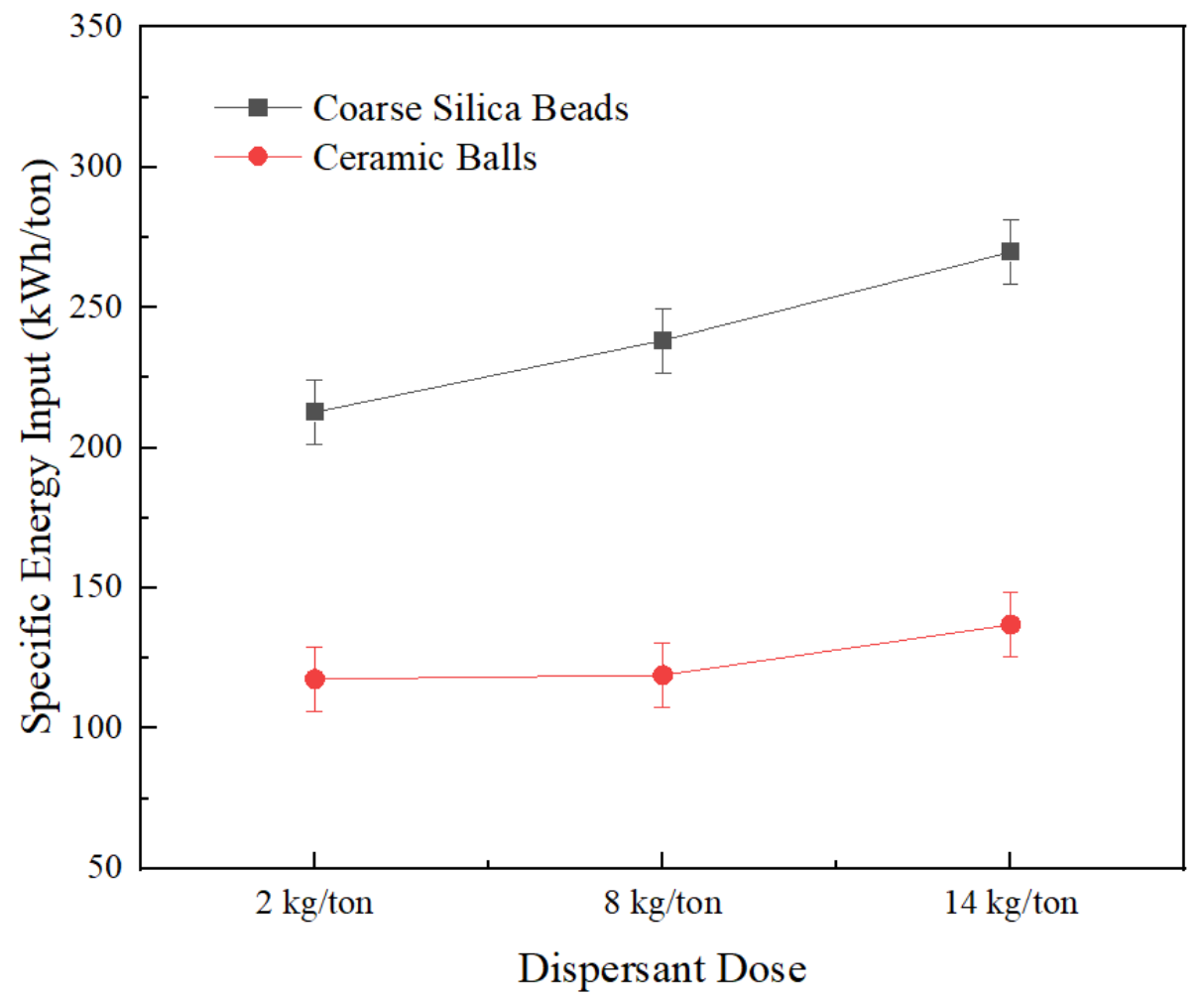

Figure 44. Specific energy input of coarse silica beads and ceramic balls employing different doses of sodium silicate as a viscosity modifier. Error bars represent one standard deviation of three replicate tests. 
In terms of particle size distribution, a finer product size was obtained with a high dosage of the viscosity modifier (Figure 45). Silica grinding media managed to reduce the cumulative passing size from $24.4 \mu \mathrm{m}$ to $2.7 \mu \mathrm{m}$ by adding $14 \mathrm{~kg} /$ ton of dispersant. This $\mathrm{P}_{80}$ value slightly increased to 3.1 and $4.9 \mu \mathrm{m}$ when the dosage was reduced to 8 and $2 \mathrm{~kg} / \mathrm{ton}$, respectively. On the other hand, the finest product size obtained using ceramic balls and $14 \mathrm{~kg} /$ ton was $11.8 \mu \mathrm{m}$, followed by the $12.9 \mu \mathrm{m}$ obtained using $8 \mathrm{~kg} /$ ton and $13.4 \mu \mathrm{m}$ using $2 \mathrm{~kg} / \mathrm{ton}$. The use of this grinding aid in stirred milling using coarse silica beads attained reduction ratio values between 4.9:1 and 9.1:1. Nonetheless, these values were around 1.8:1 and 2.1:1 when ceramic grinding media was employed. These results agree with the findings reported in Mankosa and his coworkers' study (1989) in which an improvement was observed in the mean product particle diameter by utilizing various types of dispersants.

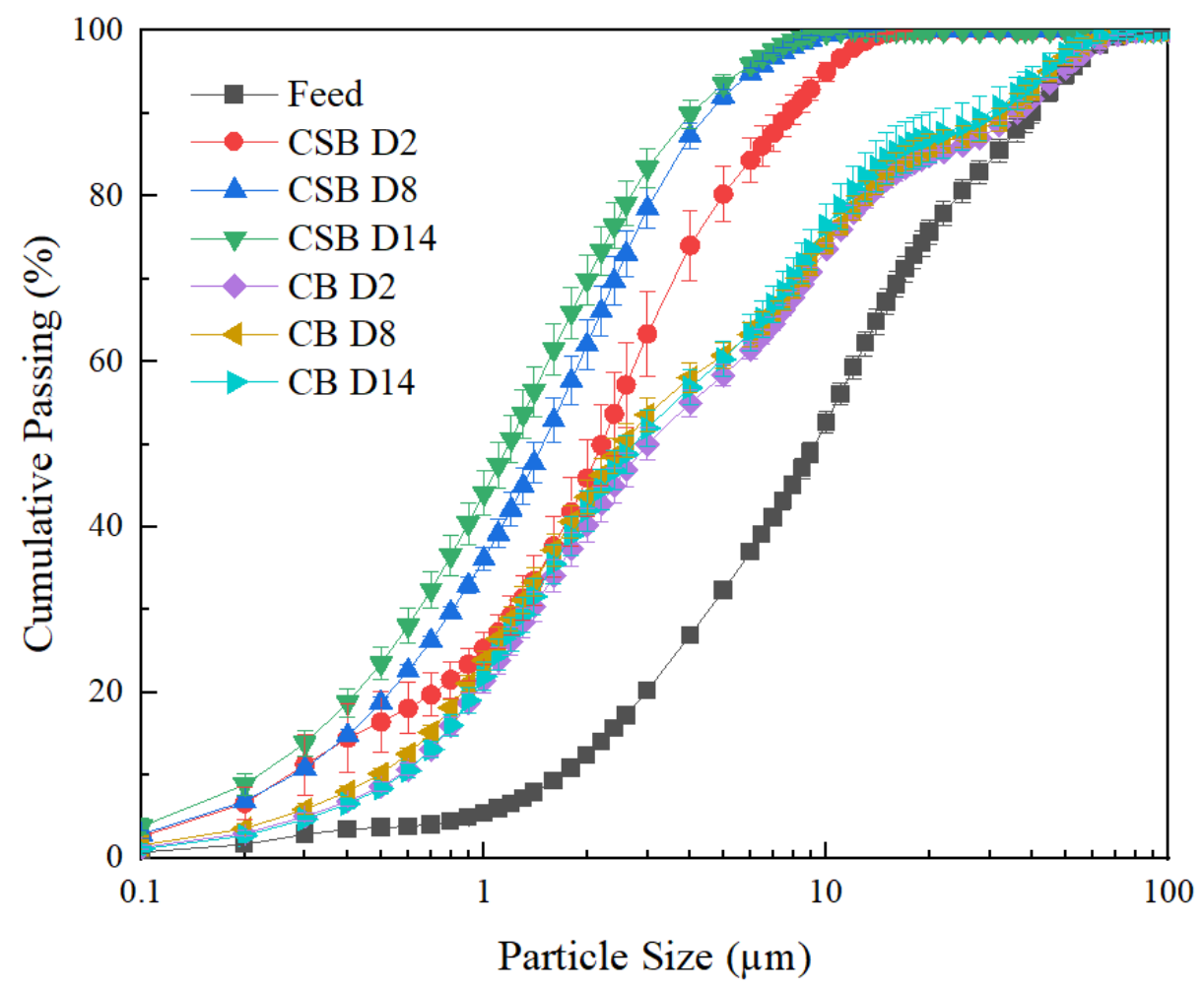

Figure 45. Particle size distribution of feed and ground products obtained using coarse silica beads with different doses of sodium silicate as a viscosity modifier. Error bars represent one standard deviation of twelve replicate tests. 
In this section, a comprehensive study is performed on the results collected during the analysis of the influence of grinding media materials, grinding media size, solids concentration by weight, and grinding aids such as dispersants on ultrafine grinding. Table 12 shows the output obtained throughout the grinding study in terms of feed size, product size, reduction ratio, and specific energy. Furthermore, Figure 46 represents the trends generated by the specific energy as a function of the product particle size.

Table 12. Overall stirred mill grinding tests output.

\begin{tabular}{lcccc}
\hline \multicolumn{1}{c}{ Test } & $\begin{array}{c}\text { Feed } \\
(\boldsymbol{\mu m})\end{array}$ & $\begin{array}{c}\text { P80 } \\
(\boldsymbol{\mu m})\end{array}$ & $\begin{array}{c}\text { Reduction } \\
\text { Ratio }\end{array}$ & $\begin{array}{c}\text { Specific Energy } \\
(\mathbf{k W h} / \text { ton) }\end{array}$ \\
\hline Ceramic Balls & 24.36 & 12.82 & 1.90 & 128.76 \\
Alumina Beads & 24.36 & 15.54 & 1.57 & 109.49 \\
Silica Beads & 24.36 & 5.86 & 4.16 & 308.97 \\
Granular Sand & 24.36 & - & - & 579.40 \\
\hline Fine Silica Beads & 24.36 & - & - & 420.75 \\
Regular Silica Beads & 24.36 & 5.86 & 4.16 & 308.97 \\
Coarse Silica Beads & 24.36 & 3.34 & 7.29 & 283.22 \\
\hline Coarse Silica Beads 20wt\% & 24.36 & 2.84 & 8.57 & 431.69 \\
Coarse Silica Beads 30wt\% & 24.36 & 3.34 & 7.29 & 283.22 \\
Coarse Silica Beads 40wt\% & 24.36 & 4.14 & 5.88 & 155.02 \\
Ceramic Balls 20wt\% & 24.36 & 9.95 & 2.45 & 197.96 \\
Ceramic Balls 30wt\% & 24.36 & 12.82 & 1.90 & 128.76 \\
Ceramic Balls 40wt\% & 24.36 & 13.04 & 1.87 & 39.22 \\
\hline Coarse Silica Beads Disp. 2kg/ton & 24.36 & 4.95 & 4.92 & 212.73 \\
Coarse Silica Beads Disp. 8kg/ton & 24.36 & 3.14 & 7.76 & 238.27 \\
Coarse Silica Beads Disp. 14kg/ton & 24.36 & 2.68 & 9.07 & 269.74 \\
Ceramic Balls Disp. 2kg/ton & 24.36 & 13.40 & 1.82 & 117.54 \\
Ceramic Balls Disp. 8kg/ton & 24.36 & 12.93 & 1.88 & 119.03 \\
Ceramic Balls Disp. 14kg/ton & 24.36 & 11.82 & 2.06 & 137.00 \\
\hline
\end{tabular}

Firstly, the selection of silica beads as the most suitable grinding media material was based on the superior performance in terms of product size. However, this potential to produce finer particle sizes demands higher power compared to other grinding media materials. Ceramic balls (BC) and alumina beads represent an alternative when low-cost grinding operations are required and the product size is not a limitation. The use of Granular Sand was ruled out due to its degradation during grinding, which would make any process infeasible due to high maintenance costs and additional separation stages. Although its $\mathrm{P}_{80}$ value could not be determined, the specific energy is displayed in the plot with the intention of providing an idea of power requirements. 
According to the results obtained in the study of the optimum grinding media size, finer product size and lower energy consumption were achieved by increasing grinding silica media size from $250 \times 420 \mu \mathrm{m}$ to $420 \times 850 \mu \mathrm{m}$. Large beads also make the wet screening separation process less time-consuming and facilitate their recovery. On the other hand, fine beads $(40 \times 210 \mu \mathrm{m})$ are not suitable for ultrafine grinding due to extra power demand and the complexity of separation. With the beads being significantly tiny, the grinding media recovery process became complex because a considerable amount of grinding media was reported to the underflow, as well as quite a few unground coal particles retained with the silica beads.

Figure 46 illustrates the trend lines obtained when the rheological properties of the slurry were modified by changing the percent of solids or adding viscosity modifiers such as sodium silicate. Finer product size distributions can be achieved by either reducing the solids concentration to 20 wt $\%$ or increasing the dose of sodium silicate up to $14 \mathrm{~kg} /$ ton. Nevertheless, producing micronized particles implies supplying high amounts of power. The reduction of the solids concentration from $40 \%$ to $20 \%$ using silica beads resulted in a specific energy increase of $178 \%$, which represents an excessive increment. For ceramic grinding media, the difference is even greater, accounting for 404\% extra power. Establishing low solids concentrations seems to be an alternative to reduce the cumulative passing size; however, it is imperative to consider the substantial drop in throughput and the significant increase in water demand that this practice represents (Yianatos et al., 2002). Generally, industrial processing plants seek to operate their grinding equipment with high solids content as this allows to improve capacity, handle more material, and boost ore production (Gao et al., 2020).

Grinding aids have also been demonstrated to have the capability to increase the comminution coefficient and reduce power consumption up to almost $40 \%$ during ultra-fine grinding using stirred mills (H. Choi et al., 2010; Heekyu Choi et al., 2009). In this case, while testing coarse silica beads, the use of $14 \mathrm{~kg} / \mathrm{ton}$ of sodium silicate produced a slightly finer product size $(2.68$ $\mu \mathrm{m})$ than a solids concentration of $20 \%(2.84 \mu \mathrm{m})$ with a specific energy $37 \%$ lower. For ceramic balls, the power savings were $31 \%$. Even though the results show the potential of these additives to enhance ultra-fine grinding, their correct selection is crucial (Paul Prziwara \& Kwade, 2020). Also, the dispersant dosage may be unreasonably high; therefore, its use should be controlled to avoid affectation in downstream processes like thickening (Chipakwe et al., 2020). 


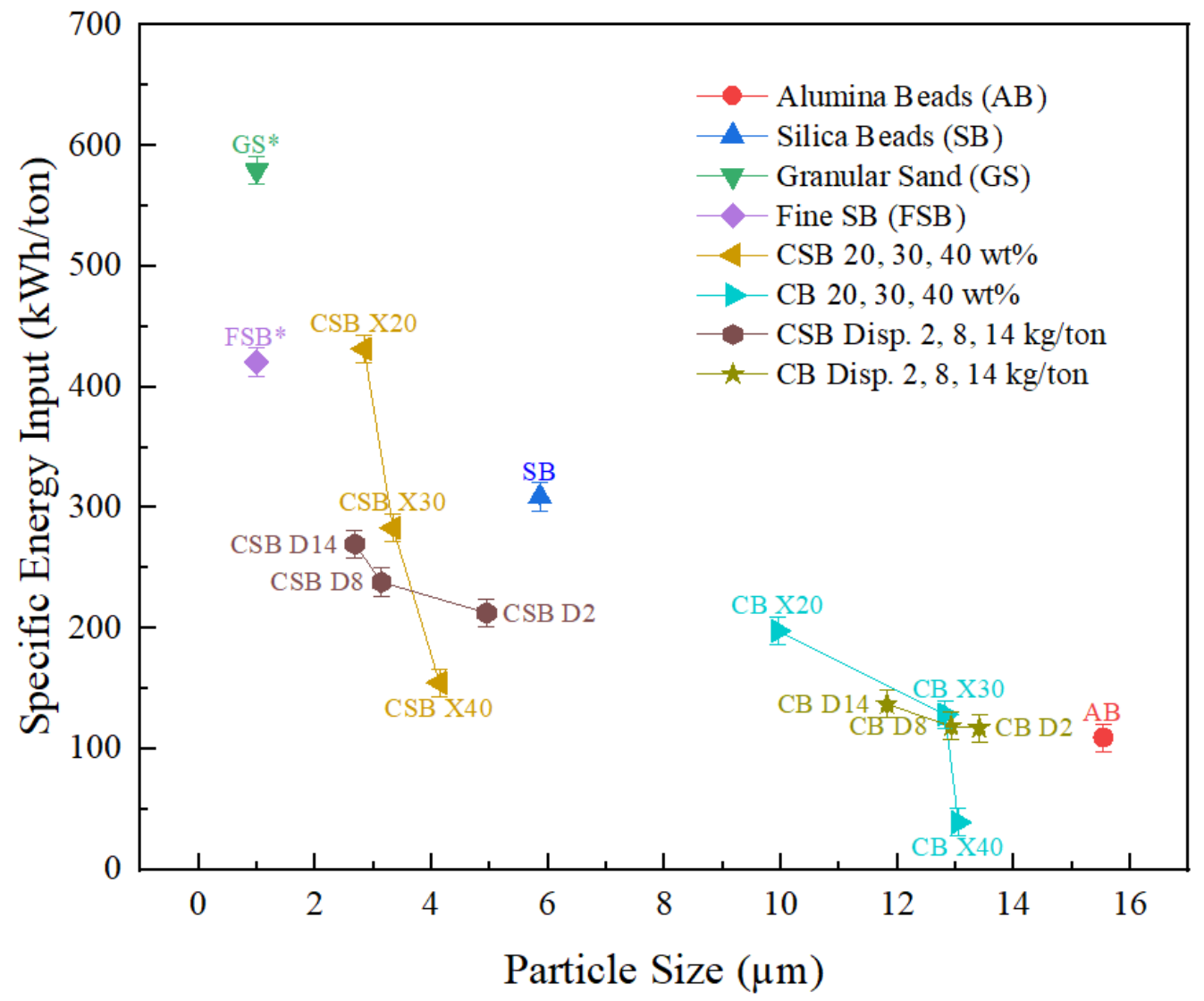

Figure 46. Overall specific energy input as a function of product size. Error bars represent one standard deviation of three replicate tests. *It was not possible to obtain the product size of tests using granular sand (GS) and fine silica beads (FSB), therefore a P80 of $1 \mu \mathrm{m}$ was used to represent the points.

As reported in the literature, the specific energy is inversely proportional to the final particle size (Martins, 2020). In other words, the finer the product size, the more energy required. This relationship is shown in Figure 47, where $\mathrm{P}_{80}$ and specific energy fluctuate in the opposite direction regardless of tests conditions. Although the energy required when using dispersant is significantly lower than varying solid concentrations, the curves show the same trend. Moreover, both silica and ceramic grinding media materials showed a similar trend under the effects of different solid concentrations and dispersant dosages, which indicates the results are consistent. 


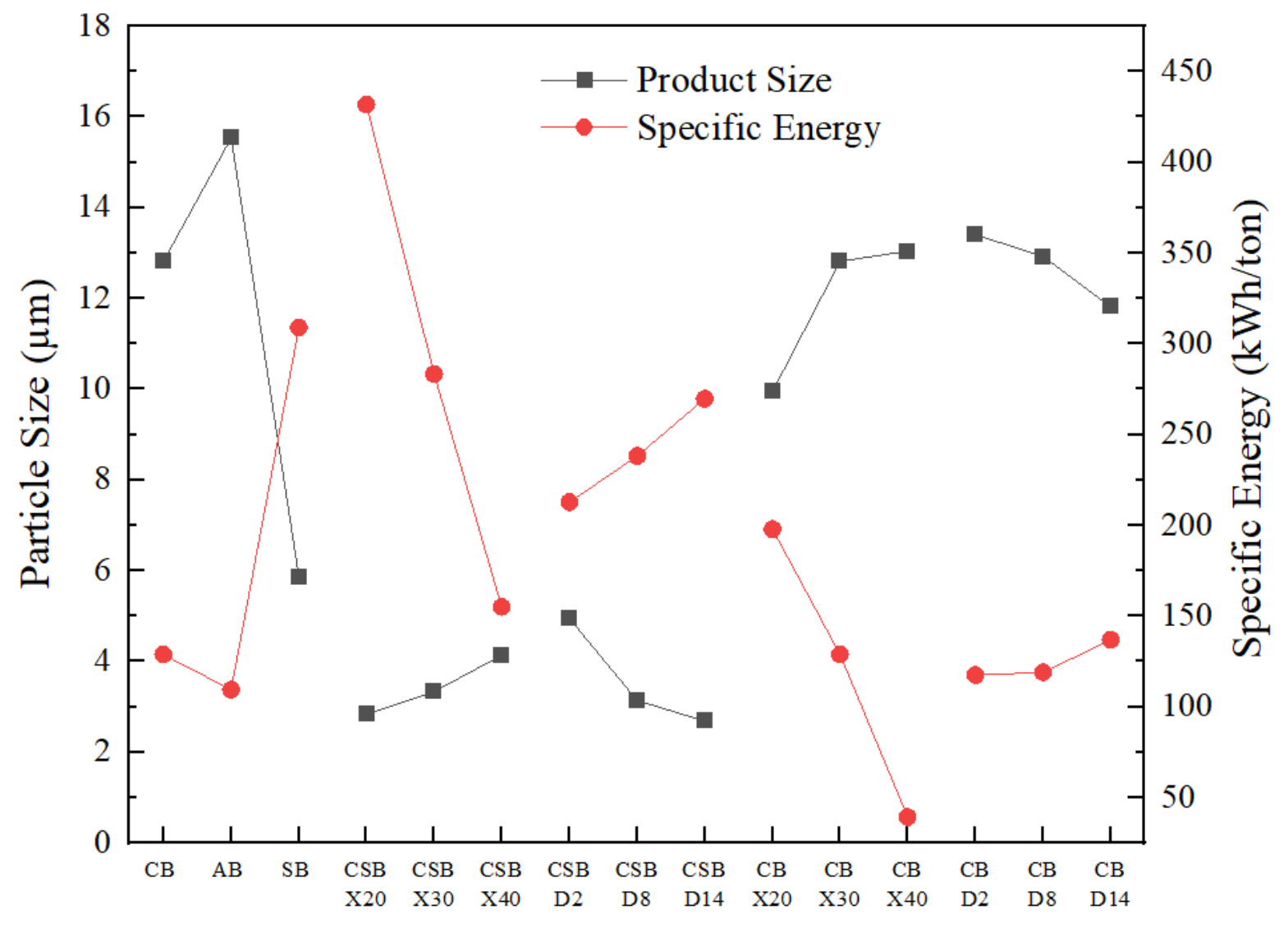

Figure 47. Trendline of specific energy and product size as a function of various grinding media materials and test conditions. 


\subsection{KINETIC GRINDING SIMULATION}

The grinding simulation was performed using Population Balance Modeling (PBM) including Breakage Function, Selection Function, and Particle Swarm Optimization (PSO) algorithm in Matlab. The input for the simulation was the cumulative percent passing of seven different particle diameters $(1.2,2,5,15,25,50$, and $100 \mu \mathrm{m})$ and feed on the actual particle size distribution of each test, as well as their corresponding specific energy. These variables are denoted as $\mathrm{m}(\overline{\mathrm{E}})$, $\mathrm{m}(0)$, and $\overline{\mathrm{E}}$ respectively. The in-built particle swarm optimization algorithm was used to simulate the batch grinding. This arrangement involved the lower and upper bounds of the selection function parameters $\left(S_{i}^{E}, \zeta_{1}, \zeta_{2}\right)$ and breakage function parameters $\left(\alpha_{1}, \alpha_{2}, \alpha_{3}\right)$. Their corresponding optimum values obtained from the numerical simulation for all tests conducted using both silica and ceramic grinding media materials are shown in Table 13.

Table 13. Confidence interval and optimum values of selection and breakage functions.

\begin{tabular}{ccccc}
\hline Parameter & Lower Bound & Upper Bound & $\begin{array}{c}\text { Optimum } \\
\text { CSB }\end{array}$ & $\begin{array}{c}\text { Optimum } \\
\text { CB }\end{array}$ \\
\hline$S_{1}^{E}$ & 0.0 & 0.1 & 0.0156 & 0.0081 \\
$\zeta_{1}$ & 0.0 & 5.0 & 0.0016 & 0.0091 \\
$\zeta_{2}$ & -4.0 & 1.0 & -0.2766 & -0.2827 \\
$\alpha_{1}$ & 0.0 & 2.0 & 0.9392 & 1.4642 \\
$\alpha_{2}$ & 0.0 & 0.5 & 0.4976 & 0.4971 \\
$\alpha_{3}$ & 10.0 & 25.0 & 15.9953 & 18.8091 \\
\hline
\end{tabular}

The numerical simulation for silica beads and ceramic balls was carried out separately. The mean squared error (MSE) for silica media was reduced to 0.003207 (Figure 48), while for ceramic media, this value reached 0.002891 (Figure 49). The particle swarm optimization was initiated with a stopping criterion of 40 iterations. 


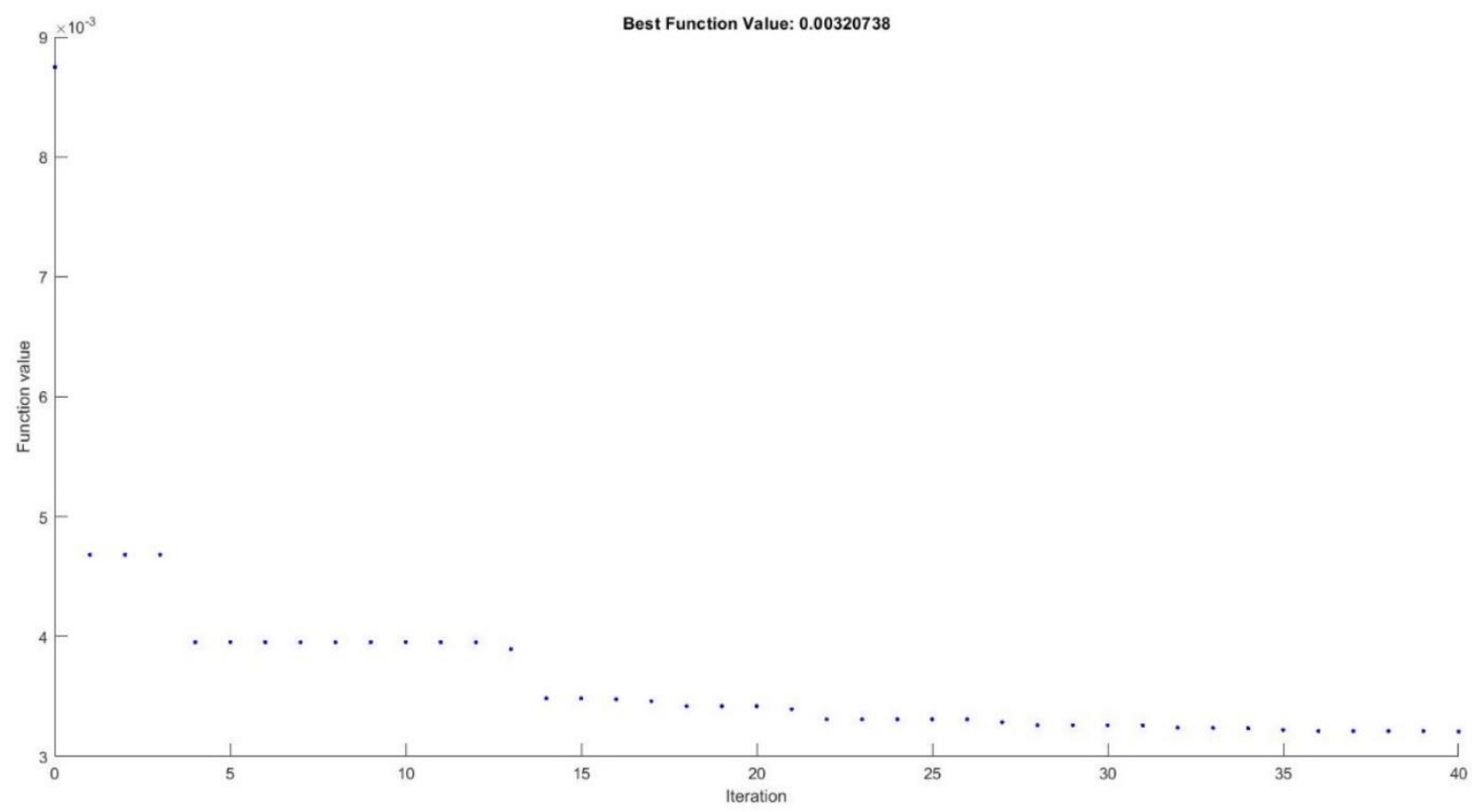

Figure 48. Mean squared error (MSE) minimization on coarse silica beads using particle swarm optimization (PSO).

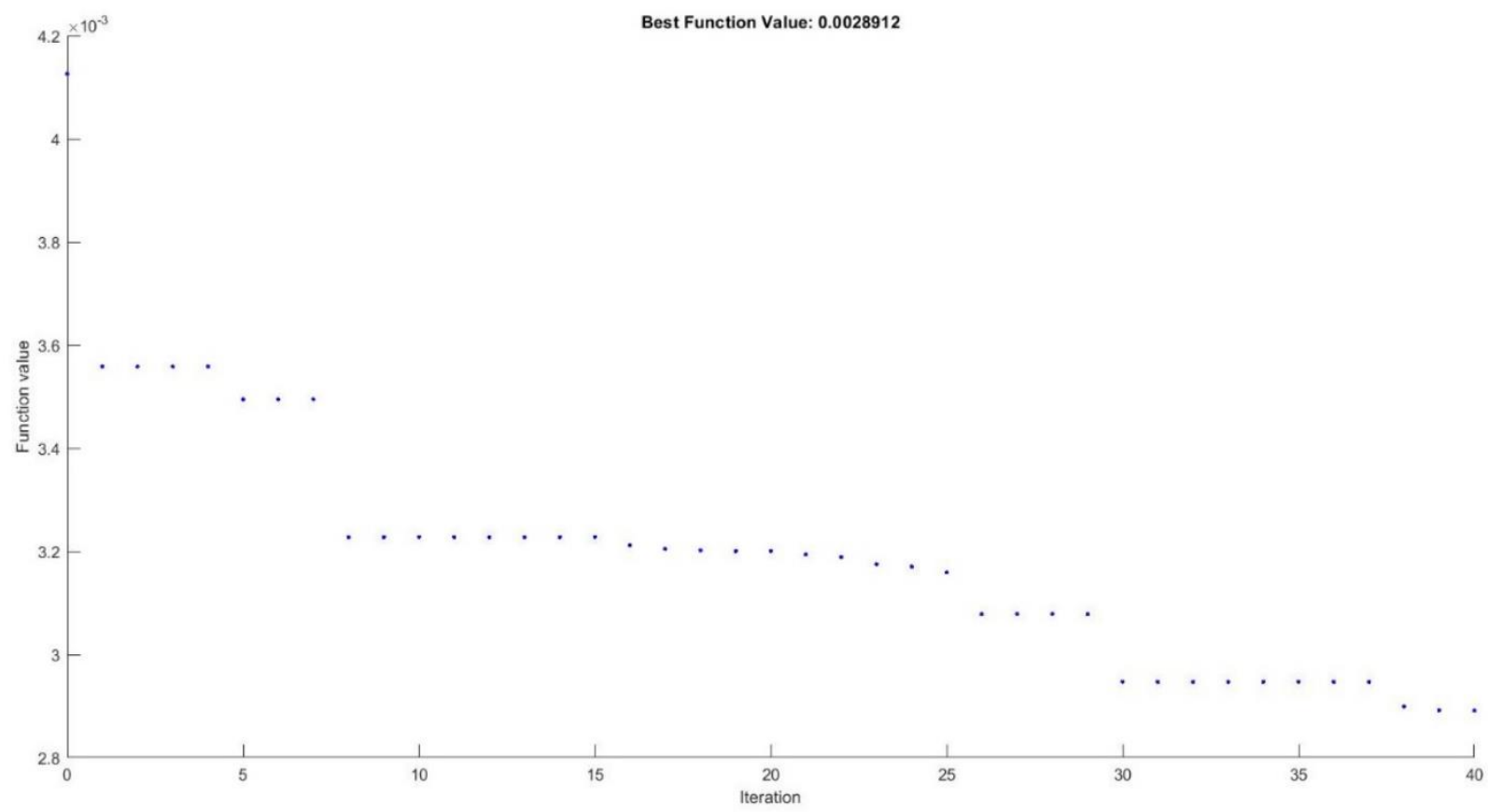

Figure 49. Mean squared error (MSE) minimization on ceramic balls using particle swarm optimization (PSO). 
The predicted particle size distribution of the ground product obtained from the simulations was compared with the actual and feed size distributions. Figure 50 shows the models in which grinding media material was studied, while Figure 51 and Figure 52 display the patterns obtained while exploring the effect of solids content and viscosity modifiers.

(a) Ceramic Balls (CB)

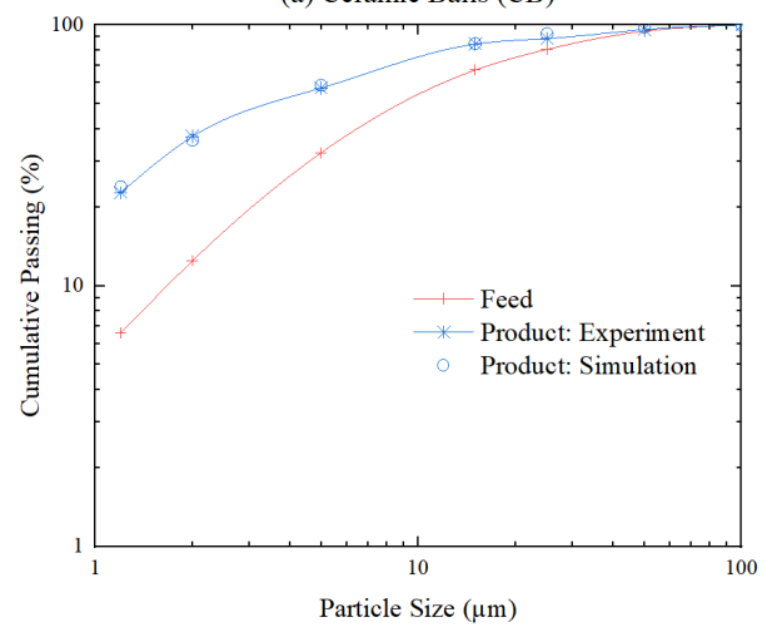

(b) Alumina Beads (AB)

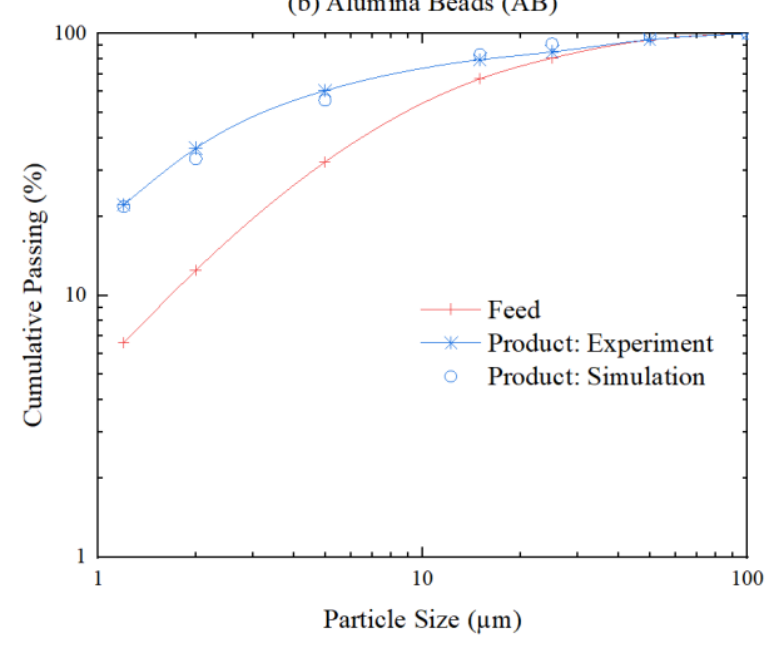

(c) Silica Beads (SB)

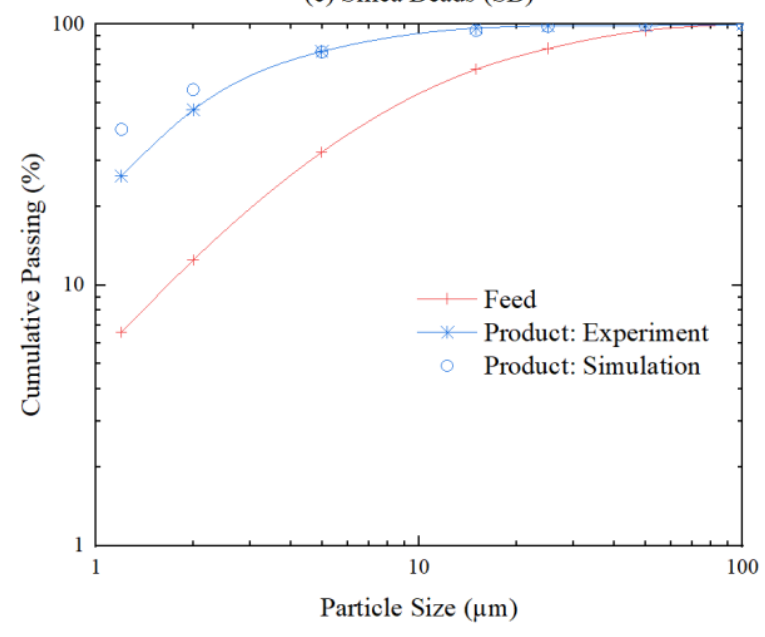

Figure 50. Simulation using population balance modeling for various grinding media materials under standard test conditions. 
(a) Coarse Silica Beads $20 \mathrm{wt} \%(\mathrm{CSB}$ X20)

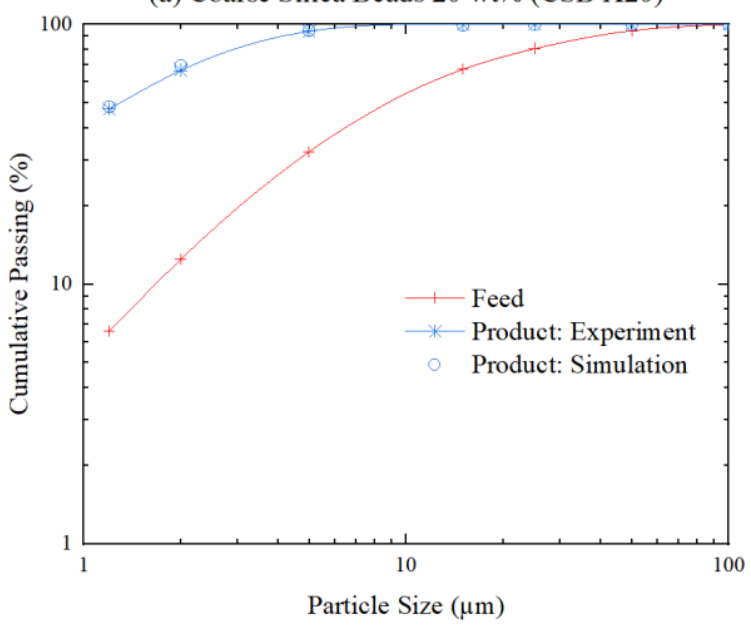

(c) Coarse Silica Beads $30 \mathrm{wt} \%$ (CSB X30)

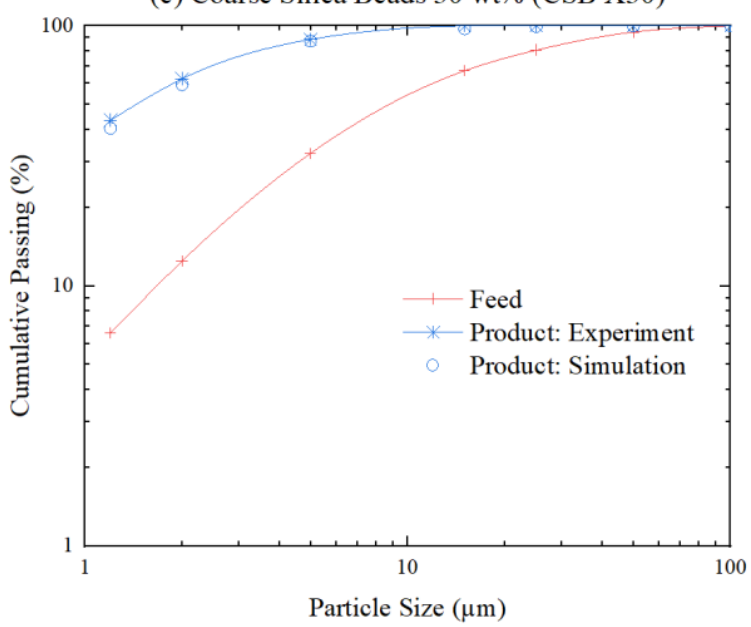

(e) Coarse Silica Beads 40 wt $\%$ (CSB X40)

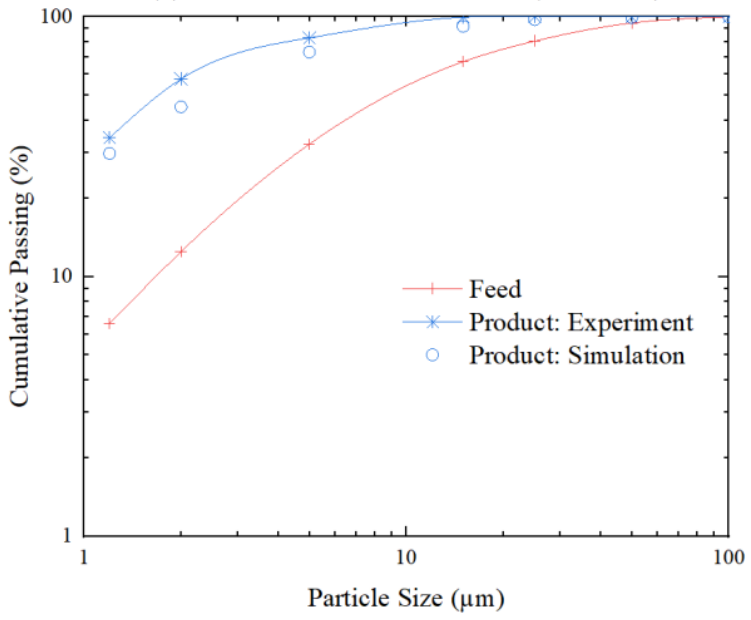

(b) Ceramic Balls $20 \mathrm{wt} \%$ (CB X20)

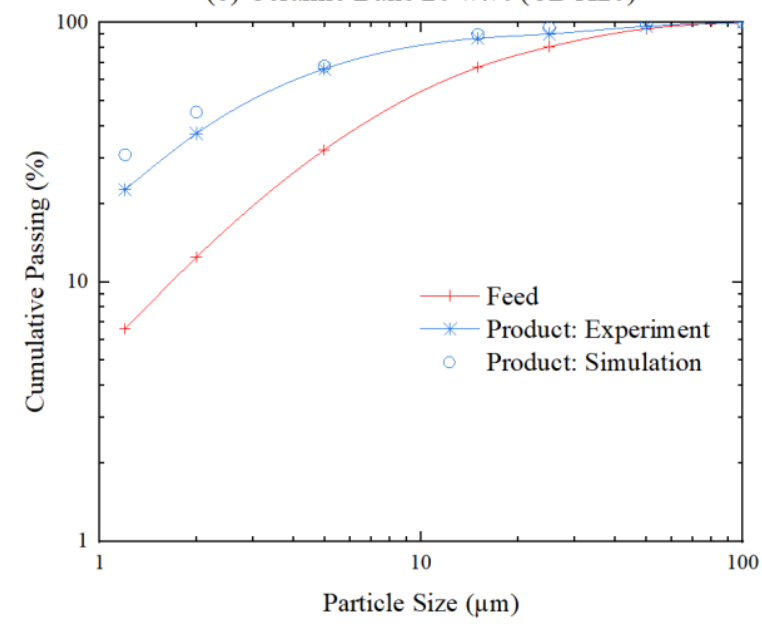

(d) Ceramic Balls $30 \mathrm{wt} \%$ (CB X30)

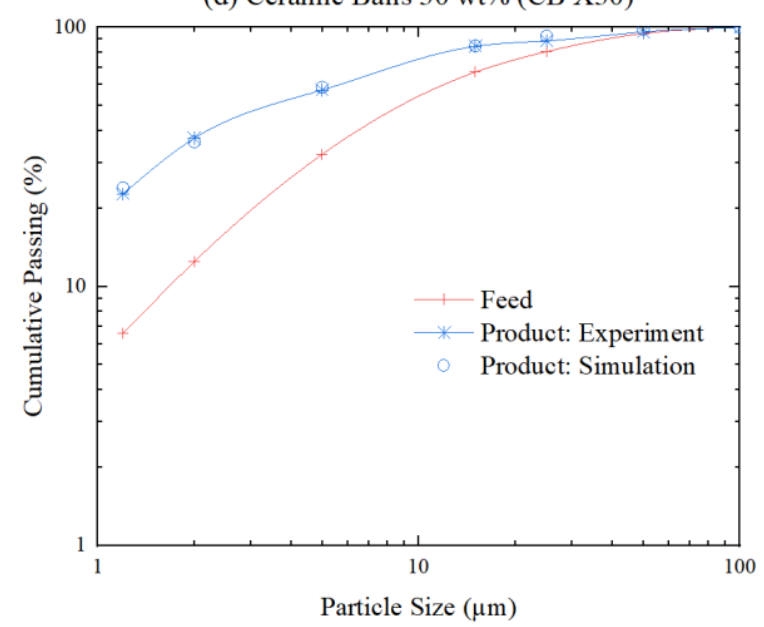

(f) Ceramic Balls $40 \mathrm{wt} \%$ (CB X40)

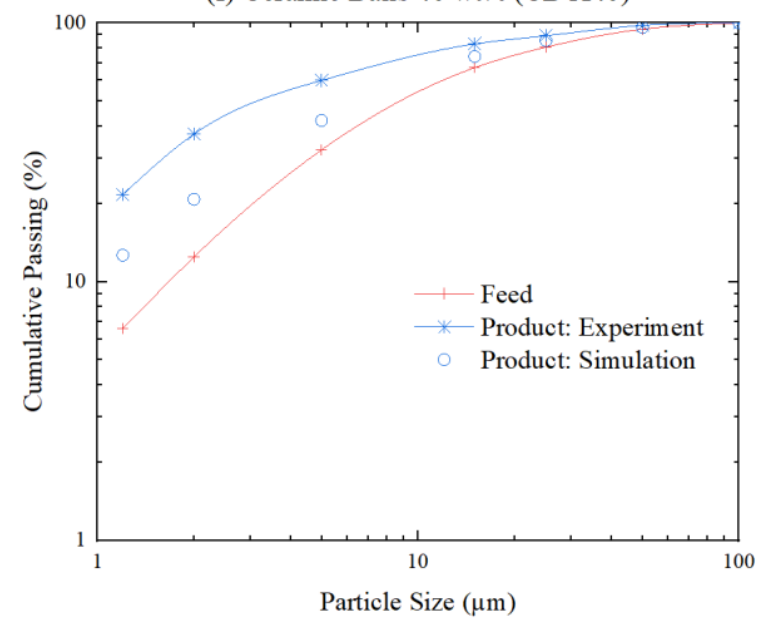

Figure 51. Simulation using population balance modeling for coarse silica beads and ceramic balls with different solids concentrations. 
(a) Coarse Silica Beads Disp. 2kg/ton (CSB D2)

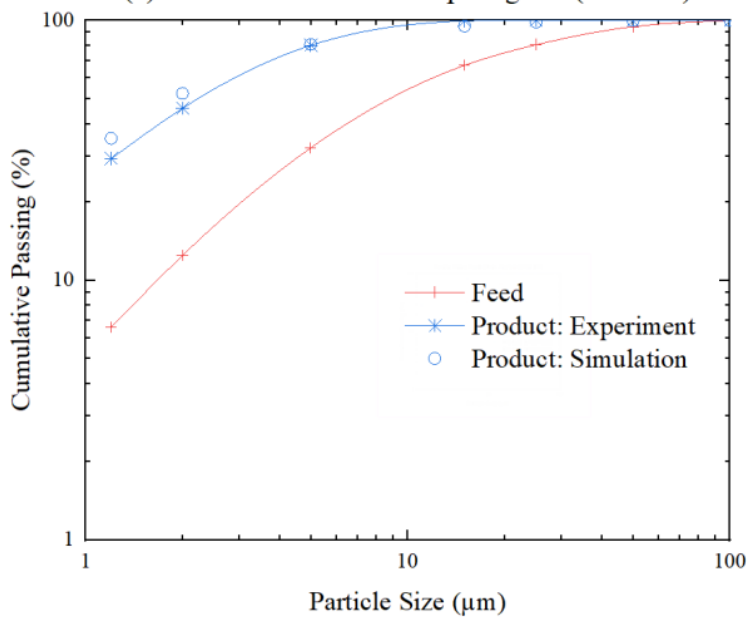

(c) Coarse Silica Beads Disp. $8 \mathrm{~kg} / \mathrm{ton}$ (CSB D8)

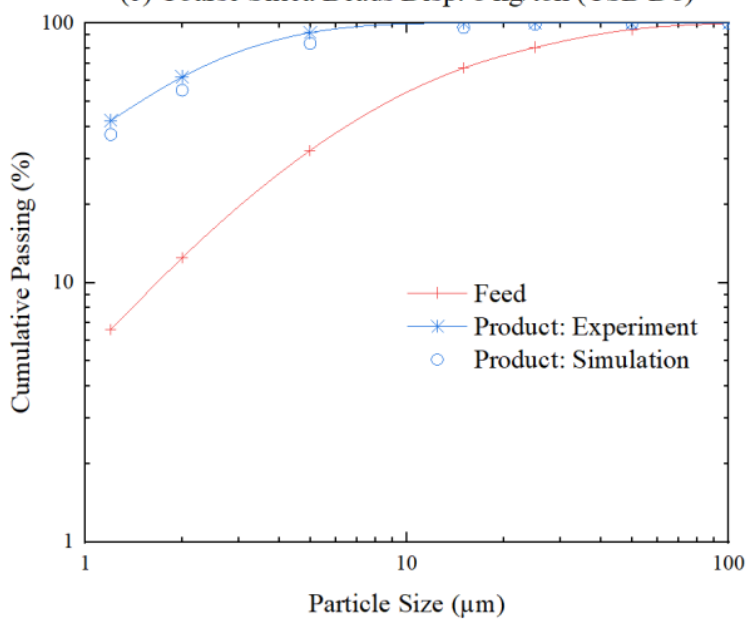

(e) Coarse Silica Beads Disp. $14 \mathrm{~kg} /$ ton (CSB D14)

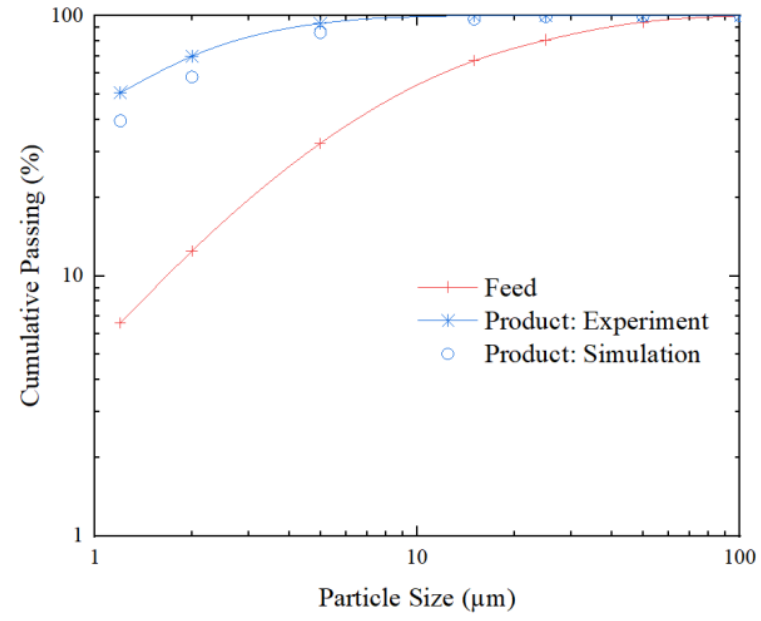

(b) Ceramic Balls Disp. 2kg/ton (CB D2)

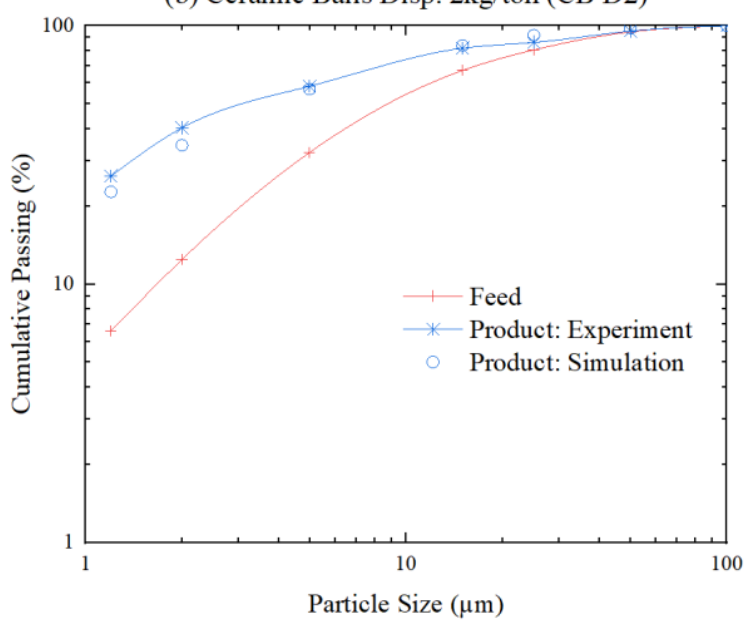

(d) Ceramic Balls Disp. $8 \mathrm{~kg} /$ ton (CB D8)

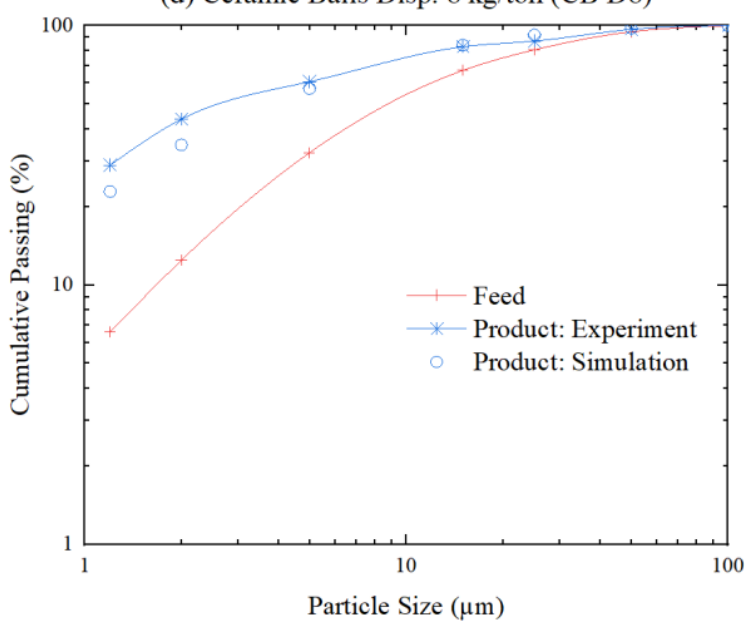

(f) Ceramic Balls Disp. 14 kg/ton (CB D14)

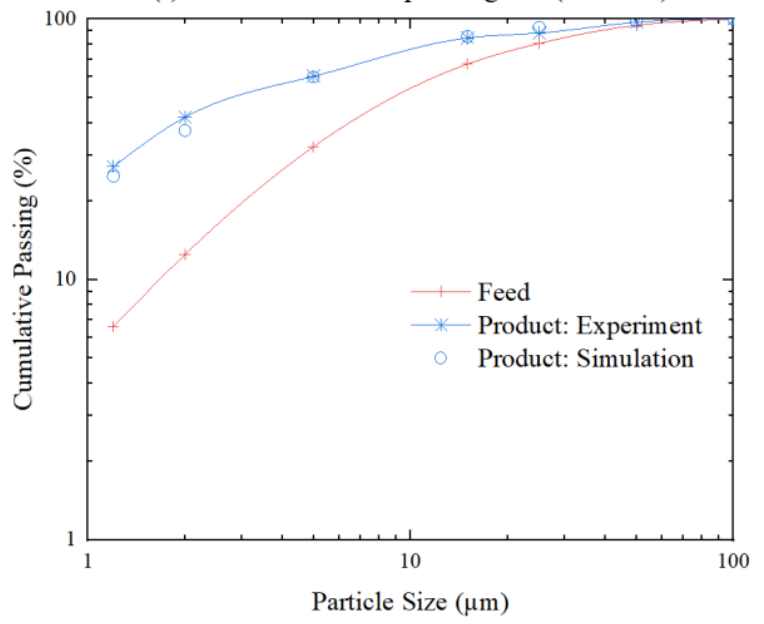

Figure 52. Simulation using population balance modeling for coarse silica beads and ceramic balls with different dosages of sodium silicate as a viscosity modifier. 
Figure 53 and Figure 54 show the Pearson correlation tests performed on the bivariate data sets. This test measures the strength and direction of a linear correlation (Puth et al., 2014). The Pearson correlation coefficients ( $r$ ) are above 0.98 , indicating a very strong correlation between the simulation and experimental data according to Table 14. Moreover, the coefficients of determination $\left(\mathrm{R}^{2}\right)$ indicate that more than $97 \%$ of the variability of the experimental data is explained by the variability of the predicted models. Considering that both variables are linearly correlated, it can be concluded that population balance modeling provides an accurate forecast of product size distributions based on the breakage function, selection function, and particle swarm optimization algorithm.

Table 14. Interpretation of Pearson correlation coefficient (R. Taylor, 1990).

\begin{tabular}{cc}
\hline Coefficient Interval & Correlation \\
\hline$\leq 0.35$ & Weak \\
$0.36-0.67$ & Moderate \\
$0.68-0.89$ & Strong \\
$0.90-1.000$ & Very Strong \\
\hline
\end{tabular}

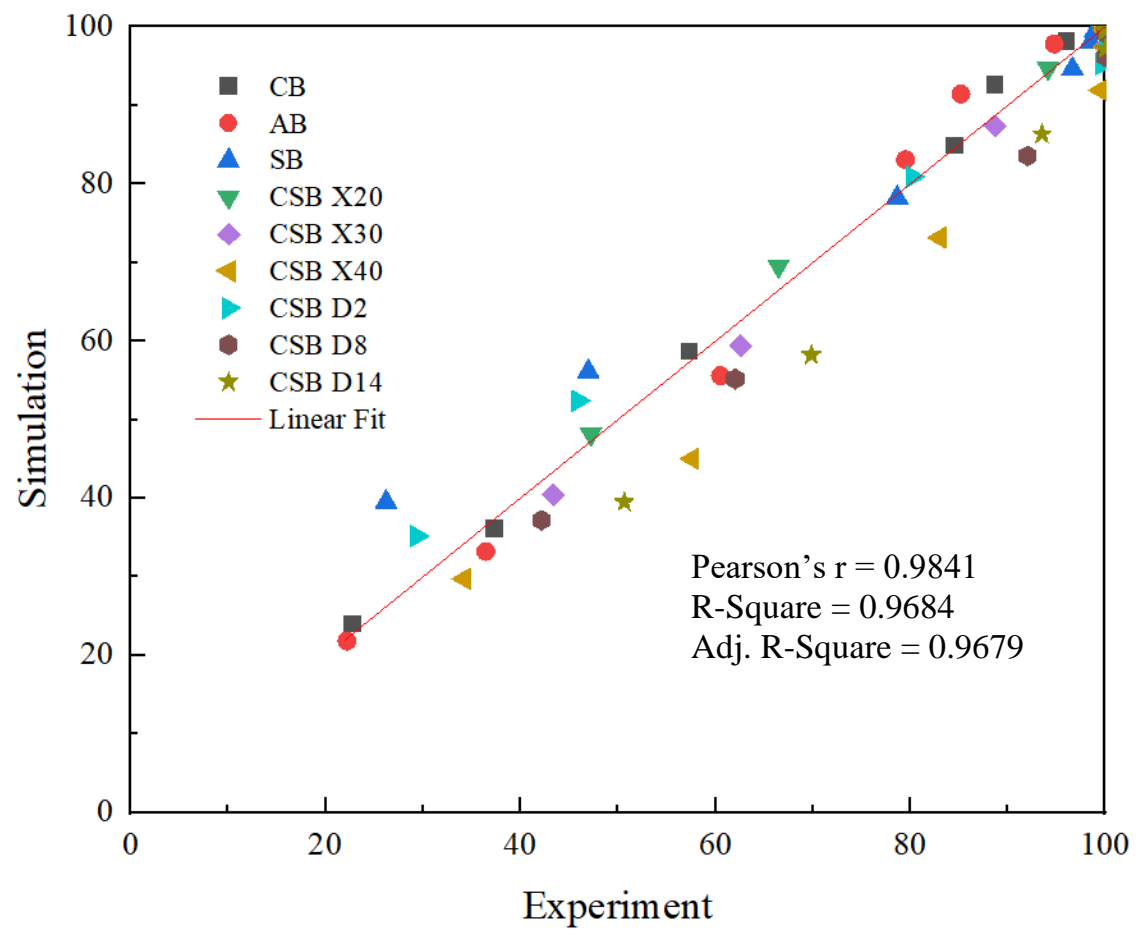

Figure 53. Correlation analysis between simulated and experimental cumulative percent passing obtained using coarse silica beads. 


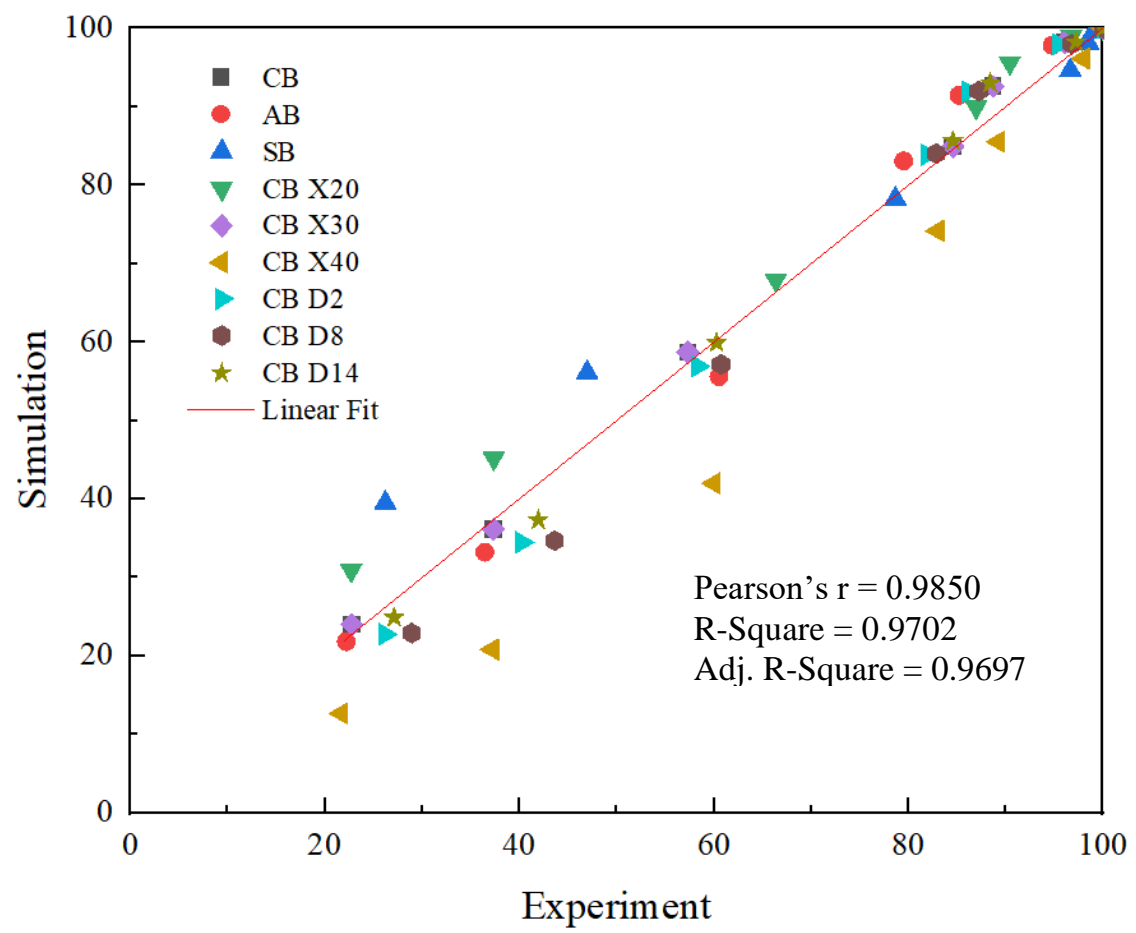

Figure 54. Correlation analysis between simulated and experimental cumulative percent passing obtained using ceramic balls. 


\section{CHAPTER 5: CONCLUSIONS}

Ultrafine coal production using stirred milling is a high-intensity process. Therefore, it is vital to optimize the operating conditions to achieve micronized particles at low energy consumptions. This study was designed to assess the influence of grinding materials on grinding performance, as well as investigate the effect of grinding media size, solids concentration, and the use of viscosity modifiers. Specific findings of this study include:

1. Low-cost grinding media, such as silica beads, developed an upper grinding performance regarding the production of ultrafine particle size distributions and power consumption compared to moderate-cost media, such as ceramic balls and alumina beads.

2. Finer product size and lower energy consumption can be obtained by increasing the media size range of silica beads from $250 \times 420 \mu \mathrm{m}$ to $420 \times 850 \mu \mathrm{m}$. This means that $\mathrm{P}_{80}$ can be further reduced from $5.9 \mu \mathrm{m}$ to $3.3 \mu \mathrm{m}$ while achieving a reduction in specific energy from $309 \mathrm{kWh} /$ ton to $283 \mathrm{kWh} /$ ton. Moreover, a coarser media size also facilitates the separation of coal from grinding media through wet screening.

3. Granular sand and fine silica beads $(40 \times 210 \mu \mathrm{m})$ have not been found suitable for ultrafine grinding due to grinding media degradation and the complexity of separation. Additional steps are required to achieve a clear separation, which would increase the cost of production and demand advanced classification techniques.

4. Minimum or no grinding media degradation was detected by conducting shape analysis on the media grains before and after being submitted to grinding stress. All media materials showed a variation in circularity ratio, sphericity, and aspect ratio less than $1 \%$ post grinding, indicating their durability.

5. Reducing solids concentration from $40 \%$ to $20 \mathrm{wt} \%$ is an alternative to producing finer product sizes. However, the energy consumption can increase up to 5 times depending on the type of grinding media material employed. Therefore, it is imperative to select the adequate solids concentration based on production goals since throughput may be considerably affected.

6. The use of dispersants such as sodium silicate represents a convincing mechanism to produce ultrafine materials at low energy consumptions. Its use avoids agglomeration and 
enhances grinding performance by reducing slurry viscosity. Nevertheless, the excessive use of viscosity modifiers can affect downstream processes such as flocculation.

7. Adjusting the rheological properties of pulp by using viscosity modifiers represents a more viable alternative than reducing the solids content. Employing a dose of $14 \mathrm{~kg} /$ ton of sodium silicate can consume up to $37.5 \%$ less power than lowering solids concentration to $20 \mathrm{wt} \%$. Additionally, a finer product size $\left(\mathrm{P}_{80}\right)$ is delivered without affecting throughput.

8. Numerical simulation using Population Balance Modeling (PBM) is an effective method to simulate grinding and predict product distributions indirectly. It provides an accurate forecast of the particle size distribution based on the experimental distribution and specific energy input. 


\section{CHAPTER 6: RECOMMENDATIONS FOR FUTURE STUDIES}

In the present study, some alternatives were addressed to enhance ultra-fine grinding through stirred milling and numerical simulation. Nevertheless, efforts must continuously be devoted to approaching grinding as a whole system. Some promising recommendations for future studies are given based on the findings obtained in this work:

1. Considering the findings obtained in this study regarding the effect of media size on grinding performance and the low-power demand characteristics of alumina beads and ceramic balls, coarser grinding media can be employed to see whether it can achieve coal particles finer than $10 \mu \mathrm{m}$ at low energy consumptions.

2. During stirred milling, a standard stirring speed of $340 \mathrm{rev} . / \mathrm{min}$ was maintained during kinetic stirred mill tests, so higher or lower shaft rotation rates can be tested to analyze its impact on the power input and product size.

3. According to the results, sodium silicate has a significant positive impact on the production of micronized particles by modifying the rheological properties of the coal slurry. Hence, other types of viscosity modifiers with their corresponding dosages can be tested to study their performance during ultra-fine grinding.

4. In this case, kinetic stirred milling tests were conducted using thickener underflow coal samples as feedstock. Different samples from various process streams or different coal sources can be used to comprehend the effect of intrinsic properties such as volatile matter, moisture content, density, etc. (Hower et al., 2021) on the comminution process.

5. Previous studies have shown that cryogenic grinding is an alternative to produce ultra-fine particles by embrittling materials (J. Liu et al., 2021). It provides significant advantages, particularly for soft and heat-sensitive materials such as coal. Therefore, the stirred mill can be adapted with a cooling system using liquid nitrogen that allows the exploration of cryogenic milling. 


\section{REFERENCES}

Adeniji, A. W. (2018). Parametric Study of Coal Liberation Behavior Using Silica Grinding Media. West Virginia University.

Administration, U. . E. I. (2020). Annual Energy Outlook.

Administration, U. . E. I. (2021). Monthly Energy Review (Vol. 0035, Issue January).

Akkaya, B., Toroglu, I., \& Bilen, M. (2015). Studying the effect of different operation parameters on the grinding energy efficiency in laboratory stirred mill. Herpetological Review, 46, 1.

Altun, O., Benzer, H., \& Enderle, U. (2013). Effects of operating parameters on the efficiency of dry stirred milling. Minerals Engineering, 43-44, 58-66. https://doi.org/10.1016/j.mineng.2012.08.003

Austin, L. G., Klimpel, R. R., \& Luckie, P. T. (1984). Process engineering of size reduction: ball milling. SME/AIME.

Baigereyev, S., \& Guryanov, G. (2019). New method for increase in product fineness in stirred mills. Archives of Civil and Mechanical Engineering, 19(3), 768-778. https://doi.org/10.1016/j.acme.2019.03.003

Barns, K., Lane, G., Osten, K., \& Scagliotta, N. (2004). Benchmarking energy efficiency - A case study at Macraes Gold Mine. Australasian Institute of Mining and Metallurgy Publication Series, 221-259.

BCS. (2007). Mining Industry Energy Bandwidth Study. US Department of Energy, 47. https://www1.eere.energy.gov/manufacturing/resources/mining/pdfs/mining_bandwidth.pdf

Becker, M., \& Schwedes, J. (1999). Comminution of ceramics in stirred media mills and wear of grinding beads. Powder Technology, 105(1-3), 374-381. https://doi.org/10.1016/S00325910(99)00161-8

Bernhardt, C., Reinsch, E., \& Husemann, K. (1999). The influence of suspension properties on ultra-fine grinding in stirred ball mills. Powder Technology, 105(1-3), 357-361. https://doi.org/10.1016/S0032-5910(99)00159-X 
Bilgili, E., Yepes, J., \& Scarlett, B. (2006). Formulation of a non-linear framework for population balance modeling of batch grinding: Beyond first-order kinetics. Chemical Engineering Science, 61(1), 33-44. https://doi.org/10.1016/j.ces.2004.11.060

Blanc, N., Mayer-Laigle, C., Frank, X., Radjai, F., \& Delenne, J. Y. (2020). Evolution of grinding energy and particle size during dry ball-milling of silica sand. Powder Technology, 376, 661667. https://doi.org/10.1016/j.powtec.2020.08.048

Bond, F. C. (1952). The third theory of comminution. 484-494.

Bond, F. C. (1985). Testing and Calculations. In SME Mineral Processing Handbook (pp. 16-27).

Breitung-Faes, S., \& Kwade, A. (2019). Mill, material, and process parameters - A mechanistic model for the set-up of wet-stirred media milling processes. Advanced Powder Technology, 30(8), 1425-1433. https://doi.org/10.1016/j.apt.2019.04.013

Broadbent, S. R., \& Callcott, T. G. (1956). A matrix analysis of processes involving particle assemblies. Philosophical Transactions of the Royal Society, A249, 99-123.

Brown, C. (2016). Chapter 5: Gyratory and Cone Crusher. Mineral Processing Design and Operations, 153-168. https://doi.org/10.1016/b978-0-444-63589-1.00005-8

Burford, B. D., \& Clark, L. W. (2013). IsaMill ${ }^{\mathrm{TM}}$ technology used in efficient grinding circuits. VIII International Conference on Non-Ferrous Ore Processing, 1-20. http://www.isamill.com/EN/Downloads/Downloaded Technical Papers/IsaMill_Technology_Used_in_Effecient_Grinding_Circuits.pdf

Celep, O., Aslan, N., Alp, I., \& Taşdemir, G. (2011). Optimization of some parameters of stirred mill for ultra-fine grinding of refractory Au/Ag ores. Powder Technology, 208(1), 121-127. https://doi.org/10.1016/j.powtec.2010.12.009

Chi, G., Fuerstenau, M. C., Bradt, R. C., \& Ghosh, A. (1996). Improved comminution efficiency through controlled blasting during mining. International Journal of Mineral Processing, 47(1-2), 93-101. https://doi.org/10.1016/0301-7516(95)00098-4

Chipakwe, V., Semsari, P., Karlkvist, T., Rosenkranz, J., \& Chelgani, S. C. (2020). A critical review on the mechanisms of chemical additives used in grinding and their effects on the 
downstream processes. Journal of Materials Research and Technology, 9(4), 8148-8162. https://doi.org/10.1016/j.jmrt.2020.05.080

Cho, H., Waters, M. A., \& Hogg, R. (1996). Investigation of the grind limit in stirred-media milling. International Journal of Mineral Processing, 44-45(SPEC. ISS.), 607-615. https://doi.org/10.1016/0301-7516(95)00069-0

Choi, H., Lee, W., Kim, D. U., Kumar, S., Kim, S. S., Chung, H. S., Kim, J. H., \& Ahn, Y. C. (2010). Effect of grinding aids on the grinding energy consumed during grinding of calcite in a stirred ball mill. Minerals Engineering, 23(1), 54-57. https://doi.org/10.1016/j.mineng.2009.09.011

Choi, Heekyu, Lee, W., \& Kim, S. (2009). Effect of grinding aids on the kinetics of fine grinding energy consumed of calcite powders by a stirred ball mill. Advanced Powder Technology, 20(4), 350-354. https://doi.org/10.1016/j.apt.2009.01.002

Cleary, P. W., Cummins, S. J., Sinnott, M. D., Delaney, G. W., \& Morrison, R. D. (2020). Advanced Comminution Modelling: Part 2 - Mills. Applied Mathematical Modelling, 88, 307-348. https://doi.org/10.1016/j.apm.2020.06.048

Cleary, P. W., Delaney, G. W., Sinnott, M. D., Cummins, S. J., \& Morrison, R. D. (2020). Advanced comminution modelling: Part 1 - Crushers. Applied Mathematical Modelling, 88, 238-265. https://doi.org/10.1016/j.apm.2020.06.049

Coelho, L. dos S., \& Sierakowski, C. A. (2008). A software tool for teaching of particle swarm optimization fundamentals. Advances in Engineering Software, 39(11), 877-887. https://doi.org/10.1016/j.advengsoft.2008.01.005

Cox, E. P. (1927). A method of assigning numerical and percentage values to the degree of roundness of sand grains. Journal of Paleontology, 1, 179-183.

Craig, I. K., \& Henning, R. G. D. (2000). Evaluation of advanced industrial control projects: A framework for determining economic benefits. Control Engineering Practice, 8(7), 769-780. https://doi.org/10.1016/s0967-0661(00)00007-1

de Bakker, J. (2014). Energy use of fine grinding in mineral processing. Metallurgical and Materials Transactions E, 1(1), 8-19. https://doi.org/10.1007/s40553-013-0001-6 
Djordjevic, N. (2010). Improvement of energy efficiency of rock comminution through reduction of thermal losses. Minerals Engineering, 23(15), 1237-1244. https://doi.org/10.1016/j.mineng.2010.08.019

Dundar, H., Benzer, H., \& Aydogan, N. (2013). Application of population balance model to HPGR crushing. Minerals Engineering, 50-51, 114-120. https://doi.org/10.1016/j.mineng.2013.07.005

Esnault, V. P. B., Zhou, H., \& Heitzmann, D. (2015). New population balance model for predicting particle size evolution in compression grinding. Minerals Engineering, 73, 7-15. https://doi.org/10.1016/j.mineng.2014.12.036

Farzanegan, A., \& Vahidipour, S. M. (2009). Optimization of comminution circuit simulations based on genetic algorithms search method. Minerals Engineering, 22(7-8), 719-726. https://doi.org/10.1016/j.mineng.2009.02.009

Foggiatto, B. (2017). Modelling and simulation approaches for exploiting multi-component characteristics of ores in mineral processing circuits.

Fuerstenau, D. W. (1995). Grinding Aids. KONA Powder and Particle Journal, 13(13), 5-18. https://doi.org/10.14356/kona.1995006

Gao, P., Zhou, W., Han, Y., Li, Y., \& Ren, W. (2020). Enhancing the capacity of large-scale ball mill through process and equipment optimization: An industrial test verification. Advanced Powder Technology, 31(5), 2079-2091. https://doi.org/10.1016/j.apt.2020.03.001

Gaudin, A. M., \& Meloy, T. P. (1962). Model and comminution distribution equation for single fracture. Trans AIME/SME, 223, 40-43.

Grace, J. R., \& Ebneyamini, A. (2021). Connecting particle sphericity and circularity. Particuology, 54, 1-4. https://doi.org/10.1016/j.partic.2020.09.006

Guo, W., Gao, P., Tang, Z., Han, Y., \& Meng, X. (2021). Effect of grinding media properties and stirrer tip speed on the grinding efficiency of a stirred mill. Powder Technology.

Gupta, A., \& Yan, D. (2006a). Chapter 6: Roll Crushers. Mineral Processing Design and Operation, 142-160. https://doi.org/10.1016/b978-044451636-7/50007-3 
Gupta, A., \& Yan, D. (2006b). Chapter 7: Tubular Ball Mills. In Mineral Processing Design and Operation. https://doi.org/10.1016/b978-044451636-7/50008-5

Gupta, A., \& Yan, D. (2016a). Chapter 10: Stirred Mills - Ultrafine Grinding. In Mineral Processing Design and Operations (pp. 287-316). https://doi.org/10.1016/b978-0-44463589-1.00010-1

Gupta, A., \& Yan, D. (2016b). Chapter 11: Mathematical Modelling of Comminution Processes. In Mineral Processing Design and Operations. https://doi.org/10.1016/b978-0-444-63589$1.00011-3$

Gupta, A., \& Yan, D. (2016c). Chapter 4: Jaw Crusher. Mineral Processing Design and Operations - 2nd Edition, 123-152. https://doi.org/10.1016/B978-0-444-63589-1/00004-6

Gupta, A., \& Yan, D. (2016d). Chapter 9: Autogenous and Semi-Autogenous Mills. Mineral Processing Design and Operations, 263-285. https://doi.org/10.1016/b978-0-444-63589$1.00009-5$

He, M., Wang, Y., \& Forssberg, E. (2005). Parameter effects on wet ultrafine grinding of limestone through slurry rheology in a stirred media mill. Powder Technology, 161, 10-21. https://doi.org/10.1016/j.powtec.2005.08.026

Henke, J. (2020). Regression Analysis. Life Course Research and Social Policies, 11, 275-286. https://doi.org/10.1007/978-3-030-36323-9_26

Hower, J. C., Bagherieh, A. H., Dindarloo, S. R., Trimble, A. S., \& Chelgani, S. C. (2021). Soft modelling of the hardgrove grindability index of bituminous coals: An overview. International Journal of Coal Geology, 247(June), 103846. https://doi.org/10.1016/j.coal.2021.103846

Huang, Q., Noble, A., Herbst, J., \& Honaker, R. (2018). Liberation and release of rare earth minerals from Middle Kittanning, Fire Clay, and West Kentucky No. 13 coal sources. Powder Technology, 332, 242-252. https://doi.org/10.1016/j.powtec.2018.03.063

Huang, Q., Noble, A., \& Talan, D. (2020). Exploratory investigation on the use of low-cost alternative media for ultrafine grinding of coal. International Journal of Coal Preparation and Utilization, 00(00), 1-18. https://doi.org/10.1080/19392699.2020.1809387 
Jayasundara, C. T., Yang, R. Y., \& Yu, A. B. (2012). Effect of the size of media on grinding performance in stirred mills. Minerals Engineering, 33, 66-71. https://doi.org/10.1016/j.mineng.2011.10.012

Jeswiet, J., \& Szekeres, A. (2016). Energy consumption in mining momminution. Procedia CIRP, 48, 140-145. https://doi.org/10.1016/j.procir.2016.03.250

Kapur, P. C., Healy, T. W., Scales, P. J., Boger, D. V., \& Wilson, D. (1996). Role of dispersants in kinetics and energetics of stirred ball mill grinding. International Journal of Mineral Processing, 47(1-2), 141-152. https://doi.org/10.1016/0301-7516(96)00003-8

Kelsall, D. F., \& Reid, K. J. (1965). Institue Chem. Engineering Symp. Series. AIChE, 14-20.

Kennedy, J., \& Eberhart, R. (1995). Particle Swarm Optimization. ICNN'95-International Conference on Neural Networks, 1942-1948.

Khademian, A., \& Bagherpour, R. (2017). Alteration of grindability of minerals due to applying different explosives in blasting operation. Minerals Engineering, 111(February), 174-181. https://doi.org/10.1016/j.mineng.2017.06.016

Kick, F. (1885). Das Gesetz der Proportionalen Widerstände und Seine Anwendungen: Nebst Versuchen über das Verhalten Verschiedener Materialien bei Gleichen Formänderungen Sowohl unter der Presse als dem Schlagwerk.

King, R. P. (2012). Chapter 5: Comminution Operations. Modeling and Simulation of Mineral Processing Systems, 4, 73-83.

Klimpel, R. R., \& Austin, L. G. (1977). The back-calculation of specific rates of breakage and non-normalized breakage distribution parameters from batch grinding data. International Journal of Mineral Processing, 4(1), 7-32. https://doi.org/10.1016/0301-7516(77)90028-X

Koh, E. J. Y., Amini, E., McLachlan, G. J., \& Beaton, N. (2021). Utilising a deep neural network as a surrogate model to approximate phenomenological models of a comminution circuit for faster simulations. Minerals Engineering, $170($ June), 107026. https://doi.org/10.1016/j.mineng.2021.107026

Kwade, A., \& Schwedes, J. (2007). Chapter 6: Wet Grinding in Stirred Media Mills. Handbook of 
Powder Technology, 12(07), 251-382. https://doi.org/10.1016/S0167-3785(07)12009-1

Lee, H., Kim, K., \& Lee, H. (2019). Analysis of grinding kinetics in a laboratory ball mill using population-balance-model and discrete-element-method. Advanced Powder Technology, 30(11), 2517-2526. https://doi.org/10.1016/j.apt.2019.07.030

Lewitt, M. (2011). Opportunities for fine coal utilisation.

Liu, J., Bai, X., Hao, J., Wang, H., Zhang, T., Tang, X., Wang, S., \& He, Y. (2021). Efficient liberation of electrode materials in spent lithium-ion batteries using a cryogenic ball mill. Journal of Environmental Chemical Engineering, 9(5), 106017. https://doi.org/10.1016/j.jece.2021.106017

Liu, X., Zhang, M., Hu, N., Yang, H., \& Lu, J. (2016). Calculation model of coal comminution energy consumption. Minerals Engineering, 92, 21-27. https://doi.org/10.1016/j.mineng.2016.01.008

Lynch, A. J. (1977). Mineral crushing and grinding circuits, their simulation, optimisation, design and control. Elsevier Scientific Publishing Company.

Mankosa, M. J., Adel, G. T., \& Yoon, R. H. (1986). Effect of media size in stirred ball mill grinding of coal. Powder Technology, 49(1), 75-82. https://doi.org/10.1016/0032-5910(86)85008-2

Mankosa, M. J., Adel, G. T., \& Yoon, R. H. (1989). Effect of operating parameters in stirred ball mill grinding of coal. Powder Technology, 59(4), 255-260. https://doi.org/10.1016/00325910(89)80084-1

Martins, S. (2020). Size-energy relationship exponents in comminution. Minerals Engineering, 149(January), 106259. https://doi.org/10.1016/j.mineng.2020.106259

Masi, C. A., Schumacher, T. A., Hilman, J., \& Dulal, R. (2021). Converting raw coal powder into polycrystalline nano-graphite by metal-assisted microwave treatment. Nano-Structures \& Nano-Objects, 25.

Mazzinghy, D. B., Lichter, J., Schneider, C. L., Galéry, R., \& Russo, J. F. C. (2017). Vertical stirred mill scale-up and simulation: Model validation by industrial samplings results. Minerals Engineering, 103-104, 127-133. https://doi.org/10.1016/j.mineng.2016.11.018 
Meyer, E. J., Olivier, M. C., Matumba, L., \& Craig, I. K. (2019). Model predictive control simulation, implementation and performance assessment of a coal comminution circuit. $\begin{array}{lll}\text { Minerals } \quad \text { Engineering, } & 106024 .\end{array}$ https://doi.org/10.1016/j.mineng.2019.106024

Mosher, J. B. (2016). Chapter 17: Comminution Circuits for Gold Ore Processing. In Gold Ore Processing. Elsevier B.V. https://doi.org/10.1016/b978-0-444-63658-4.00017-7

Mucsi, G., Rácz, Á., \& Mádai, V. (2013). Mechanical activation of cement in stirred media mill. Powder Technology, 235, 163-172. https://doi.org/10.1016/j.powtec.2012.10.005

Mwanga, A., Parian, M., Lamberg, P., \& Rosenkranz, J. (2017). Comminution modeling using mineralogical properties of iron ores. Minerals Engineering, 111(June), 182-197. https://doi.org/10.1016/j.mineng.2017.06.017

Nadolski, S., Klein, B., Kumar, A., \& Davaanyam, Z. (2014). An energy benchmarking model for mineral comminution. Minerals Engineering, 65, 178-186. https://doi.org/10.1016/j.mineng.2014.05.026

Nesset, J., Radziszewski, P., Hardie, C., \& Leroux, D. (2006). Assessing the performance and efficiency of fine grinding technologies. Proceedings of the 38th Annual Meeting of the Canadian Mineral Processors Conference, 283-309.

Nielsen, K., \& Kristiansen, J. (1996). Blasting-crushing-grinding: Optimisation of an integrated comminution system. 5th Int Symp on Rock Fragmentation by Blasting, 269-277.

Nielsen, K., \& Malvik, T. (1999). Grindability enhancement by blast-induced microcracks. Powder Technology, 105(1-3), 52-56. https://doi.org/10.1016/S0032-5910(99)00117-5

Nielsen, K., \& Mick Lownds, C. (1997). Enhancement of taconite crushing and grinding through primary blasting. 34(226), 3-4.

Noble, A., \& Luttrell, G. H. (2015). A review of state-of-the-art processing operations in coal preparation. International Journal of Mining Science and Technology, 25(4), 511-521. https://doi.org/10.1016/j.ijmst.2015.05.001

Ortiz-Landazuri, I., \& Colay, M. J. O. (2019). Maintenance cost influence in a comminution layout 
design. Procedia Manufacturing, 41, 851-858. https://doi.org/10.1016/j.promfg.2019.10.007

Ouattara, S., \& Frances, C. (2014). Grinding of calcite suspensions in a stirred media mill: Effect of operational parameters on the product quality and the specific energy. Powder Technology, 255, 89-97. https://doi.org/10.1016/j.powtec.2013.11.025

Partyka, T., \& Yan, D. (2007). Fine grinding in a horizontal ball mill. Minerals Engineering, 20(4), 320-326. https://doi.org/10.1016/j.mineng.2006.12.003

Patel, Chetan M., Murthy, Z. V. P., \& Chakraborty, M. (2012). Effects of operating parameters on the production of barium sulfate nanoparticles in stirred media mill. Journal of Industrial and Engineering Chemistry, 18(4), 1450-1457. https://doi.org/10.1016/j.jiec.2012.02.005

Patel, Chetankumar M., Chakraborty, M., \& Murthy, Z. V. P. (2014). Enhancement of stirred media mill performance by a new mixed media grinding strategy. Journal of Industrial and Engineering Chemistry, 20(4), 2111-2118. https://doi.org/10.1016/j.jiec.2013.09.040

Peng, G., Sharshir, S. W., Wang, Y., An, M., Ma, D., Zang, J., Kabeel, A. E., \& Yang, N. (2021). Potential and challenges of improving solar still by micro/nano-particles and porous materials - A review. Journal of Cleaner Production, 311(June 2020), 127432. https://doi.org/10.1016/j.jclepro.2021.127432

Pinchuk, V. A., Sharabura, T. A., \& Kuzmin, A. V. (2017). Improvement of coal-water fuel combustion characteristics by using of electromagnetic treatment. Fuel Processing Technology, 167, 61-68. https://doi.org/10.1016/j.fuproc.2017.06.014

Pokrajicic, Z. (2008). Energy efficient comminution circuits - A modified grinding strategy and the selection of a target product size. CSRP08, 2nd Annual Conference.

Portnikov, D., \& Kalman, H. (2019). Material comminution functions of wet particles. Powder Technology, 343, 29-39. https://doi.org/10.1016/j.powtec.2018.11.009

Process, U. (2008). Media Milling Advances. Small, November, 12-15.

Process, U. (2017). Union Process Cryogenic Attrition Mills. Metal Powder Report, 72(6), 445. https://doi.org/10.1016/j.mprp.2017.10.044

Prziwara, P., Hamilton, L. D., Breitung-Faes, S., \& Kwade, A. (2018). Impact of grinding aids and 
process parameters on dry stirred media milling. Powder Technology, 335, 114-123. https://doi.org/10.1016/j.powtec.2018.05.021

Prziwara, Paul, \& Kwade, A. (2020). Grinding aids for dry fine grinding processes - Part I: Mechanism of action and lab-scale grinding. Powder Technology, 375, 146-160. https://doi.org/10.1016/j.powtec.2020.07.038

Puth, M. T., Neuhäuser, M., \& Ruxton, G. D. (2014). Effective use of Pearson's product-moment correlation coefficient. Animal Behaviour, 93, 183-189. https://doi.org/10.1016/j.anbehav.2014.05.003

Rajaonarivony, K. R., Mayer-Laigle, C., Piriou, B., \& Rouau, X. (2021). Comparative comminution efficiencies of rotary, stirred and vibrating ball-mills for the production of $\begin{array}{lllll}\text { ultrafine biomass } & \text { powders. } & \text { Energy, } & 227, & 120508 .\end{array}$ https://doi.org/10.1016/j.energy.2021.120508

Revnivtsev, V. . (1988). We really need revolution in comminution. XVI International Mineral Processing Congress SME, 93-114.

Rozenblat, Y., Grant, E., Levy, A., Kalman, H., \& Tomas, J. (2012). Selection and breakage functions of particles under impact loads. Chemical Engineering Science, 71, 56-66. https://doi.org/10.1016/j.ces.2011.12.012

Semsari Parapari, P., Parian, M., \& Rosenkranz, J. (2020). Breakage process of mineral processing comminution machines - An approach to liberation. Advanced Powder Technology, 31(9), 3669-3685. https://doi.org/10.1016/j.apt.2020.08.005

Sharshir, S. W., Peng, G., Wu, L., Essa, F. A., Kabeel, A. E., \& Yang, N. (2017). The effects of flake graphite nanoparticles, phase change material, and film cooling on the solar still performance. Applied Energy, 191, 358-366. https://doi.org/10.1016/j.apenergy.2017.01.067

Sharshir, S. W., Peng, G., Wu, L., Yang, N., Essa, F. A., Elsheikh, A. H., Mohamed, S. I. T., \& Kabeel, A. E. (2017). Enhancing the solar still performance using nanofluids and glass cover cooling: Experimental study. Applied Thermal Engineering, 113, 684-693. https://doi.org/10.1016/j.applthermaleng.2016.11.085

Shi, F., Morrison, R., Cervellin, A., Burns, F., \& Musa, F. (2009). Comparison of energy efficiency 
between ball mills and stirred mills in coarse grinding. Minerals Engineering, 22(7-8), 673680. https://doi.org/10.1016/j.mineng.2008.12.002

Shukla, S. C., Kukade, S., Mandal, S. K., \& Kundu, G. (2008). Coal-oil-water multiphase fuel: Rheological behavior and prediction of optimum particle size. Fuel, 87(15-16), 3428-3432. https://doi.org/10.1016/j.fuel.2008.05.027

Silva, L. F. O., Crissien, T. J., Schneider, I. L., Blanco, É. P., \& Sampaio, C. H. (2020). Nanometric particles of high economic value in coal fire region: Opportunities for social improvement. Journal of Cleaner Production, 256. https://doi.org/10.1016/j.jclepro.2020.120480

Silverman, A. J. (1981). Comminution and Energy Consumption. In Comminution and Energy Consumption. https://doi.org/10.17226/19669

Simpson, A. B. G., Byrne, J. A., McLaughlin, J. A. D., \& Strawhorne, M. (2015). Effect of solids concentration on particle size distribution of deagglomerated barium titanate in stirred media mills. Chemical Engineering Research and Design, 93, 287-292. https://doi.org/10.1016/j.cherd.2014.04.006

Song, T., Yang, T. H., Zhou, J. W., \& Wang, Q. K. (2018). Process modelling and univariate analysis of comminution circuits. IFAC-PapersOnLine, 51(21), 19-23. https://doi.org/10.1016/j.ifacol.2018.09.386

Stamboliadis, E. T. (2007). The energy distribution theory of comminution specific surface energy, mill efficiency and distribution mode. Minerals Engineering, 20(2), 140-145. https://doi.org/10.1016/j.mineng.2006.07.009

Stanujkic, D., Zavadskas, E. K., Karabasevic, D., Milanovic, D., \& Maksimovic, M. (2019). An approach to solving complex decision-making problems based on IVIFNs: A case of comminution circuit design selection. Minerals Engineering, 138(April), 70-78. https://doi.org/10.1016/j.mineng.2019.04.036

Stehr, N. (1988). Recent developments in stirred ball milling. International Journal of Mineral Processing, 22(1-4), 431-444. https://doi.org/10.1016/0301-7516(88)90077-4

Takashimizu, Y., \& Iiyoshi, M. (2016). New parameter of roundness R: circularity corrected by aspect ratio. Progress in Earth and Planetary Science, 3(1). https://doi.org/10.1186/s40645- 
015-0078-x

Tanaka, T. (1995). Determining the optimum diameter of grinding media used for ultrafine grinding mechanisms. Advanced Powder Technology, 6(2), 125-137. https://doi.org/10.1163/156855295X00121

Taylor, L., Skuse, D., Blackburn, S., \& Greenwood, R. (2020). Stirred media mills in the mining industry: Material grindability, energy-size relationships, and operating conditions. Powder Technology, 369, 1-16. https://doi.org/10.1016/j.powtec.2020.04.057

Taylor, R. (1990). Interpretation of the Correlation Coefficient: A Basic review. Journal of Diagnostic Medical Sonography, 1, 35-39.

Ureta, F., Goni, C., \& Sbarbaro, D. (2019). A flexible steady state comminution circuits simulator. IFAC-PapersOnLine, 52(14), 13-17. https://doi.org/10.1016/j.ifacol.2019.09.156

Von Rittinger, P. R. (1867). Lehrbuch der Aufbereitungs Kunde.

Walker, W. H., Lewis, W. K., McAdams, W. H., \& Gilliland, E. R. (1937). Principles of Chemical Engineering.

Wang, C., Nadolski, S., Mejia, O., Drozcliak, J., \& Klein, B. (2013). Energy and cost comparisons of hpgr-based circuits. Engineering and Mining Journal, 214(12), 102-108.

Wang, Y., \& Forssberg, E. (2007). Enhancement of energy efficiency for mechanical production of fine and ultra-fine particles in comminution. China Particuology, 5(3), 193-201. https://doi.org/10.1016/j.cpart.2007.04.003

Wills, B., \& Finch, J. (2016a). Chapter 1: Introduction. Wills' Mineral Processing Technology, 127. https://doi.org/10.1016/b978-0-08-097053-0.00001-7

Wills, B., \& Finch, J. (2016b). Chapter 5: Comminution. In Will's Mineral Processing Technology (8th ed., pp. 109-122). https://doi.org/10.1016/B978-0-08-097053-0.00005-4

Wills, B., \& Finch, J. (2016c). Chapter 6: Crushers. In Will's Mineral Processing Technology (8th ed., pp. 123-146). https://doi.org/10.1016/B978-0-08-097053-0.00006-6

Wills, B., \& Finch, J. (2016d). Chapter 7: Grinding Mills. In Will's Mineral Processing Technology (8th ed., pp. 147-179). https://doi.org/10.1016/B978-0-08-097053-0.00007-8 
Yao, W., Li, M., Zhang, M., Cui, R., Jiang, H., Li, Y., \& Zhou, S. (2019). Effects of grinding media on flotation performance of calcite. Minerals Engineering, 132(December 2018), 9294. https://doi.org/10.1016/j.mineng.2018.12.005

Yianatos, J. B., Lisboa, M. A., \& Baeza, D. R. (2002). Grinding capacity enhancement by solid concentration control of hydrocyclone underflow. Minerals Engineering, 15(5), 317-323. https://doi.org/10.1016/S0892-6875(02)00027-4

Yokoyama, T., \& Inoue, Y. (2007). Chapter 10: Selection of Fine Grinding Mills. Handbook of Powder Technology, 12(07), 487-508. https://doi.org/10.1016/S0167-3785(07)12013-3

Zhang, X., Han, Y., Gao, P., \& Li, Y. (2020). Effects of grinding media on grinding products and flotation performance of chalcopyrite. Minerals Engineering, 145(October 2019), 106070. https://doi.org/10.1016/j.mineng.2019.106070

Zhang, X., Qin, Y., Han, Y., Li, Y., Gao, P., Li, G., \& Wang, S. (2021). A potential ceramic ball grinding medium for optimizing flotation separation of chalcopyrite and pyrite. Powder Technology, 392, 167-178. https://doi.org/10.1016/j.powtec.2021.07.006 


\section{APPENDIX}

\section{Appendix A: Comminution Equipment}

Table 15. Industrial stirred mills in mineral processing (Wills \& Finch, 2016d).

\begin{tabular}{|c|c|c|c|c|c|c|}
\hline \multicolumn{2}{|l|}{ Mill Name } & IsaMill & $\begin{array}{l}\text { Vertmill/ } \\
\text { TowerMill }\end{array}$ & $\begin{array}{l}\text { Stirred Media } \\
\text { Detritor }\end{array}$ & VXP Mill & HIGMill \\
\hline \multicolumn{2}{|l|}{ Manufacturer } & Glencore & Metso/Eirich & Mesto & FLSmidth & Outotec \\
\hline \multirow{4}{*}{ Description } & Orientation & Horizontal & Vertical & Vertical & Vertical & Vertical \\
\hline & $\begin{array}{l}\text { Impeller } \\
\text { shape }\end{array}$ & Disc & Screw & Pin & Disc & Disc \\
\hline & Shell & Smooth & Smooth & Smooth & Smooth & Disc \\
\hline & Speed & High & Low & Medium & Medium & Medium \\
\hline \multicolumn{2}{|c|}{ Density \% Solids $\left(\mathrm{v} \mathrm{v}^{-1}\right)$} & $10-30$ & $30-50$ & $10-30$ & $10-30$ & $10-30$ \\
\hline \multicolumn{2}{|c|}{ Impeller tip speed $\left(\mathrm{m} \mathrm{s}^{-1}\right)$} & $19-23$ & $<3$ & $3-8$ & $10-12$ & $8-12$ \\
\hline \multicolumn{2}{|c|}{ Power intensity $\left(\mathrm{kW} \mathrm{m}^{-3}\right)$} & $300-1,000$ & $20-40$ & $50-100$ & $240-765$ & $100-300$ \\
\hline \multirow{2}{*}{$\begin{array}{l}\text { Typical size range } \\
(\mu \mathrm{m})\end{array}$} & Feed $\left(F_{80}\right)$ & $300-70$ & $6,000-800$ & $300-70$ & $300-70$ & $300-70$ \\
\hline & $\begin{array}{l}\text { Product } \\
\left(P_{80}\right)\end{array}$ & $<10$ & 20 & $<10$ & $<10$ & $<10$ \\
\hline \multicolumn{2}{|c|}{ Grinding media size $(\mathrm{mm})$} & $1-3$ & $12-38$ & $1-8$ & $1.5-3$ & $1-6$ \\
\hline \multirow[t]{2}{*}{ Largest unit } & Model & $50,000 \mathrm{~L}$ & $\begin{array}{l}\text { VTM6000/ } \\
\text { ETM1500 }\end{array}$ & SMD1100 & VXP10000 & HIG5000 \\
\hline & Power & $8 \mathrm{MW}$ & $\begin{array}{l}4.5 \mathrm{MW} / \\
1.1 \mathrm{MW}\end{array}$ & $1.1 \mathrm{MW}$ & $3 \mathrm{MW}$ & $5 \mathrm{MW}$ \\
\hline
\end{tabular}




\section{Appendix B: Energy-Size Relationship}

Table 16. Energy-size relationships of comminution operations.

\begin{tabular}{|c|c|c|c|c|}
\hline Source & Operation & $\mathrm{F}_{80}(\mathrm{~mm})$ & $\mathrm{P}_{80}(\mathrm{~mm})$ & Specific Energy $(\mathrm{kWh} / \mathrm{t})$ \\
\hline \multirow[t]{3}{*}{ Nadolski et al. (2014) } & Primary crusher & 260.00 & 51.00 & 0.35 \\
\hline & SAG mill and pebble crusher & 51.00 & 3.11 & 9.82 \\
\hline & Balls mills and cyclone & 3.11 & 0.16 & 9.78 \\
\hline \multirow[t]{2}{*}{ Pokrajicic (2008) } & Grinding circuit & 1.61 & 0.08 & 16.30 \\
\hline & & 1.61 & 0.15 & 10.20 \\
\hline \multirow[t]{5}{*}{ (Barns et al., 2004) } & SAG mill & 82.90 & 0.80 & 3.84 \\
\hline & & 106.80 & 3.32 & 5.04 \\
\hline & & 72.70 & 0.80 & 4.32 \\
\hline & & 56.80 & 2.22 & 4.02 \\
\hline & & 51.40 & 2.04 & 3.76 \\
\hline \multirow[t]{20}{*}{ (Foggiatto, 2017) } & AG mill & 20.00 & 0.31 & 5.30 \\
\hline & & 28.70 & 0.26 & 6.30 \\
\hline & & 29.50 & 0.24 & 7.40 \\
\hline & Ball mill & 0.23 & 0.09 & 6.20 \\
\hline & & 0.22 & 0.09 & 8.80 \\
\hline & & 0.22 & 0.08 & 13.40 \\
\hline & Secondary crushers & 124.10 & 58.60 & 0.38 \\
\hline & HPGR circuit & 40.00 & 17.10 & 1.52 \\
\hline & SAG mill & 23.60 & 2.77 & 5.87 \\
\hline & SAG mill, crushers and HPGR & 98.50 & 2.19 & 7.65 \\
\hline & Ball mill and cyclone circuit & 2.19 & 0.13 & 15.41 \\
\hline & & 2.40 & 0.18 & 11.82 \\
\hline & SAG mill circuit & 85.00 & 0.74 & 9.45 \\
\hline & & 89.10 & 0.78 & 10.74 \\
\hline & & 99.80 & 0.76 & 12.74 \\
\hline & & 92.80 & 0.82 & 11.42 \\
\hline & Ball mill circuit & 0.74 & 0.13 & 9.14 \\
\hline & & 0.78 & 0.15 & 10.43 \\
\hline & & 0.76 & 0.14 & 12.44 \\
\hline & & 0.82 & 0.14 & 11.11 \\
\hline \multirow[t]{3}{*}{ Wang et al. (2013) } & HPGR - ball mill circuit & 23.00 & 2.18 & 1.89 \\
\hline & HPGR & 23.00 & 0.34 & 1.89 \\
\hline & & 23.00 & 0.34 & 1.45 \\
\hline \multirow{8}{*}{$\begin{array}{l}\text { (Nielsen \& Mick } \\
\text { Lownds, 1997) }\end{array}$} & Primary crushing & 840.00 & 150.00 & $0.2-0.3$ \\
\hline & & 470.00 & 80.00 & $0.2-0.3$ \\
\hline & Secondary/tertiary & 150.00 & 20.00 & 2.80 \\
\hline & & 80.00 & 12.00 & 2.80 \\
\hline & Coarse grinding & 20.00 & 0.21 & 6.80 \\
\hline & & 12.00 & 0.20 & 6.80 \\
\hline & Fine grinding & 0.21 & 0.05 & 18.20 \\
\hline & & 0.20 & 0.05 & 16.80 \\
\hline
\end{tabular}




\section{Appendix C: Advances in Ultrafine Grinding}

Table 17. Examples of cryogenic grinding for different kinds of materials (Yokoyama \& Inoue, 2007).

\begin{tabular}{|c|c|c|c|c|c|c|}
\hline Feed materials & & $\begin{array}{l}\text { Temperature } \\
\left({ }^{\circ} \mathrm{C}\right)\end{array}$ & $\begin{array}{l}\text { Capacity } \\
(\mathrm{kg} / \mathrm{kWh})\end{array}$ & $\begin{array}{l}\mathrm{LN}_{2} \text { consumption } \\
\text { (kg-LN } / \text { kg-feed) }\end{array}$ & $\begin{array}{l}\text { Product particle } \\
\text { size }\end{array}$ & Product status \\
\hline \multirow[t]{7}{*}{ Resin } & Nylon 12 & -100 & 0.7 & 12.6 & $100 \mu \mathrm{m}>95.3 \%$ & Powder (RT) \\
\hline & Nylon 12 & -100 & 2.0 & 5.0 & $100 \mu \mathrm{m}>83 \%$ & Powder (RT) \\
\hline & Polyethylene & -120 & 0.1 & 87.2 & $150 \mu \mathrm{m}>99.5 \%$ & Powder (RT) \\
\hline & Polyethylene & -120 & 1.1 & 9.2 & $150 \mu \mathrm{m}>74 \%$ & Powder (RT) \\
\hline & Polypropylene & -100 & 0.1 & 120.0 & $150 \mu \mathrm{m}>94 \%$ & Powder (RT) \\
\hline & Polypropylene & -100 & 0.3 & 30.5 & $150 \mu \mathrm{m}>72 \%$ & Powder (RT) \\
\hline & Polyvinylchloride(PVC) & -50 & 18.8 & 0.4 & $150 \mu \mathrm{m}>45 \%$ & Powder (RT) \\
\hline \multirow[t]{3}{*}{ Corns } & Husked rice & -100 & 18.2 & 1.9 & $47 \mu \mathrm{m}>85 \%$ & Powder (RT) \\
\hline & Polished rice & -40 & 10.7 & 2.2 & $47 \mu \mathrm{m}>91 \%$ & Powder (RT) \\
\hline & Polished sticky rice & -100 & 8.7 & 2.8 & $47 \mu \mathrm{m}>97 \%$ & Powder (RT) \\
\hline \multirow[t]{6}{*}{ Beans } & Soybeans (raw) & -100 & 22.4 & 3.5 & $14 \mu \mathrm{m}$ & Paste (RT) \\
\hline & Coffee beans (roasted) & -100 & 16.1 & 1.9 & $15 \mu \mathrm{m}$ & Powder (RT) \\
\hline & Almond & -160 & 8.7 & 3.4 & $44 \mu \mathrm{m}>99 \%$ & Paste (RT) \\
\hline & Cacao beans & -100 & 13.4 & 2.2 & $44 \mu \mathrm{m}>99 \%$ & Paste (RT) \\
\hline & Peanuts & -140 & 12.7 & 2.5 & $500 \mu \mathrm{m}$ & Paste (RT) \\
\hline & Sesame & -140 & 33.5 & 1.5 & $44 \mu \mathrm{m}$ & Paste (RT) \\
\hline \multirow[t]{3}{*}{ Leaves } & Ground tea & -100 & 1.6 & 11.0 & $35 \mu \mathrm{m}>98 \%$ & Powder (RT) \\
\hline & Natural leaf tea & -100 & 2.4 & 7.5 & $35 \mu \mathrm{m}>98 \%$ & Powder (RT) \\
\hline & Mandarin orange & -100 & 15.0 & 2.2 & $74 \mu \mathrm{m}$ & Powder (RT) \\
\hline \multirow[t]{4}{*}{ Fish/sea weed } & Kelp & -100 & 5.9 & 3.7 & $74 \mu \mathrm{m}>97 \%$ & Powder (RT) \\
\hline & Shrimp & -100 & 14.2 & 1.8 & NRT & Paste (RT) \\
\hline & Clam & -120 & 10.3 & 2.7 & NRT & Paste (Frozen) \\
\hline & Bonito & -100 & 16.1 & 1.6 & NRT & Paste (Frozen) \\
\hline \multirow[t]{3}{*}{ Meat } & Chicken & -100 & 23.1 & 1.7 & NRT & Paste (RT) \\
\hline & Beef & -100 & 15.8 & 1.9 & NRT & Paste (RT) \\
\hline & Pork & -100 & 12.7 & 2.8 & NRT & Paste (RT) \\
\hline \multirow[t]{2}{*}{ Crude drug } & Puerariae radix & -80 & 8.6 & 2.7 & $27 \mu \mathrm{m}>90 \%$ & Powder (RT) \\
\hline & Rehmanniae radix & -100 & 13.4 & 2.2 & $150 \mu \mathrm{m}>99 \%$ & Powder (RT) \\
\hline \multirow[t]{5}{*}{ Vegetables } & Dried mushroom & -100 & 4.7 & 2.3 & $74 \mu \mathrm{m}$ & Powder (RT) \\
\hline & Spinach & -50 & 14.3 & 2.0 & $74 \mu \mathrm{m}$ & Powder (RT) \\
\hline & Cabbage & -80 & 10.7 & 2.8 & $74 \mu \mathrm{m}$ & Powder (RT) \\
\hline & Onion & -100 & 10.1 & 2.5 & NRT & Paste (RT) \\
\hline & Sweet corn & -100 & 16.1 & 2.3 & NRT & Paste (Frozen) \\
\hline
\end{tabular}

